\title{
RATCHETING RESPONSE OF BIOLOGICAL TISSUES OVER ASYMMETRIC LOADING CYCLES
}

\author{
by \\ Mahboubeh Sadat Hashemi \\ B.Sc. in Biomedical Engineering, \\ Azad University, Tehran-Iran, 2001
}

\author{
A thesis \\ presented to Ryerson University \\ in partial fulfillment of the \\ requirements for the degree of \\ Master of Applied Science \\ in the Program of \\ Mechanical and Industrial Engineering
}

Toronto, Ontario, Canada, 2019

(C)Mahboubeh Sadat Hashemi 2019 


\section{AUTHOR'S DECLARATION}

I hereby declare that I am the sole author of this thesis. This is a true copy of the thesis, including any required final revisions, as accepted by my examiners.

I authorize Ryerson University to lend this thesis to other institutions or individuals for the purpose of scholarly research.

I further authorize Ryerson University to reproduce this thesis by photocopying or by other means, in total or in part, at the request of other institutions or individuals for the purpose of scholarly research.

I understand that my thesis may be made electronically available to the public. 


\begin{abstract}
Ratcheting Response of Biological Tissues over Asymmetric Loading Cycles, Mahboubeh Sadat Hashemi, Master of Applied Science Thesis in Mechanical and Industrial Engineering, Ryerson University, Toronto, Canada, 2019.
\end{abstract}

The purpose of this study is to examine the ratcheting phenomenon in a variety of biological tissues including the trabecular bone, meniscus, articular cartilage and skin, and propose a parametric model to predict the ratcheting strain of these tissues. Furthermore, utilizing experimental data, and the influence of different mechanical and biological parameters on the ratcheting strain are discussed. The dependency of ratcheting on frequency, stress rate, stress variation, physiological environment, and tissue sites is demonstrated. Besides, stiffness of the toe and linear regions in each cycle, and the modulus of the failure region of the stress-strain curve are computed. The energy dissipation in different cycles at two frequencies of $1 \mathrm{~Hz}$ and $10 \mathrm{~Hz}$ is discussed. A parametric model was employed to predict ratcheting behavior of the said biological tissues. The model predictions of the strain accumulation in tissues are found in agreement with the experimental data. 


\section{Acknowledgments}

After several months of research and study, writing these words is not considered the final point of my learning journey but, it is a significant milestone in my academic and professional life.

First and foremost, I would like to express my profound gratitude to my dear supervisor Professor

A. Varvani-Farahani for his consistent guidance, support, and providing such a great learning opportunity. He has been supportive to me since the day I started my studies at the Ryerson University and without his guidance, completion of this thesis was impossible.

Also, I would extend my special thanks to Dr. Ahmad Ghasempoor for his support and assistance during my years of study at the Ryerson University.

I would like to take this opportunity to express my appreciation to fellow researchers who helped me through their professional works to conduct this study, but I would specifically acknowledge Professor Guozheng Kang from Southwest Jiaotong University who generously provided me with the data of experimental results through email communication.

The Financial support through Natural Sciences and Engineering Research Council (NSERC) of Canada is greatly appreciated.

Finally, my special thanks are due to my family for providing me with unconditional support and everlasting encouragement throughout my years of study and writing this thesis. This accomplishment would not have been possible without them. Thank you! 


\section{Table of Contents}

Author's Declaration ..................................................................... i

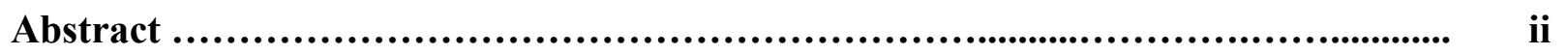

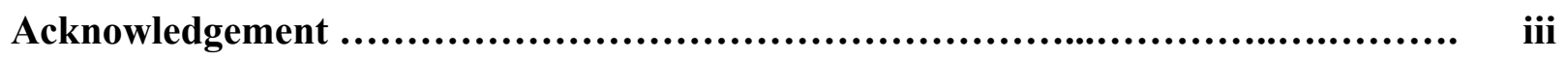

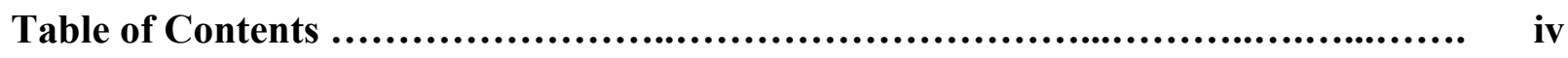

List of Tables .............................................................................. ix

List of Figures ...............................................................................

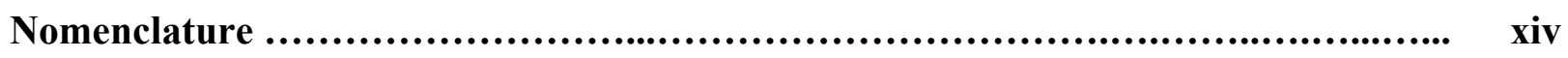

Units Used.......................................................................... xvii

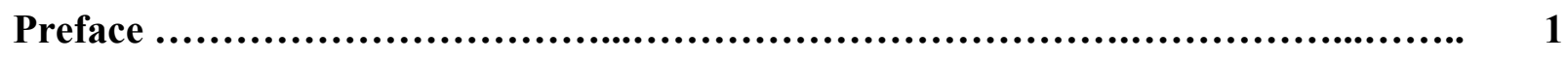

Chapter 1 Composition and Structure of Biological Tissues …........................... 3

1.1. Meniscus ............................................................ 3

1.1.1. Composition of Meniscus ....................................... 4

1.1.1.1. Water ................................................ 4

1.1.1.2. Collagen .............................................. 5

1.1.1.3. Proteoglycans ............................................ 5

1.1.2. Structure of Meniscus ......................................... 5

1.2. Articular Cartilage ..................................................... 6

1.2.1. Composition of Articular Cartilage ................................. 7

1.2.1.1. Water ................................................ 8

1.2.1.2. Collagen ............................................. 8

1.2.1.3. Proteoglycans ............................................ 8 
1.2.1.4. Chondrocyte …....................................... 9

1.2.2. Structure of Articular Cartilage ...................................... 9

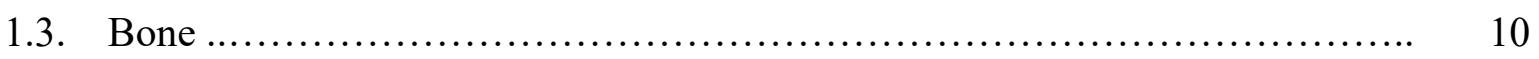

1.3.1. Bone Composition ............................................... 11

1.3.1.1. Osteoblasts ................................................ 11

1.3.1.2. Osteocytes ............................................ 11

1.3.1.3. Osteoclast ......................................... 12

1.3.2. Bone Modeling and Remodeling ................................... 12

1.3.3. Bone Structure …............................................ 13

1.3.3.1. Bone Macrostucture ...................................... 13

1.3.3.2. Bone Microstucture ..................................... 14

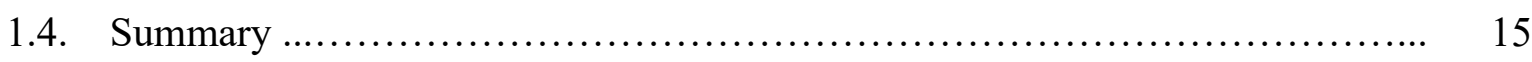

Chapter 2 Mechanical Properties of Biological Tissues .................................. 16

2.1. Meniscus ….......................................................... 16

2.1.1. Load Bearing as a Biphasic Material ............................... 17

2.1.2. Mechanical Properties of the Meniscus under Load ..................... 18

2.1.3. Meniscus Behavior under Tension ................................ 18

2.1.4. Factors Influencing Mechanical Properties of the Meniscus ............. 19

2.1.4.1. Strain Rate ............................................ 19

2.1.4.2. Load Repetition ...................................... 21

2.1.4.3. Osteoarthritis ....................................... 22

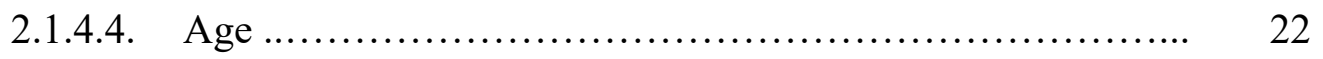

2.2. Articular Cartilage ..................................................... 23 
2.2.1. Load Bearing as a Biphasic Material ................................. 24

2.2.2. Articular Cartilage Behavior under Compression ...................... 25

2.2.3. Articular Cartilage Behavior under Tension ......................... 26

2.2.4. Factors Influencing Mechanical Properties of the Articular Cartilage .... 26

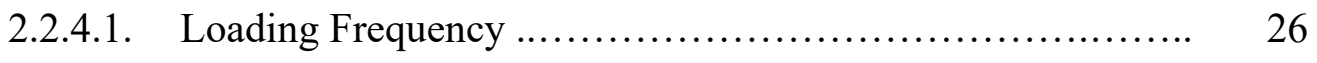

2.2.4.2. Strain Rate ............................................ 27

2.2.4.3. Load Repetition ....................................... 29

2.2.4.4. Osteoarthritis ........................................... 30

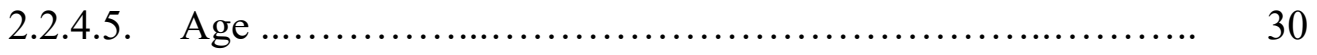

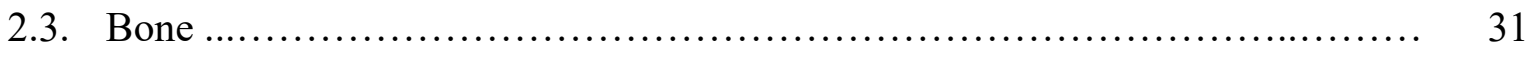

2.3.1. Bone as a Composite Material ..................................... 31

2.3.2. Mechanical Behavior of Trabecular Bone under Static Load ............ 34

2.3.3. Mechanical Behavior of Trabecular Bone under Uniaxial Compression. 35

2.3.4. Mechanical Response of the Trabecular Bone under Uniaxial Tension .. 36

2.3.5. Factors Influencing Mechanical Behavior of the Trabecular Bone ...... 37

2.3.5.1. Bone Density .......................................... 37

2.3.5.2. Degree of Anisotropy ….................................. 39

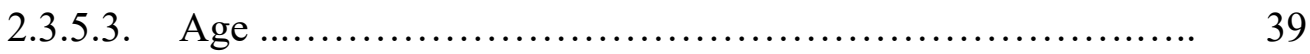

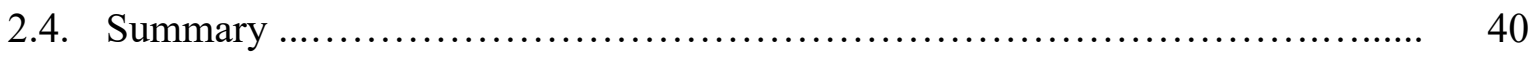

Chapter 3 Ratcheting of Biological Tissues ............................................ 41

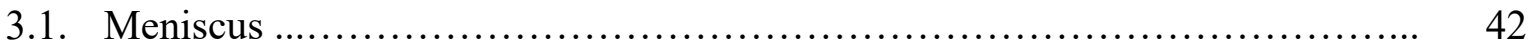

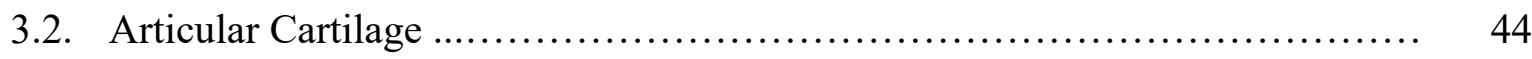

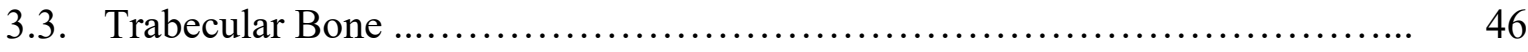


3.4. Cortical Bone ….................................................... 47

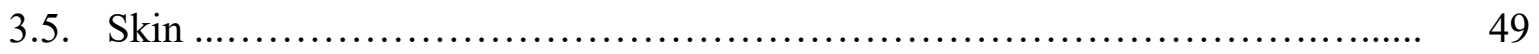

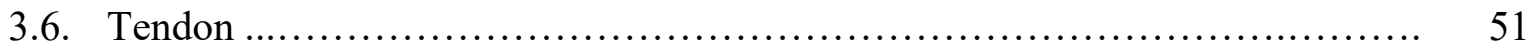

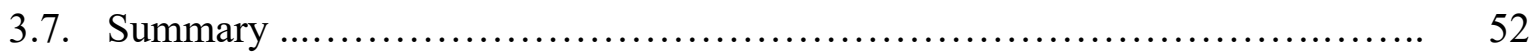

Chapter $4 \quad$ Models for Strain Calculation ..................................................... 53

4.1. NVC Model for Trabecular Bone ....................................... 53

4.2. Kafalas' Model .......................................................... 55

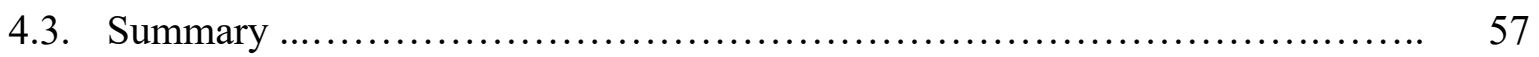

Chapter 5 Parametric Ratcheting Model and Formulation ........................... 58

5.1. Bovine Meniscus ...................................................... 60

5.2. Porcine Articular Cartilage .............................................. 63

5.3. Porcine Trabecular Bone ............................................... 70

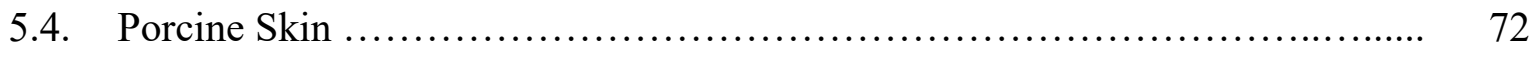

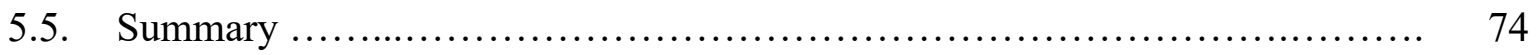

Chapter $6 \quad$ Results and Discussion .................................................... 75

6.1. Ratcheting of Meniscus and Influential Parameters ......................... 76

6.1.1. Loading Frequency and Water Content …........................... 76

6.1.2. Time dependency and Ratcheting ................................... 77

6.1.3. Stress-Strain Hysteresis Loops and Ratcheting ............................... 78

6.1.4. Effect of Ratcheting on Modulus .................................... 81

6.1.5. Energy Dissipation During Ratcheting Phenomenon .................... 85

6.2. Ratcheting of Articular Cartilage and Influential Parameters ................. 86

6.2.1. Effect of Frequency and Stress Rate on Ratcheting ..................... 87 
6.2.2. Effect of Stress Variation on Ratcheting ............................. 88

6.2.3. Effect of Physiological and Testing Environment on Ratcheting ........ 90

6.2.4. Dependency of Ratcheting Strain on Depth of the Tissue ............... 91

6.2.5. Young's Modulus Dependency on Depth of the Cartilage ................. 93

6.3. Ratcheting of Trabecular Bone and Influential Parameters ..................... 94

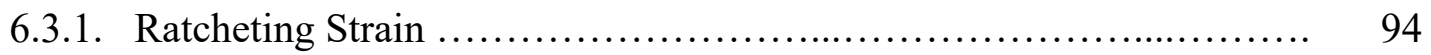

6.3.2. Hysteresis Loops and Stress-Strain Curve ........................... 94

6.3.3. Effect of Bone Marrow on Ratcheting Strain ............................. 94

6.3.4. Ratcheting Strain on different depths of the Trabecular bone .............. 96

6.4. Ratcheting Prediction through Phenomenological Model ...................... 97

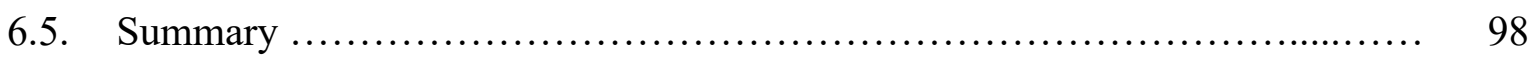

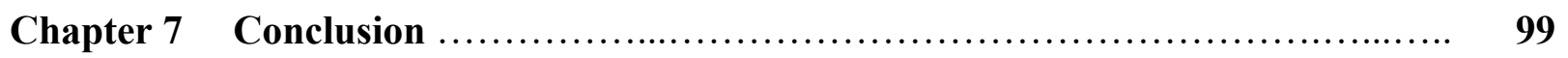

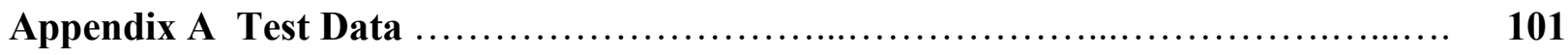

A.1. Data of Bovine Meniscus .................................................... 101

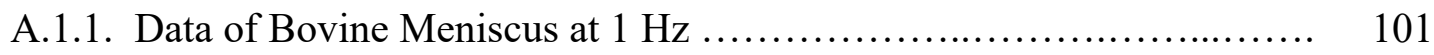

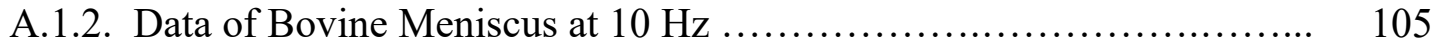

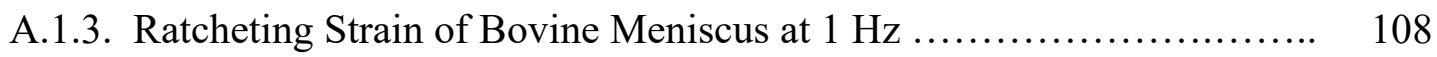

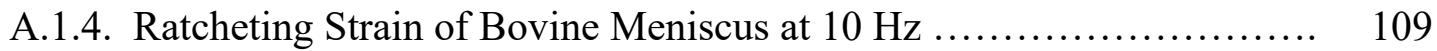

A.2. Data of Porcine Articular Cartilage ........................................... 110

A.3. Data of Porcine Trabecular Bone ....................................... 112

A.4. Data of Porcine Skin .......................................................... 113

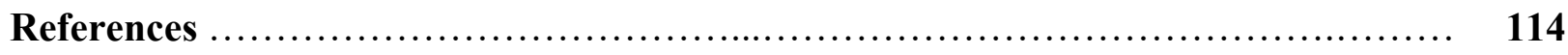




\section{List of Tables}

Table 1.1: Comparison of different layers of articular cartilage $\ldots \ldots \ldots \ldots \ldots \ldots \ldots \ldots \ldots, 10$

Table 1.2: Properties of the cortical bone and cancellous bone ........................ 14

Table 2.1: Permeability and aggregate modulus of bovine meniscus under compression... 18

Table 2.2: Mechanical properties of bovine meniscus under tension ................... 19

Table 2.3: Articular Cartilage aggregate modulus and poison's ratio in different species 25 and sites

Table 2.4: Mechanical properties of the bovine articular cartilage under tension .......... 26

Table 2.5: Elastic properties of trabecular bone form human distal tibia ............... 34

Table 5.1: Material properties for bovine meniscus tissue $\ldots \ldots \ldots \ldots \ldots \ldots \ldots \ldots \ldots \ldots \ldots .61$

Table 5.2: Material properties for porcine articular cartilage...................... 67

Table 5.3: Experimental data of tested cartilage samples and their life cycles ........... 68

Table 5.4: Material properties for trabecular bone tissue $\ldots \ldots \ldots \ldots \ldots \ldots \ldots \ldots \ldots \ldots \ldots . \ldots 1$

Table 5.5: Material properties assigned to the porcine skin ........................ 73 


\section{List of Figures}

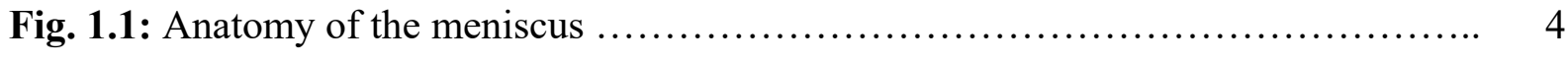

Fig. 1.2: Layers of meniscus (1) Superficial (2) Lamellar layer (3) Central main layer ... 6

Fig. 1.3: Composition of the articular cartilage through depth of tissue ................ 7

Fig. 1.4: Illustration of four zones of articular cartilage .......................... 9

Fig. 1.5: Trabecular and Cortical bones' hierarchical structure from mineralized collagen 13

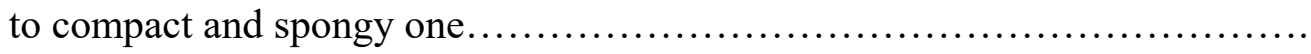

Fig. 1.6: Composition of trabecular bone from nanoscale to macroscale ................ 14

Fig. 1.7: Primary (woven) and secondary (lamellar) bones $\ldots \ldots \ldots \ldots \ldots \ldots \ldots \ldots \ldots \ldots, 15$

Fig. 2.1: Biphasic behavior of meniscus, (A) before applying load (B) at the time of load application (C) after load removal

Fig. 2.2: Strain rate sensitivity of meniscus mechanical properties (A) Young's modulus and yield stress $(\mathrm{B})$ stress-strain variations based on strain rate

Fig. 2.3: The effect of cyclic loading on modulus of human and ovine meniscus (A) at 15,000 cycles (B) at cycles 1,50 and 5,000

Fig. 2.4: Changes of water content of the meniscus during degeneration

Fig. 2.5: Load bearing performance of (A) fluid and (B) solid phases of the articular cartilage

Fig. 2.6: Variation of storage modulus with changes in frequency

Fig. 2.7: Stress-strain relation of articular cartilage at different compressive axial strain rates

Fig. 2.8: Variation of Young's modulus and yield stress with changes in strain rate 
Fig. 2.9: Changes in articular cartilage in early and late osteoarthritis

Fig. 2.10: Change in maximum tensile strength of hip articular cartilage by age ....

Fig. 2.11: The response of the bone under load

Fig. 2.12: Different stages of stress-strain curve of the spongy bone under uniaxial 36 compression

Fig. 2.13: Different stages of stress-strain curve of cancellous bone under tension 37

Fig. 2.14: Relationship between yield stress and apparent density in longitudinal direction 38 in trabecular bone

Fig. 3.1: Typical 20th hysteresis loop to calculate ratcheting strain in bovine meniscus ...

Fig. 3.2: Stress-strain curves of bovine meniscus (A) $10 \mathrm{~Hz}$ (B) $1 \mathrm{~Hz}$

Fig. 3.3: Ratcheting strain of the meniscus under cyclic compression (A) $10 \mathrm{~Hz}$ (B) $1 \mathrm{~Hz}$ 44

Fig. 3.4: Articular cartilage under cyclic load (A) Stress-strain curve, (B) Ratcheting strain 45 curve

Fig. 3.5: Trabecular bone under cyclic load (A) Stress-strain curve (B) Ratcheting strain 46 curve

Fig. 3.6: Cortical bone under cyclic tension and compression (A) Stress-strain curve (B) Compressive ratcheting strain $(\mathrm{C})$ Tensile ratcheting strain

Fig. 3.7: Porcine skin under cyclic tension (A) Stress- strain diagram (B) Ratcheting strain 50

Fig. 3.8: Human Achilles tendons (A) Stress-strain diagram (B) Ratcheting strain 51

Fig. 4.1: Comparison of experimental data and nonlinear viscoelastic model in trabecular 55 bone under compressive stress

Fig. 4.2: Trabecular bone stress-strain curve from Kefalas \& Eftaxiopoulos' model against the experimental data in a bone density of $1.43\left(\mathrm{~g} / \mathrm{cm}^{3}\right)$ 
Fig. 5.1: Different stages of ratcheting strain in metals and associated equation

Fig. 5.2: Experimental data and predicted ratcheting curves by equation (5.1) for meniscal tissue at (A) $10 \mathrm{~Hz}$ (B) $1 \mathrm{~Hz}$

Fig. 5.3: Slope of the toe region of $1^{\text {st }}$ and $2^{\text {nd }}$ cycles of the porcine articular cartilage....

Fig. 5.4: (A) Young's modulus of different layers of the articular cartilage, (B), (C), (D) 64 The best fitted curves for different layers of the articular cartilage (E) Young's modulus of the tissue

Fig. 5.5: Experimental and predicted ratcheting curves by equation (5.1) for cartilage tissue

Fig. 5.6: Ratcheting strain of tested articular cartilage samples at different loading 69 conditions

Fig. 5.7: Life cycles at various maximum stress while minimum stress kept constant 70

Fig. 5.8: Experimental and predicted ratcheting values by equation (5.1) for trabecular 72 bone tissue

Fig. 5.9: The stress-strain hysteresis loops obtained for porcine skin tissue 73

Fig. 5.10: Experimental and predicted ratcheting values by equation (5.1) for porcine skin

Fig. 6.1: Experimental ratcheting data for bovine meniscus tissue samples tested at $1 \mathrm{~Hz}$ and $10 \mathrm{~Hz}$

Fig. 6.2: Ratcheting strain data at different frequency plotted versus time 78

Fig. 6.3: Experimental hysteresis loops of tested meniscus sample at (A) $10 \mathrm{~Hz}$ and (B) 1 79 $\mathrm{Hz}$

Fig. 6.4: Hysteresis loops for cycles 20, 100, 500, and 1,000 for meniscus tissue samples 80 tested at $10 \mathrm{~Hz}$ and $1 \mathrm{~Hz}$

Fig. 6.5: Minimum strains at $20^{\text {th }}$ cycle at two frequencies of $1 \mathrm{~Hz}$ and $10 \mathrm{~Hz}$

Fig. 6.6: Schematic presentation of stress-strain curve of a viscoelastic material 
Fig. 6.7: Typical stress-strain curve of the meniscus and the slope of the two regions .....

Fig. 6.8: Slopes of three regions of stress-strain curves of the meniscus at (A) $10 \mathrm{~Hz}$, (B) 83

$1 \mathrm{~Hz}$, and (C) both frequencies

Fig. 6.9: Dissipated energy during different cycles at two frequencies for meniscus tissue 86

Fig. 6.10: Ratcheting strain of the porcine articular cartilage at different frequencies 87

Fig. 6.11: Ratcheting strain of the porcine articular cartilage at different stress rates 88

Fig. 6.12: Ratcheting strain of articular cartilage at different stress levels (A) all cycles, 89 (B) cycles 30, 50, and 90

Fig. 6.13: Ratcheting strain values at different stress levels and frequencies 90

Fig. 6.14: Ratcheting strain of soaked and unsoaked articular cartilage tissue samples .... 91

Fig. 6.15: Ratcheting strain of different zones of the cartilage under cyclic compression... 92

Fig. 6.16: The variation of modulus at layers of cartilage tissue and at different cycles ... 93

Fig. 6.17: Comparison of ratcheting strain of the marrowy and marrowless trabecular bone 95

Fig. 6.18: Comparison of ratcheting strain of three points in marrowy trabecular bone .... 96

Fig. 6.19: Predicted and experimental ratcheting data for various biological tissues 97 examined in this study 


\section{Nomenclature}

\begin{tabular}{|c|c|}
\hline$C$ & Elastic matrix \\
\hline$E$ & Young modulus \\
\hline$E^{(s)}$ & A material parameter related to the trabecular structure \\
\hline$E_{1}$ & $\begin{array}{l}\text { Stiffness of the toe region of the stress-strain curve of a } \\
\text { viscoelastic material }\end{array}$ \\
\hline$E_{2}$ & $\begin{array}{l}\text { Stiffness of the linear region of the stress-strain curve of a } \\
\text { viscoelastic material }\end{array}$ \\
\hline$E_{i j}$ & Young's modulus of the material in direction $\mathrm{ij}$ \\
\hline$f$ & Loading frequency \\
\hline$G_{i j}$ & Shear Modulus in direction $\mathrm{ij}$ \\
\hline$H_{A}$ & Aggregate modulus \\
\hline$K_{i}(t)$ & Material's function \\
\hline$n$ & Cyclic strain hardening exponent \\
\hline$N$ & Number of stress cycle \\
\hline$N_{f}$ & Number of life cycles \\
\hline$P$ & Nominal normal stress \\
\hline$S$ & Second Piola-Kirchoff stress tensor \\
\hline$t$ & Time \\
\hline$V_{f}$ & Volume fraction \\
\hline (ts) & Represents trabecular structure \\
\hline$(\mathrm{tm})$ & Represents compact trabecular mass \\
\hline
\end{tabular}




\begin{tabular}{|c|c|}
\hline$\alpha$ & Coefficient \\
\hline$\alpha^{*}$ & Coefficient $\alpha$ in ratcheting model for biological tissues \\
\hline$\alpha_{i}$ & Damage factor \\
\hline$\beta$ & Stiffness of the failure region of the stress-strain curve of \\
\hline & viscoelastic materials \\
\hline$\gamma_{i}$ & Material parameters, associated to the stack of trabecular \\
\hline & deformation under compression \\
\hline$\gamma_{i}^{\prime}$ & New parameters under compressive load \\
\hline$\Delta \sigma$ & Stress variation \\
\hline$\varepsilon$ & Strain \\
\hline$\varepsilon_{\max }$ & Maximum strain \\
\hline$\varepsilon_{\min }$ & Minimum strain \\
\hline$\varepsilon_{r}$ & Ratcheting strain \\
\hline$\lambda$ & Stretch ratio along the direction of compression \\
\hline$\mu$ & The Lagrangian normal strain component \\
\hline$\mu_{i}$ & Material constant \\
\hline$v_{i j}$ & Poisson's ratio in direction $\mathrm{ij}$ \\
\hline$\rho_{a p p}$ & Apparent density \\
\hline $\rho$ tissue & Tissue density \\
\hline$\sigma$ & Stress \\
\hline$\sigma^{\prime}(t)$ & $\partial \sigma / \partial \mathrm{t}$ \\
\hline$\sigma_{0}^{\prime}$ & Stress rate \\
\hline
\end{tabular}


$\sigma_{m}$

$\sigma_{u l t}$

$\sigma_{y}$
Mean stress

Ultimate strength

Yield stress

- xvi - 


\section{Units Used}

$\begin{array}{ll}\mathrm{g} / \mathrm{cm}^{3} & \text { Density } \\ \mathrm{GPa} & \text { Giga Pascal } \\ \mathrm{Hz} & \text { Hertz (One cycle per second) } \\ \mathrm{m}^{4} / \mathrm{N} . \mathrm{s} & \text { Permeability } \\ \mathrm{mm} & \text { Millimeter } \\ \mathrm{MPa} & \text { Mega Pascal } \\ \mathrm{MPa} / \mathrm{s} & \text { Stress Rate } \\ \mathrm{s}^{-1} & \text { Strain Rate }\end{array}$

- xvii - 


\section{Preface}

This study is mainly focused on the ratcheting behavior of hard and soft biological tissues including the trabecular bone, meniscus, articular cartilage, and skin. It also introduces a model for prediction of this phenomenon in these tissues based on available experimental data. A brief description of the materials covered in this thesis is as follows.

Chapter 1 provides a succinct introduction to biological properties of the meniscus, articular cartilage, and bone. Important concepts like tissues composition and structure, as well as different types of the bone from macrostructure and microstructure points of view are explained.

The mechanical properties of the aforementioned tissues are discussed in Chapter 2, where behavior of tissues under different types of loading, as well as some biological and mechanical factors that impact tissue characterization are reviewed.

In Chapter 3, responses of the meniscus, articular cartilage, trabecular bone, cortical bone, skin, and tendon to stress cycles and corresponding hysteresis loops are discussed.

Chapter 4 focuses on physical models for predicting strain accumulation of the biological tissues under cyclic load.

Chapter 5 is dedicated to evaluate and adopt functionality of an earlier developed model for prediction of the ratcheting strain of tissues. Experimental data are employed to evaluate the model capability. The outcome of the prediction is consistent with experimental data.

In Chapter 6, the effects of different mechanical and biological parameters on the ratcheting strain of tissues are discussed and the determinant factors including frequency, stress rate, stress 
variation, physiological environment, and tissue sites, are introduced based on the available experiments. The effect of ratcheting on tissue stiffness and energy dissipation is also investigated.

Finally, the points and subjects discussed in Chapters 1-6 are summarized in Chapter 7, which is followed by more detailed experiments and test data. Appendices are placed at the end of thesis holding some experimental data of biological tissues studied in this research work. 


\section{Chapter 1}

\section{Composition and Structure of Biological}

\section{Tissues}

The knowledge of biological tissues, due to its role in human health, mobility, and wellbeing has been of great interest for a long period of time. This field has experienced a vast improvement in recent years through advances in super-resolution microscopy, maintaining biological environments, hygiene implementation, and development of mathematical simulation software. The human body is a collection of organs made of tissues, which in their own turn are composed of cells. In this chapter, the structure and composition of the bone, articular cartilage, and meniscus which are categorized as connective tissues, will be reviewed.

\subsection{Meniscus}

Meniscus is a cartilaginous tissue which belongs to the fibroelastic cartilage group [1]. It is a pair of crescent shaped tissues located in the knee joint (see Fig. 1.1). Healthy meniscus plays an important role in protecting articular cartilage and prevention of osteoarthritis [2]. 


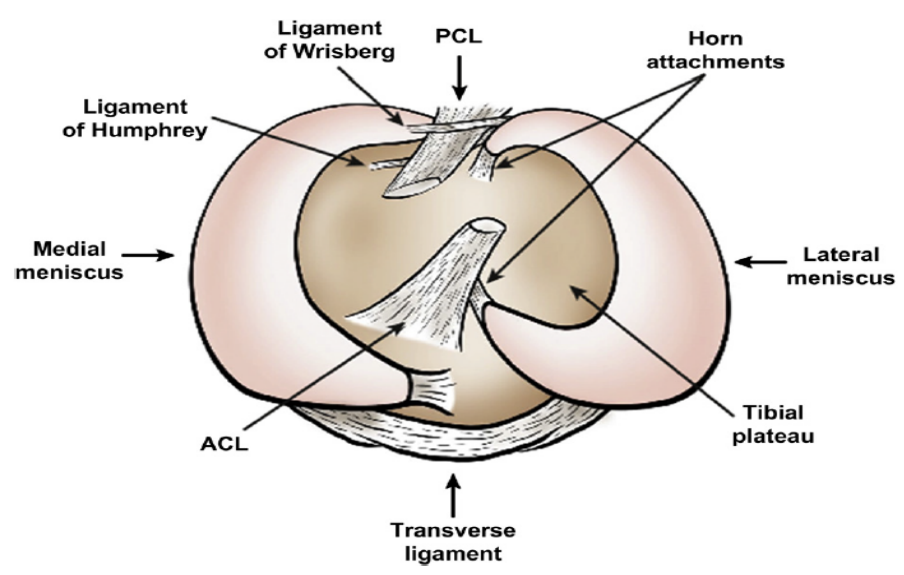

Fig. 1.1: Anatomy of the meniscus [2].

\subsubsection{Composition of Meniscus}

The meniscus is a biphasic material consisting of fluid and solid phases. The predominant ingredient of the meniscus is water. The rest of the tissue is filled by collagen, DNA, adhesion glycoproteins, and elastin. The amount of each ingredient varies based on the depth of the tissue, contracted diseases, and age. DNA and glycosaminoglycan compose $0.12 \%$ and $0.8 \%$ of the tissue respectively [3].

\subsubsection{Water}

As the main component, water constitutes about $70-75 \%$ of a healthy meniscus. However, in a degenerated tissue, the water content increases to $85 \%$ of the tissue's wet weight [3]. According to the literature, there is variation in water content of different locations of the meniscus [4]. 


\subsubsection{Collagen}

Collagen, which fills $22 \%$ of the meniscus [3], is the predominant ingredient of the dry phase of this tissue. It counts for $70 \%$ of the dry weight of the meniscus [5] of which more than $90 \%$ is collagen type I $[6,7]$.

\subsubsection{Proteoglycans}

Proteoglycans, consisting of a protein, are covered with glycosaminoglycans [2] and contribute to compression resistance of the meniscus tissue [8]. Proteoglycans are classified as small or large according to their size. The main large proteoglycan of the meniscus is called Aggrecan [2] and the small proteoglycans are named Decorin, Biglycan, and Fibromodulin. Their distribution throughout different locations of the meniscus is not the same. Among small proteoglycans, biglycan's contribution to porcine meniscus is higher and it plays an important role during cyclic compressive stress [8].

\subsubsection{Structure of Meniscus}

Meniscus is an anisotropic inhomogeneous cartilage. The architecture and mechanical properties of the meniscus is not constant throughout the tissue. Observing tissue through a scanning electron microscope, Petersen and Tillmann [9] found three distinct layers: the superficial layer, lamellar layer, and central main layer, as illustrated in Fig. 1.2. The superficial layer is covered with fibrils of $35 \mathrm{~nm}$ diameter which are randomly orientated. Collagen fibrils with diameter of $120 \mathrm{~nm}$ are located underneath the superficial layer forming the lamellar layer. The central main layer contains 
the main part of the collagen fibrils of the meniscus. Collagen bundles are oriented in a circular pattern in this layer [9].

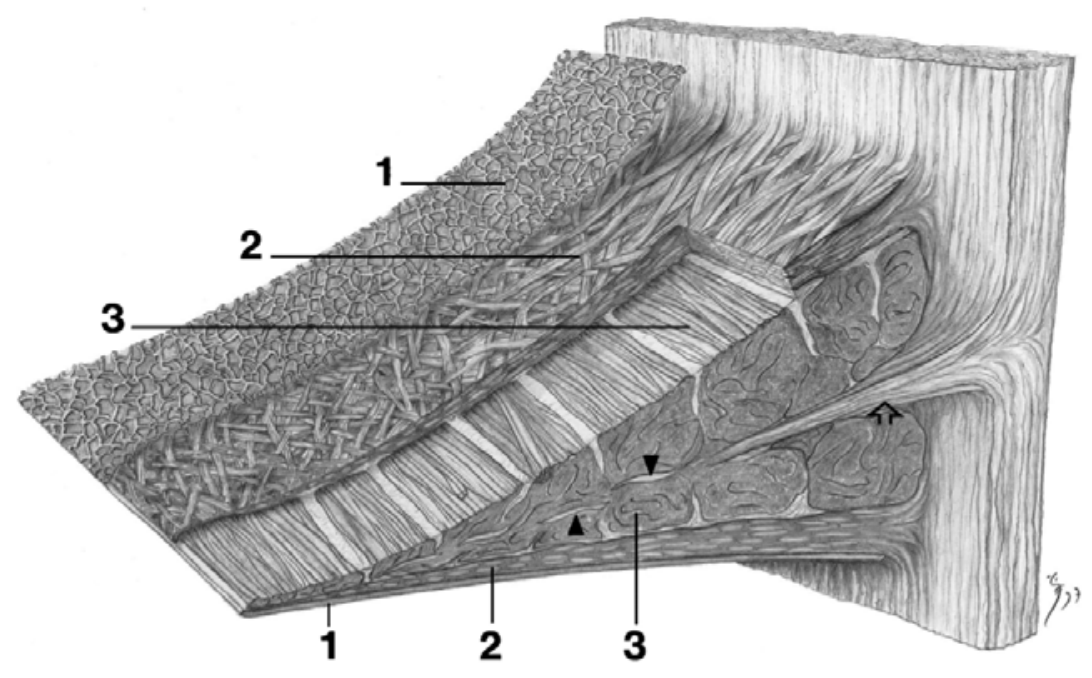

Fig. 1.2: Layers of meniscus (1) Superficial (2) Lamellar layer (3) Central main layer [9].

\subsection{Articular Cartilage}

Articular cartilage is a collagenous connective tissue that covers the end of articulating bones. In synovial joints, articular cartilage connects opposing bones and helps in transmitting loads while providing a smooth low friction surface [10,11]. Five different types of cartilage are named as hyaline, fibroelastic, fibrocartilage, elastic, and physeal cartilage, of which articular cartilage is a hyaline cartilage with a smooth surface [1]. This tissue is vascular and has a limited ability to repair and regenerate [12], so, injuries and degeneration of this tissue is common. In this section, the biological structure and composition of the articular cartilage will be reviewed. 


\subsubsection{Composition of Articular Cartilage}

Similar to meniscus, the articular cartilage is a biphasic material composed of fluid and solid phases. Water is the main ingredient of the tissue. Since, the articular cartilage is surrounded by synovial fluid in the knee joint, moisture is an important factor in structure and healthiness of the tissue.

The solid phase itself has different components. The main content of the solid phase is collagen (mostly of type II). Proteoglycans are other important parts of the tissue's solid phase [10]. The architecture of articular cartilage and percentage of its components differs based on the tissue depth (see Fig. 1.3).

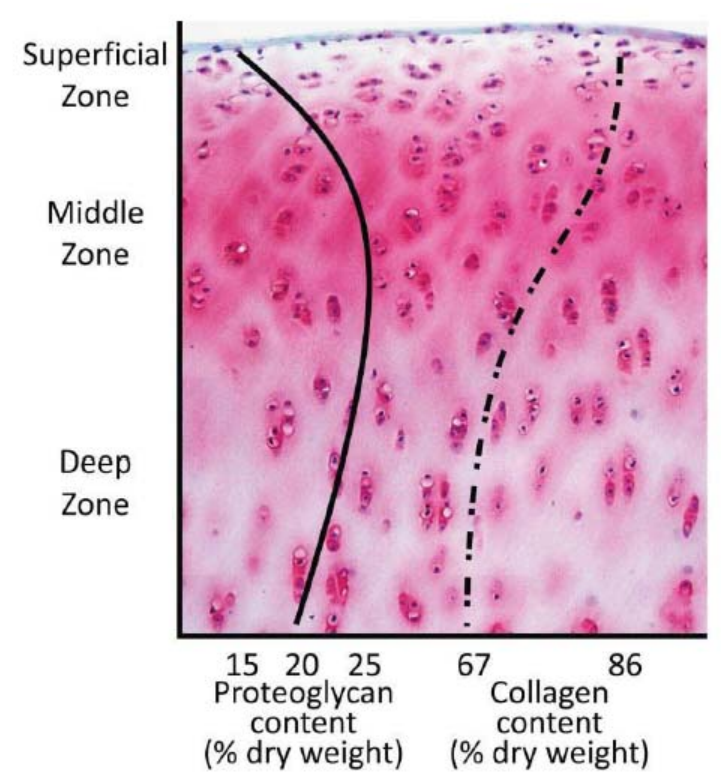

Fig. 1.3: Composition of the articular cartilage through depth of tissue [11].

Besides collagen and proteoglycans, other proteins and glycoproteins are also available in the articular cartilage [11] which will be discussed in the following section. 


\subsubsection{Water}

Water is the main component of the articular cartilage. About $80 \%$ of the fluid phase is composed of water. Sodium, calcium, chloride, and potassium are other components of this phase [13]. The fluid phase plays an important role in the tissue's mechanical properties. Preventing damages to the tissue, suddenly applied loads are born by the fluid phase [11]. Any change in the water content is linked to improper tissue function [10].

\subsubsection{Collagen}

There are different types of collagen in the human body. Collagen is a protein and the main component of the connective tissue [11]. This protein forms about $60-70 \%$ of the weight of the articular cartilage's solid phase [10]. The majority (90-95\%) of the collagen in the articular cartilage is of type II [1,11], which is responsible for tensile strength of the tissue [14].

\subsubsection{Proteoglycan}

Proteoglycans are large macromolecules [11] that constitute about $30 \%$ of the dry weight of the articular cartilage [10]. Their contribution to the tissue ingredients varies in different zones of the connective tissue. The main type of proteoglycan in articular cartilage is called Aggrecan [11].

The importance of the aggrecan function is linked to its contribution to compressive resistance of the articular cartilage and obviously its reduction causes changes in the tissue's functionality. Decorin, biglycan, and fibromodulin are other types of proteoglycans in the articular cartilage [13]. 


\subsubsection{Chondrocyte}

Chondrocytes form about $10 \%$ of the total volume of articular cartilage [15]. Although, their contribution to the tissue formation is little, they perform very important tasks like maintenance and synthesis of the collagen. Any alterations in the chondrocytes' volume or density from the healthy state results in destructive changes in mechanical properties of the tissue [15].

\subsubsection{Structure of Articular Cartilage}

Articular cartilage, from the surface to the subchondral bone, is divided into four layers: the superficial layer, mid layer, deep layer, and calcified layer that are shown in Fig. 1.4. The calcified layer is attached to the bone, and the tidemark is located between the deep layer and calcified layer. Each zone has specific structure, composition, and consequently different mechanical behavior. The superficial zone covers $10-20 \%$ of the tissue's thickness. Collagen concentration in this zone is high [14]. Collagen fibrils in the superficial zone are parallel $[11,13]$ and strengthen the layer against shear and tensile forces [14].

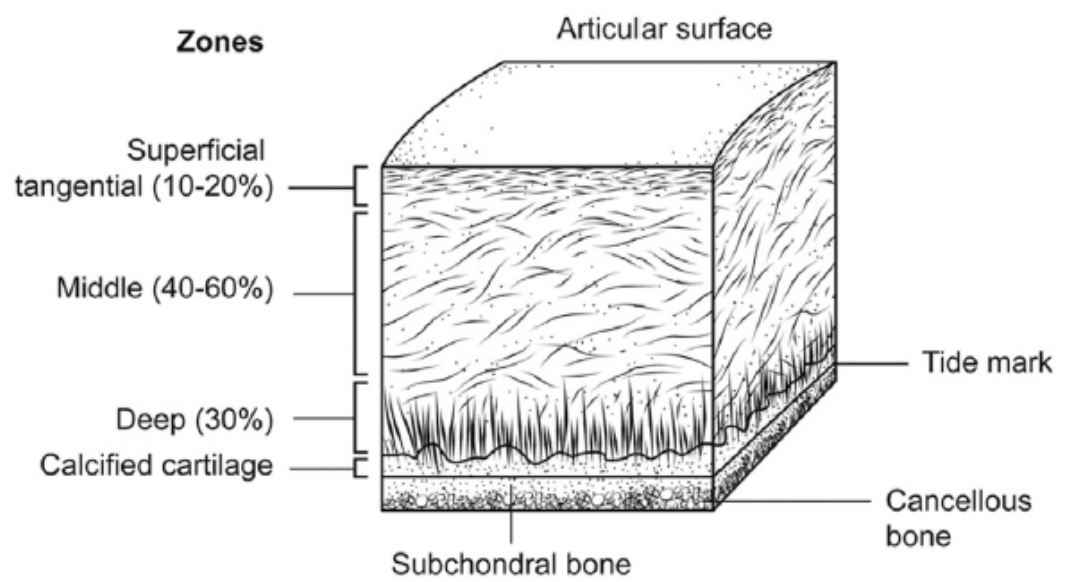

Fig. 1.4: Illustration of four zones of articular cartilage [15]. 
The middle zone, which is called the intermediate zone, forms $40-60 \%$ of the whole tissue thickness. Unlike the superficial layer, thicker collagen fibrils are randomly orientated in the transitional zone $[11,14]$. Collagen fibrils in the deep zone are arranged perpendicular to the articular surface $[11,13]$ and these fibers have the biggest diameter compared to other zones [14]. Moving from the superficial layer to the deep layer, the water content of the tissue decreases. Three layers of the articular cartilage and their properties are summarized in Table 1.1.

Table 1.1: Comparison of different layers of articular cartilage [13,14,15].

\begin{tabular}{|c|c|c|c|c|c|}
\hline Zone & $\begin{array}{c}\text { Contribution } \\
\text { to the Tissue } \\
\text { Thickness }\end{array}$ & Collagen & $\begin{array}{c}\text { Collagen } \\
\text { Orientation }\end{array}$ & Water & $\begin{array}{c}\text { Mechanical } \\
\text { Properties }\end{array}$ \\
\hline $\begin{array}{c}\text { Superficial } \\
\text { Zone }\end{array}$ & $10-20 \%$ & $\begin{array}{c}\text { Collagen type I } \\
\text { and IX }\end{array}$ & $\begin{array}{c}\text { Parallel and } \\
\text { aligned }\end{array}$ & $\begin{array}{c}\text { Highest } \\
\text { level }\end{array}$ & $\begin{array}{c}\text { Greatest tensile and } \\
\text { shear resistance }\end{array}$ \\
\hline $\begin{array}{c}\text { Middle } \\
\text { Zone }\end{array}$ & $40-60 \%$ & $\begin{array}{c}\text { Thicker } \\
\text { collagen fibrils }\end{array}$ & $\begin{array}{c}\text { Obliquely } \\
\text { arranged }\end{array}$ & $\begin{array}{c}\text { Moderate } \\
\text { (in between) }\end{array}$ & $\begin{array}{c}\text { Resistant to } \\
\text { compression forces }\end{array}$ \\
\hline Deep Zone & $30 \%$ & $\begin{array}{c}\text { Thickest } \\
\text { collagen fibrils }\end{array}$ & $\begin{array}{c}\text { perpendicular to } \\
\text { tissue surface }\end{array}$ & $\begin{array}{c}\text { Lowest } \\
\text { level }\end{array}$ & $\begin{array}{c}\text { Highest resistant to } \\
\text { compression }\end{array}$ \\
\hline
\end{tabular}

\subsection{Bone}

Bone is a vascular, dynamic, complex tissue, consisting of organic and inorganic phases. It undergoes dynamic and static loads during daily activities. This hard tissue has special architecture and features that make it strong, repairable and adaptable [16] to environmental changes which are important characteristics of a healthy bone. 
In this section, bone composition, structure and an important feature of the bone (bone remodeling) will be discussed.

\subsubsection{Bone Composition}

Three special types of cells that partake in bone biological activities are osteoblasts, osteocytes, and osteoclasts, which will be discussed in further detail.

\subsubsection{Osteoblasts}

Osteoblasts are known for their bone formation responsibility. They are seen during bone growth and fracture healing. They produce collagen and also some non-collagenous proteins [17]. Osteoblasts produce osteoid, or bone tissue, an unmineralized and organic material, which will be mineralized later and turn into the mature bone. Osteoblasts respond to the mechanical loads by modifying the size and shape of the bone [17]. The number of osteoblasts is regarded as a factor in determining the relationship between bone modeling (formation) and bone resorption (which will be discussed later in this chapter). This number drops in older people [18], which indicates reduction in bone density.

\subsubsection{Osteocytes}

During bone formation, some osteoblasts surrounded by the bone matrix change to osteocytes cells [18]. Their surrounding environment - which is not mineralized - gives them the unique ability of sensing mechanical loads $[17,18]$. Descended from osteoblasts, osteocytes cells constitute about 95\% of an adult bone's living cells. They are responsible for transferring signals to osteoblasts during mechanical loads and addressing them in bone formation. 


\subsubsection{Osteoclast}

Osteoclast is found at the surface of the bone that undergoes resorption. As mentioned before, osteoblast determines bone formation. Osteoclast is responsible for destroying bone and together with osteoblast, determines bone remodeling (formation and resorption) [17].

\subsubsection{Bone Modeling and Remodeling}

Bone, as a vascular and active tissue, is always in the process of replacing old bone tissue with the new ones. This process continues throughout the bone's entire life. Bone remodeling process is very important in bone healing, growth, as well as bone density. This phenomenon has two phases: (a) bone resorption, and (b) bone formation. During bone resorption, the old bone's tissue cells are broken and bone formation is responsible for forming new bone cells. This process determines the bone density. Bone density is crucial in genuine bones as well as cracked or broken bones for further treatment options and higher success rates. Although, bone remodeling is an ongoing process throughout human life, the ratio of its components - i.e. bone resorption and formation is not constant among individuals and at different stages of life. This ratio is controlled by different factors like age, level of activity, minerals intake and general health. The rate of bone formation is higher than bone resorption before the age of thirty compared to older ages and it is greater in active people than inactive individuals, especially in individuals experiencing long time bed rest which results in lessening bone density. For instance, for old individuals, the rate of modeling is less than resorption rate which yields to lessening bone density $[17,18]$. 


\subsubsection{Bone Structure}

\subsubsection{Bone Macrostucture}

Macro-structurally, there are two types of bone tissue in the human body: (a) the cortical or compact bone (Fig. 1.5), and (b) the trabecular, spongy or cancellous bone (Fig. 1.5 and 1.6). The cortical bone, which makes up to $80 \%$ of skeletal mass [19], is found in the outer side of long bones like the femur. Compact bone with a porosity of less than $30 \%$ and volume fraction of $70 \%$ is much denser than trabecular [20]. The trabecular bone is porous (75\%-95\%), like a sponge, and located at the ends of long bones, flat bones as well as vertebrae [19] and contains bone marrow.

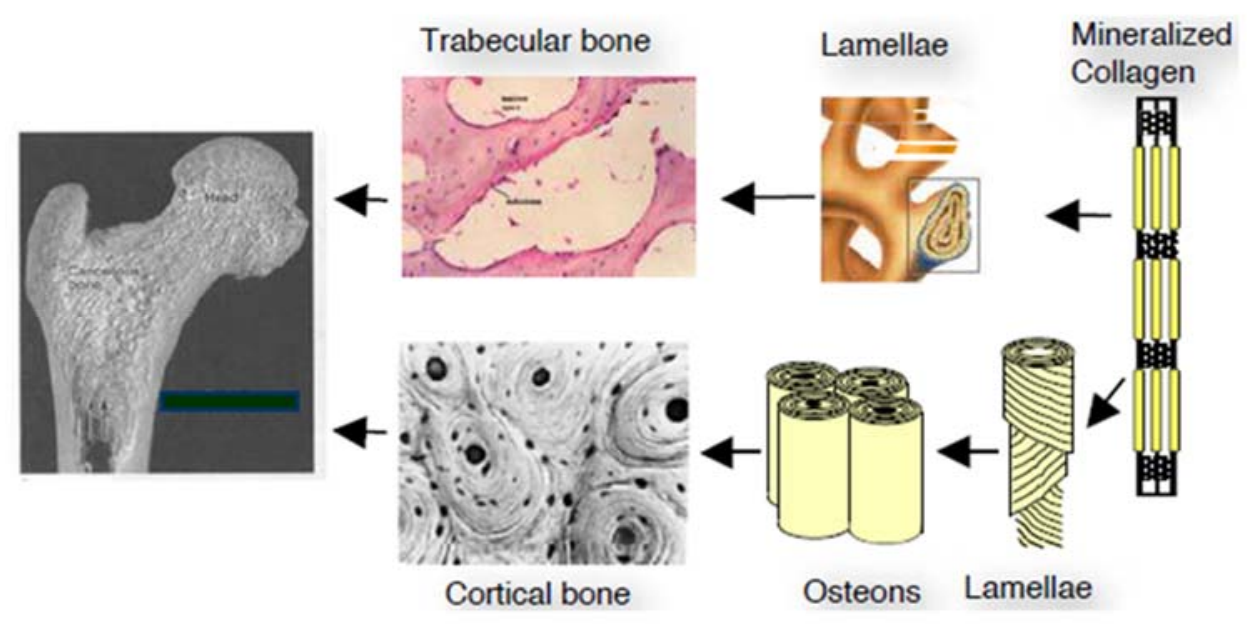

Fig. 1.5: Trabecular and Cortical bones' hierarchical structure from mineralized collagen to compact and spongy bone [19].

The hierarchical arrangement of the spongy bone, at the nanoscale, is composed of mineralized collagen fibrils, followed by lamella at the sub-micron level, single trabecula at the micron level and finally the trabecular bone (see Fig. 1.6). 


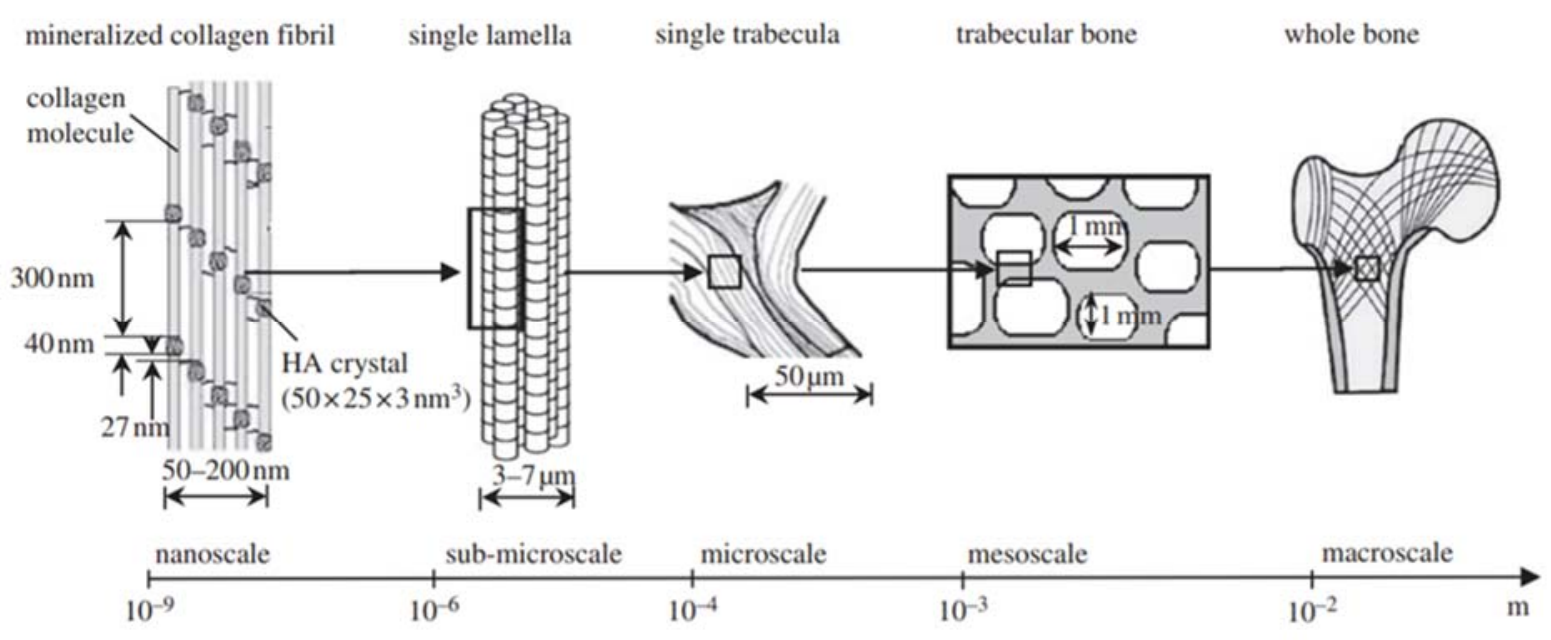

Fig. 1.6: Composition of trabecular bone from nanoscale to macroscale [21].

Loading conditions, as well as some diseases can affect bone porosity [22]. A comparison of some mechanical properties of compact and spongy bone is provided in Table 1.2.

Table 1.2: Properties of the cortical bone and cancellous bone.

\begin{tabular}{|c|c|c|c|c|c|}
\hline $\begin{array}{c}\text { Type of } \\
\text { Bone }\end{array}$ & Porosity & $\begin{array}{c}\text { Tissue } \\
\text { Density } \\
\left(\mathbf{g} / \mathbf{c m}^{3}\right)\end{array}$ & $\begin{array}{c}\text { Apparent Density } \\
\left(\mathbf{g} / \mathbf{c m}^{\mathbf{3}}\right)\end{array}$ & $\begin{array}{c}\text { Contribution to } \\
\text { Total Mass of } \\
\text { Skeleton }\end{array}$ & $\begin{array}{c}\text { Ultimate } \\
\text { Strain }\end{array}$ \\
\hline $\begin{array}{c}\text { Cortical } \\
\text { Bone }\end{array}$ & $\begin{array}{c}5-30 \% \\
{[18]}\end{array}$ & $2[20]$ & $1.85[20]$ & $80 \%[19]$ & $2 \%[22]$ \\
\hline $\begin{array}{c}\text { Spongy } \\
\text { Bone }\end{array}$ & $\begin{array}{c}30-90 \% \\
{[18]}\end{array}$ & $2[20]$ & $\begin{array}{c}0.1-0.6(\text { based on } \\
\text { anatomic site) }[20]\end{array}$ & $20 \%$ & $75 \%[22]$ \\
\hline
\end{tabular}

\subsubsection{Bone Microstucture}

Regardless of previous categorization of the bone (compact or cancellous), from microstructural perspective, bone is classified in two different groups: (a) lamellar bone, and (b) woven bone (see Fig. 1.7). 
The lamellar bone, also known as the secondary bone, is a mature type of bone that is a result of remodeling processes of the primary bone. Most of the bones of an adult human are of the lamellar type. This type of bone consists of organized collagens and is strong and mineralized.

The woven or primary bone is a temporary, immature bone. It will turn into a lamellar bone later. During the fracture healing process, the initial type of bone forming in the fracture site is the primary bone that will be mineralized later and become the lamellar. The orientation of collagen fibers in primary bone is random [17].

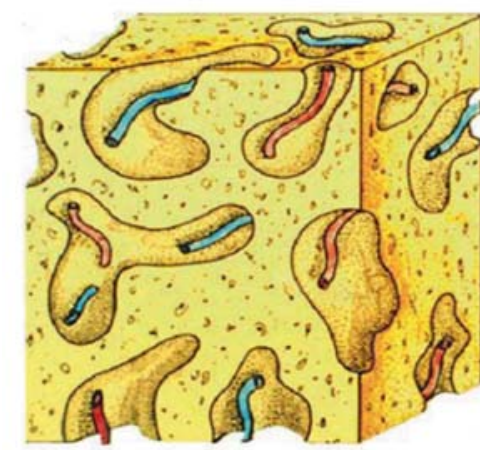

Woven

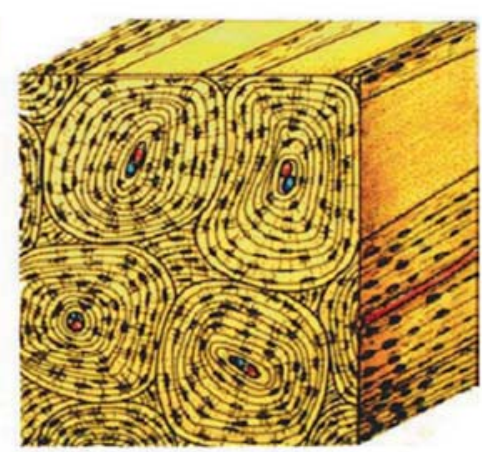

Lamellar

Fig. 1.7: Primary (woven) and secondary (lamellar) bones [17].

\subsection{Summary}

In this chapter, biological properties of three different connective tissues were reviewed. Collagen is an important component of the meniscus, cartilage and bone which plays a vital role in their functionality. Type and arrangements of collagen differ in each tissue.

Meniscus and articular cartilage have depth dependency composition and structure. Bone is divided into two groups of cortical and trabecular bones from the macrostructure aspect, and into two sets of primary and secondary bones in respect to microstructure. 


\section{Chapter 2}

\section{Mechanical Properties of Biological}

\section{Tissues}

In the hierarchy of the human body, tissue is located between human cells and organs. There are different types of tissue in the human biological system including (a) Epithelial tissue, (b) Connective tissue, (c) Nervous tissue, and (d) Muscular tissue [22].

Epithelial tissue covers the exterior surface of the body and the interior surface of organs, cavities of organs, and vessels. Skin is an example of epithelial tissue. Connective tissue connects other tissues in addition to supporting them. Bone, tendons, ligaments and even blood are some examples of connective tissues. Nervous tissue makes the communication between the brain and other parts of the body possible [22]. For each tissue type, biological properties and mechanical behavior has an important role in the whole system functionality and wellbeing. In this chapter, the structural and mechanical properties of meniscus, articular cartilage and bone, which are categorized under connective tissue, will be reviewed.

\subsection{Meniscus}

Meniscus is an important tissue which is located between the femur and tibia. Like other soft tissues, meniscus' major component is water which contributes to viscoelasticity of the tissue. It has an important role in load transferring in the knee joint and any damage and degeneration, can 
lead to lack of functionality of the joint as well as defect to the underlying bone. In this section the mechanical properties of meniscus will be discussed.

\subsubsection{Load Bearing as a Biphasic Material}

Meniscus shows the response of a biphasic material under load. It combines the elastic and viscous behavior of its components and performs a viscoelastic behavior. Subjecting to constant load, meniscus' response is categorized to initial and past initial behavior. The first one, is elastic like behavior, which after, the viscosity of the tissue and permeability regulate the tissue deformation based on the stress rate (see Fig. 2.1) [23]. During this process, fluid is discharged from the tissue. After force is removed, this fluid returns to the tissue. Feeding meniscus and adjacent cartilage and carrying out the waste and tissue rehydration are done through fluid flow after load removal [24].

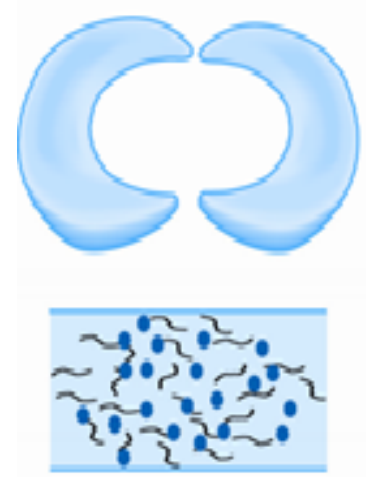

A
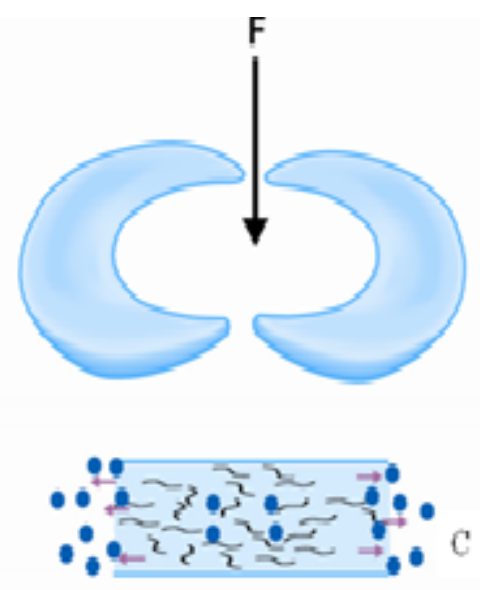

B

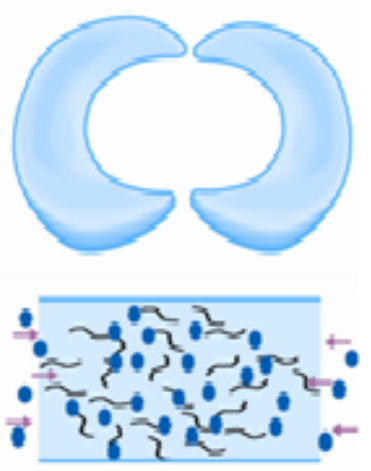

C

Blak lines: Glycosaminoglycans

Blue dots: Water

Fig. 2.1: Biphasic behavior of meniscus, (A) before applying load (B) at the time of load application (C) after load removal [25]. 


\subsubsection{Mechanical Properties of the Meniscus under Load}

Meniscus behavior under compression is site dependent. Proctor et al. [4] reported the mechanical properties of bovine meniscus in three different depths of tissue and also anterior and posterior sides. An important factor in biomechanical behavior of this tissue that is also related to its viscoelasticity is Aggregate Modulus $\left(\mathrm{H}_{\mathrm{A}}\right)$ which is defined as stiffness of the biological tissue at a stable condition when moisture flow has stopped [10]. The mean aggregate modulus of the bovine meniscus is reported $0.410 \pm 0.088 \mathrm{MPa}$ [4]. The measure of how freely the fluid moves through a solid is defined as Permeability, which is an important factor in mechanical properties of the soft tissue. The permeability and aggregate modulus of the bovine medial meniscus in different locations of the tissue are summarized in Table 2.1.

Table 2.1: Permeability and aggregate modulus of bovine medial meniscus under compression [4].

\begin{tabular}{|c|c|c|c|c|c|}
\hline \multirow{2}{*}{ Property } & \multicolumn{2}{|c|}{ Superficial } & \multicolumn{2}{c|}{ Deep } & \multirow{2}{*}{ Mean } \\
\cline { 2 - 5 } & posterior & Anterior & posterior & Anterior & \\
\hline $\begin{array}{c}\text { Permeability } \\
\left(\mathbf{1 0}^{-\mathbf{1 5}} \mathbf{m} / \mathbf{N} . \mathbf{s}\right)\end{array}$ & $0.76 \pm 0.47$ & $0.63 \pm 0.47$ & $0.91 \pm 0.52$ & $0.74 \pm 0.14$ & $0.81 \pm 0.45$ \\
\hline $\begin{array}{c}\text { Aggregate } \\
\text { Modulus } \\
\mathbf{( M P a )}\end{array}$ & $0.393 \pm 0.109$ & $0.440 \pm 0.108$ & $0.491 \pm 0.042$ & $0.375 \pm 0.042$ & $0.410 \pm 0.088$ \\
\hline
\end{tabular}

\subsubsection{Meniscus Behavior under Tension}

Meniscal tissue stiffness to tensile forces is 1,000 times greater than that of compressive forces [26]. Proctor et al. [4] tested meniscus behavior under tensile stress. They found that in terms of 
tensile mechanical properties, meniscus surface behaves like an isotropic material with approximately the same Young's modulus in circumferential and radial orientation. The average tensile Young's modulus is 59.8 $\pm 35.4 \mathrm{MPa}$ for the superficial layer [4]; however, for areas within the meniscus no isotopic behavior was reported. Additionally, depth wise, the meniscus showed inhomogeneous behavior. Mean tensile modulus of circumferentially orientated meniscus samples rises from the surface to the middle layer and decreases from the middle layer to the deep layer [4]. Tensile mechanical properties of the bovine meniscus are summarized in Table 2.2.

Table 2.2: Mechanical properties of bovine meniscus under tension [27].

\begin{tabular}{|c|c|c|c|}
\hline Yield Stress (MPa) & $\begin{array}{c}\text { Yield Strain } \\
\mathbf{( \% )}\end{array}$ & Ultimate Tensile Strength (MPa) & $\begin{array}{c}\text { Ultimate Strain } \\
\mathbf{( \% )}\end{array}$ \\
\hline $16.6 \pm 4.6$ & $36.8 \pm 10.9$ & $18.9 \pm 5.2$ & $48.7 \pm 11.5$ \\
\hline
\end{tabular}

\subsubsection{Factors Influencing Mechanical Properties of the Meniscus}

Meniscus is a viscoelastic, anisotropic, inhomogeneous living tissue. Its mechanical performance is affected by biological and non-biological factors. In this section, some of these key factors will be discussed.

\subsubsection{Strain Rate}

In dynamic loading, the strain rate has a positive correlation with the Young's modulus, yield stress and strength. Porcine Young's modulus and yield stress rise from $35.63 \mathrm{MPa}$ and $5.55 \mathrm{MPa}$ at the strain rate of $690 \mathrm{~s}^{-1}$ to $148.14 \mathrm{MPa}$ and $23.83 \mathrm{MPa}$ at the strain rate of $1560 \mathrm{~s}^{-1}$ respectively [28]. As illustrated in Fig. 2.2A, the Young's modulus and yield stress increase in line with the strain 
rate. Nevertheless, these changes are nonlinear and higher strain rates yield to greater increases in stiffness and ultimate stress.
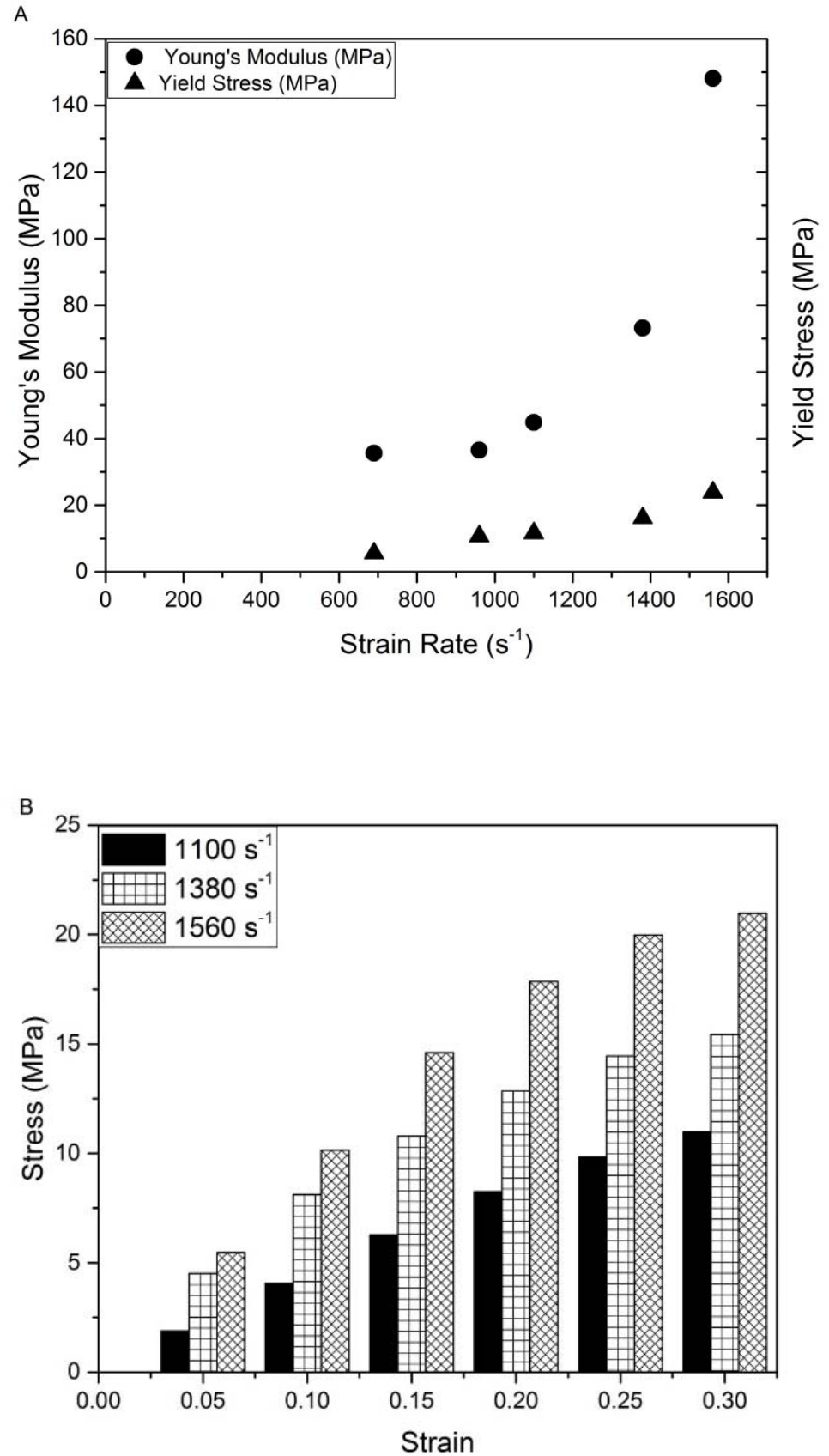

Fig. 2.2: Strain rate sensitivity of meniscus mechanical properties (A) Young's modulus and yield stress (B) stress-strain variations based on strain rate (data from [28]). 
The strain rate affects the amount of stress on a given strain. As the strain rate increases, higher stress is required to develop the same strain. As illustrated in Fig. 2.2B, to produce the strain of 0.25 , at strain rates of $1100 \mathrm{~s}^{-1}, 1380 \mathrm{~s}^{-1}$, and $1560 \mathrm{~s}^{-1}$, the stresses of $9.8 \mathrm{MPa}, 14.4 \mathrm{MPa}$, and 19.9 $\mathrm{MPa}$ are required respectively.

\subsubsection{Load Repetition}

Fischenich et al. [29] investigated the effect of repetitive force on modulus of the human and ovine meniscus. The samples were tested to the strain of $12 \%$ under the compressive load at $1 \mathrm{~Hz}$ frequency. As per the results, the compressive modulus in both ovine and human samples decreased as more cyclic stress (time) was applied (see Fig. 2.3A). However, as shown in Fig. 2.3B, the modulus of ovine meniscus in all stages was higher than that of human [29].

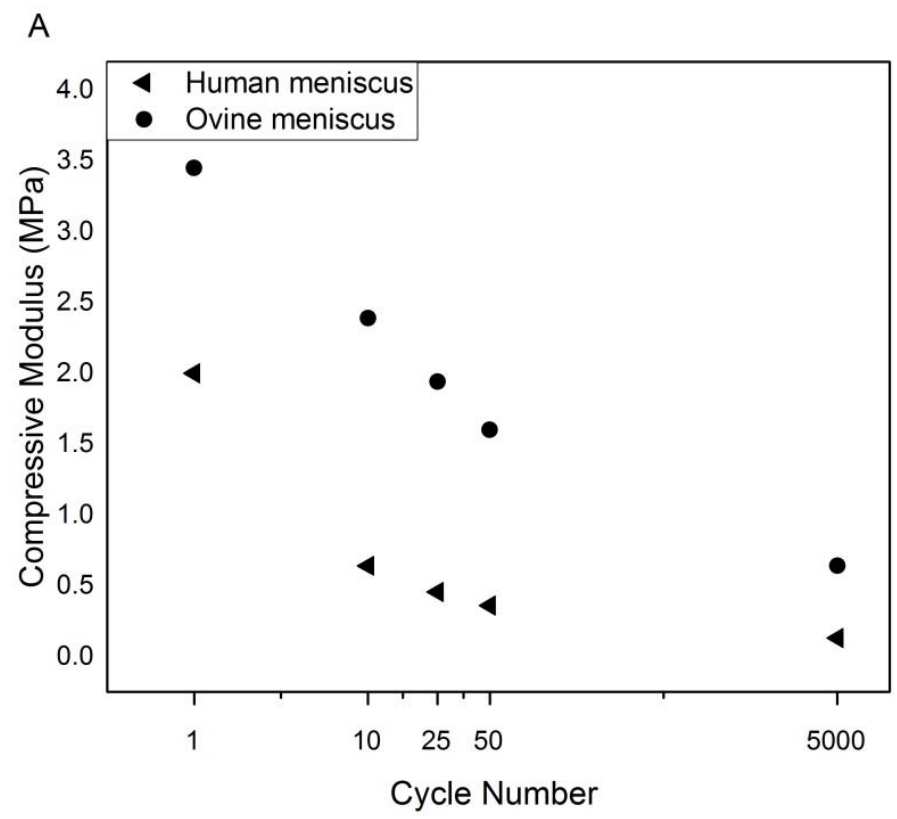

Fig. 2.3: The effect of cyclic loading on modulus of human and ovine meniscus (A) at 1-5,000 cycles (B) at cycles 1, 50 and 5,000 (data from [29]). 


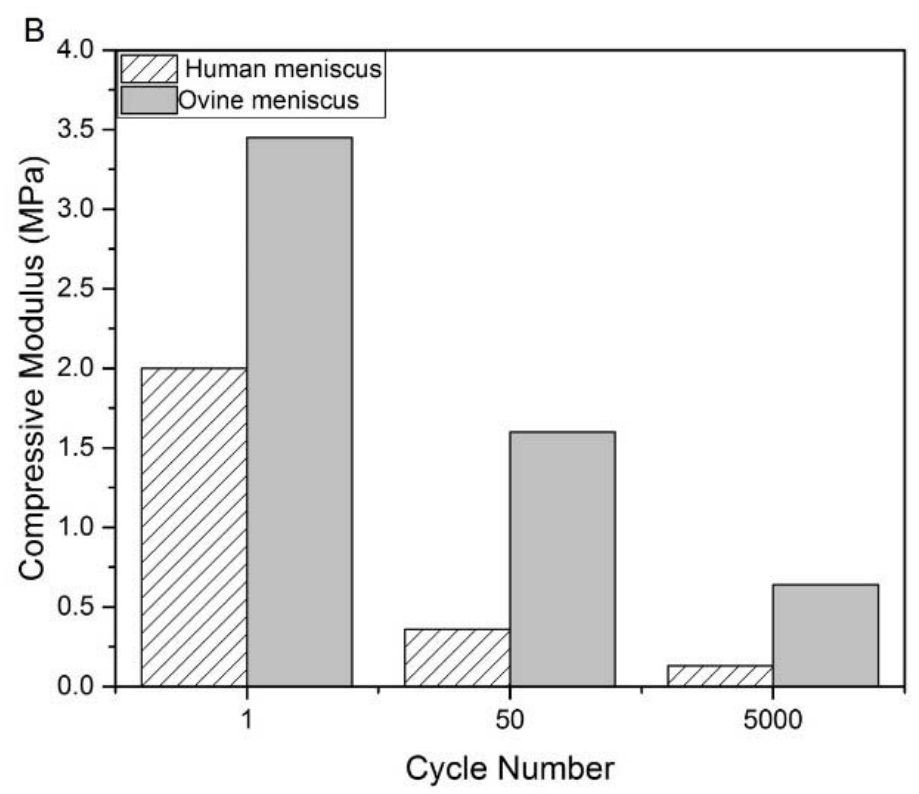

Fig. 2.3: (Continued)

\subsubsection{Osteoarthritis}

Osteoarthritis affects the meniscus, bone, and articular cartilage and causes degeneration that leads to lack of functionality of the tissue. In a knee joint affected by osteoarthritis, defects in the articular cartilage and meniscus are similar [30]. Osteoarthritis causes some compositional changes in the glycosaminoglycans and water content of the tissue [31].

\subsubsection{Age}

Aging affects meniscus directly, through changes in the tissue, and indirectly, through changing its environmental conditions. The synovial joint fluid acts as a lubricant in the knee joint. Nonetheless, its composition and properties vary by age. These changes cause increase in frictional forces and consequently meniscus damage [32]. As illustrated in Fig. 2.4, during the aging process, 
the water content of the tissue increases from $70 \%$ at the first stage (healthy stage) to $85 \%$ at the later stage (degenerated meniscus) [3].

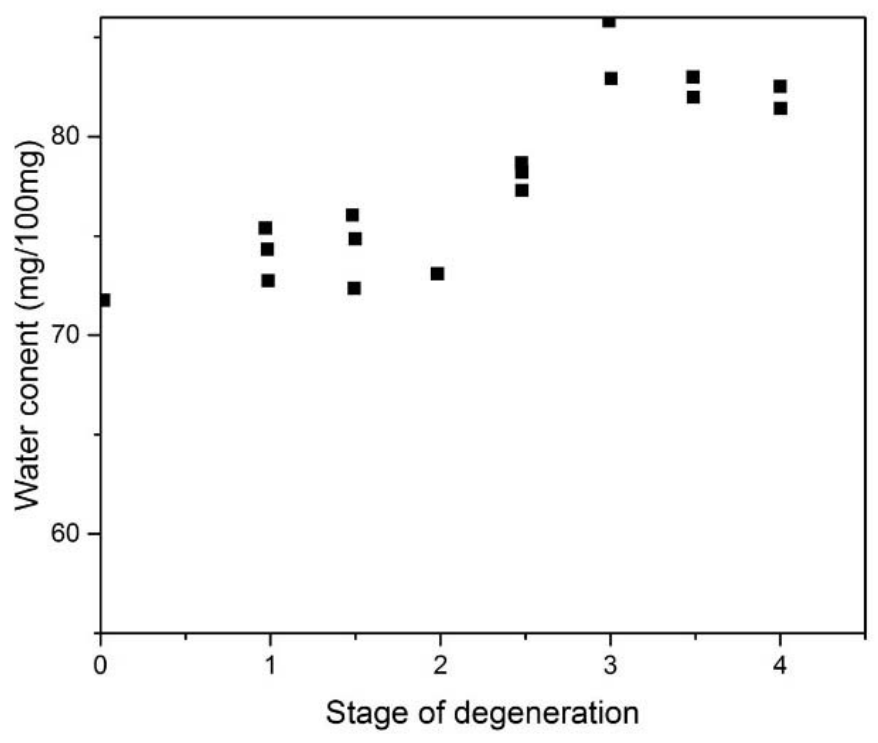

Fig. 2.4: Changes of water content of the meniscus during degeneration (data from [3]).

\subsection{Articular Cartilage}

Another essential connective tissue of the knee is articular cartilage. The role and functionality of this tissue located in the most complex joint of the human body is of major interest. An important function of the articular cartilage is provision of a low-friction surface for the bone, which is provided through the tissue's low friction coefficient and its fluid environment. The knee should withstand loads up to 3.5 times bigger than the weight of the body [11] and the articular cartilage makes this possible through its load bearing and load transition capabilities. In this section, the mechanical properties of the articular cartilage and some of the influencing parameters will be discussed. 


\subsubsection{Load Bearing as a Biphasic Material}

Articular cartilage, composed of wet and dry phases, as a viscoelastic material has time dependent behavior. As illustrated in Fig. 2.5A, upon applying forces, the wet phase of the articular cartilage bears a very high percentage of the applied force. However, as time advances, the moisture discharges from the tissue and the dry phase withstands most of the applied stress on the tissue [11].
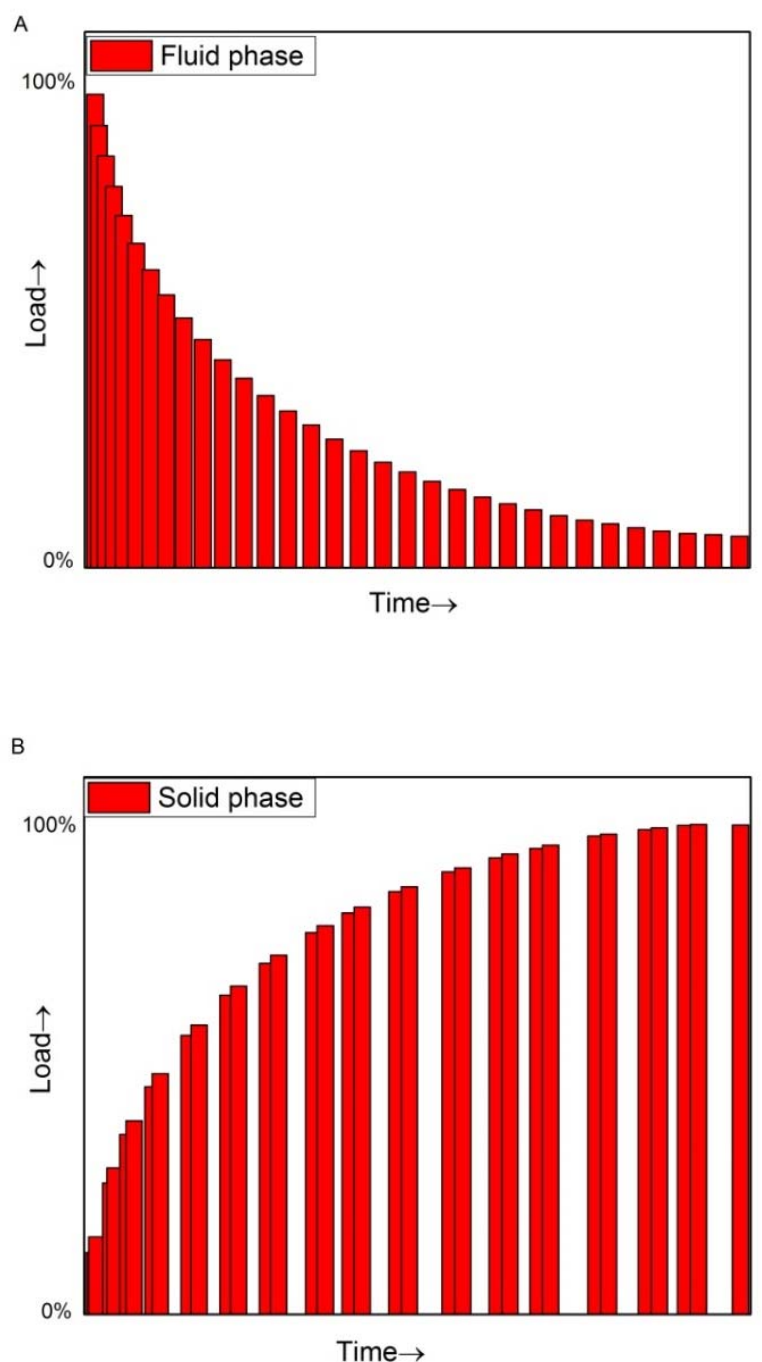

Fig. 2.5: Load bearing performance of (A) fluid and (B) solid phases of the articular cartilage (data from [11]). 


\subsubsection{Articular Cartilage Behavior under Compression}

Articular cartilage is subjected to compression forces frequently. This soft tissue, like other viscoelastic materials, has time dependent behavior under compression. Aggregate modulus is not the same among species or in different sites of the tissue. For instance, aggregate modulus of human articular cartilage varies from $0.701 \pm 0.228 \mathrm{MPa}$ in the lateral condyle to $0.530 \pm 0.094 \mathrm{MPa}$ in the patellar groove [33]. The aggregate modulus and poison's ratio of human, bovine and dog articular cartilage are summarized in Table 2.3.

Table 2.3: Articular cartilage aggregate modulus and poison's ratio in different species and sites

[33].

\begin{tabular}{|c|c|c|c|c|}
\hline \multirow{2}{*}{ Species } & \multicolumn{2}{|c|}{ Aggregate Modulus (MPa) } & \multicolumn{2}{c|}{ Poisson's Ratio } \\
\cline { 2 - 5 } & Lateral condyle & Patellar groove & Lateral condyle & Patellar groove \\
\hline Human & $0.701 \pm 0.228$ & $0.530 \pm 0.094$ & $0.098 \pm 0.069$ & $0.000 \pm 0.000$ \\
\hline Bovine & $0.894 \pm 0.293$ & $0.472 \pm 0.147$ & $0.396 \pm 0.023$ & $0.245 \pm 0.065$ \\
\hline Dog & $0.603 \pm 0.237$ & $0.555 \pm 0.144$ & $0.300 \pm 0.075$ & $0.093 \pm 0.067$ \\
\hline
\end{tabular}

Articular cartilage is a biphasic material with a porous structure. Compression of this tissue is mostly regulated by the movement of moisture in the tissue [11]. As illustrated in Fig. 2.5, upon load application, load sharing occurs between the fluid and solid phases of the tissue. In the event the tissue loses all its fluid due to changes in permeability, the entire force shall be borne by the dry phase, which may lead to tissue failure [10]. Different factors determine permeability of the tissue, like microstructure, arrangement of the collagen fibers, and the tissue composition. Since the material property and structure differs in different zones of the articular cartilage, it can be postulated the permeability is not constant throughout the tissue depth [10]. 


\subsubsection{Articular Cartilage Behavior under Tension}

The knee's articular cartilage is subject to tensile forces in physiological activities. At initial stage of applying tension, since the collagen fibers are not aligned in the load direction and the tissue stiffness is low, the cartilage undergoes large deformations. This phenomenon is followed by a slower deformation rate and a linear stress-strain curve, which results from alignment of the collagen fibers.

Mechanical properties of the articular cartilage under tension are summarized in Table 2.4.

Table 2.4: Mechanical properties of the bovine articular cartilage under tension [27].

\begin{tabular}{|c|c|c|c|}
\hline $\begin{array}{c}\text { Yield Stress } \\
\mathbf{( M P a )}\end{array}$ & $\begin{array}{c}\text { Yield Strain } \\
\mathbf{( \% )}\end{array}$ & $\begin{array}{c}\text { Ultimate Tensile Strength } \\
\mathbf{( M P a )}\end{array}$ & $\begin{array}{c}\text { Ultimate Strain } \\
\mathbf{( \% )}\end{array}$ \\
\hline $4.7 \pm 2.1$ & $113.8 \pm 25.1$ & $4.7 \pm 2.1$ & $113.8 \pm 25.1$ \\
\hline
\end{tabular}

\subsubsection{Factors Influencing Mechanical Properties of the Articular Cartilage}

Articular cartilage is a viscoelastic, anisotropic, inhomogeneous living tissue. Its mechanical performance is affected by biological and non-biological factors. In this section, some of the important factors impacting the articular cartilage's mechanical responses will be discussed.

\subsubsection{Loading Frequency}

The measure of how frequently the load is applied has an impact on the storage modulus and crack growth in the articular cartilage [34,35]. The storage modulus of human and bovine articular cartilage has a positive correlation with the loading frequency. However, its variation in frequency changes is not constant. Based on the experiment results [34], increasing frequency from $1 \mathrm{~Hz}$ to 
$20 \mathrm{~Hz}$ causes significant increase in the storage modulus. Nonetheless, raising the frequency at higher rates (from $20 \mathrm{~Hz}$ to $88 \mathrm{~Hz}$ ) does not have much effect on the storage modulus (see Fig. 2.6) [34].

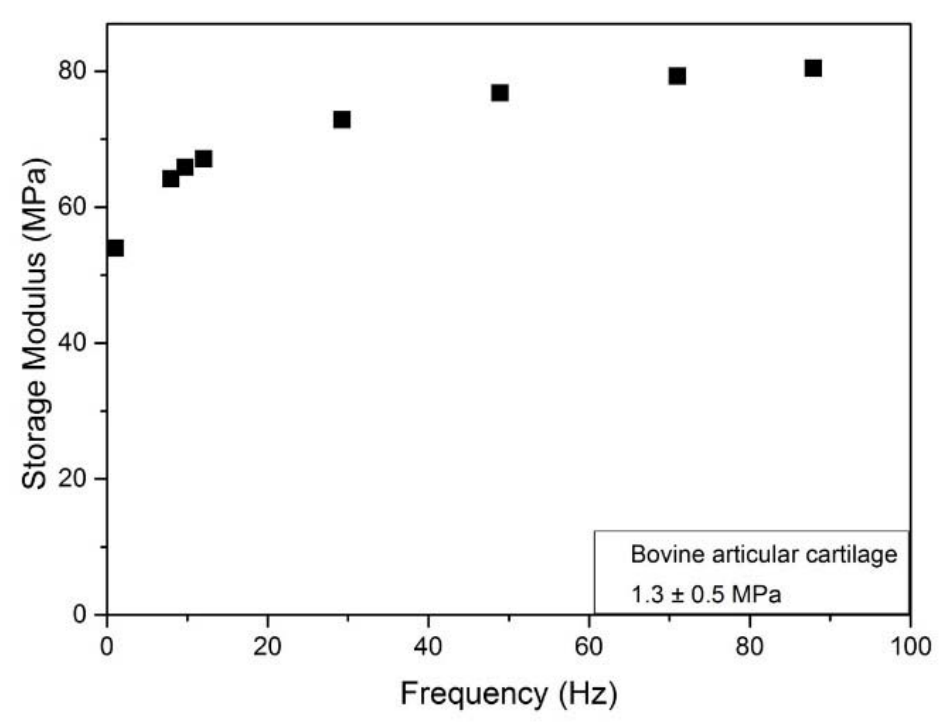

Fig. 2.6: Variation of storage modulus with changes in frequency (data from [34]).

Sadeghi et al. [35] found that loading frequency affects the crack propagation. According to their experiment, a pre-existed crack in bovine articular cartilage grows as tissue withstands more cyclic loads. Subjecting the tissue to higher frequency stress cycles results in more crack growth. For instance, after 10,000 cycles, the maximum crack growth was found as $0.6 \pm 0.3$ and $1.1 \pm 0.4 \mathrm{~mm}$ at frequencies of 1 and $100 \mathrm{~Hz}$ respectively [35].

\subsubsection{Strain Rate}

Load sharing of the two phases of articular cartilage is an important factor in tissue resistance to loads. Li and Herzog [36] investigated the effect of the strain rate on load sharing between solid and liquid phases of articular cartilage. The results indicate that more than $80 \%$ of the load is born 
by the solid phase at the strain rate of $0.005 \% \mathrm{~s}^{-1}$ at $15 \%$ compression, whilst raising the strain rate to $0.05 \% \mathrm{~s}^{-1}$, increases load bearing of the fluid phase to about $60 \%$ of the subjected load. Furthermore, the same study observed the axial compressive stress has a positive correlation with the strain rate at a given strain [36]. As illustrated in Fig. 2.7, at any strain, the higher strain rate is always linked to higher stress.

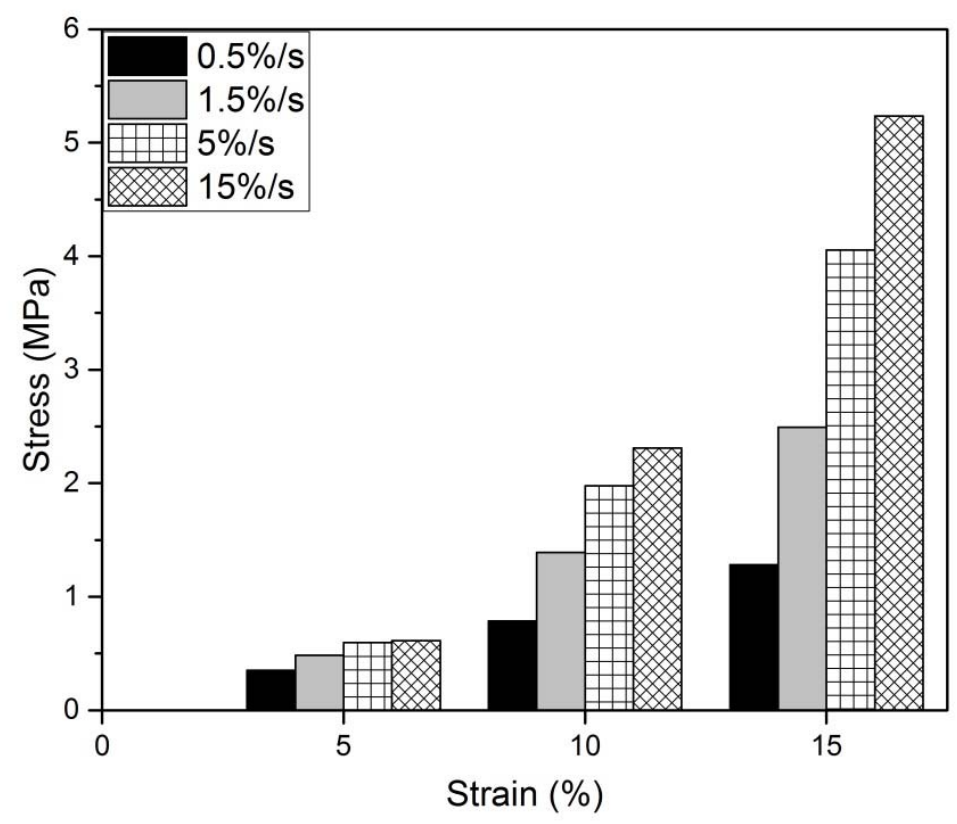

Fig. 2.7: Stress-strain relation of articular cartilage at different compressive axial strain rates (data from [36]).

Juang et al. [28] studied dynamic responses of the porcine articular cartilage and found that Young's modulus has a negative correlation with the strain rate. However, dependency of the yield stress on the strain rate is not predictable since, they both show positive and negative correlations at different strain rates (see Fig. 2.8). 


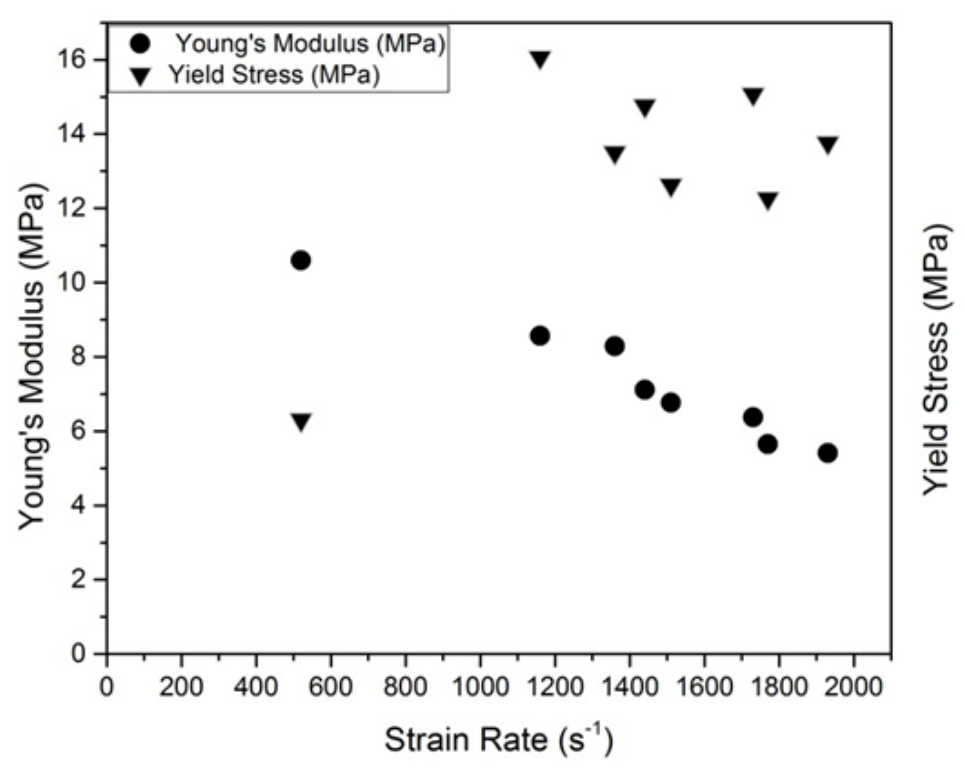

Fig. 2.8: Variation of Young's modulus and yield stress with changes in strain rate (data from [28]).

\subsubsection{Load Repetition}

Whereas, behavior of the articular cartilage under compressive and tensile forces was previously discussed in the sections of (2.2.2) and (2.2.3), the effect of such forces on mechanical properties of the tissue is also of interest. Studies showed that cyclic compression loading in large numbers of cycles will change the maximum tensile stress the tissue can withstand. McCormack and Mansour [37] tested the bovine articular cartilage under a compression force of about $65 \mathrm{~N}$. The load was repeated for $64,800-97,200$ cycles. The results indicate that applying 97,200 stress cycles, caused a reduction in maximum tensile stress of the tissue while this property remained unchanged when the articular cartilage born only 64,800 cycles. This change happened without causing failure of tissue or damage to underlying bone [37]. The effect of the repetitive loads is not limited to the compression, as repeated tensile cyclic loads result in decreasing the maximum tensile strength of the articular cartilage as well [10]. 


\subsubsection{Osteoarthritis}

Osteoarthritis is a common disease which affects the articular cartilage. Patients with osteoarthritis suffer from painful joints, loss of mobility and other related problems. In osteoarthritis, a shift in the joint's articular cartilage structure from a healthy state leads to a decline in proteoglycan content [1] and an increase in permeability and water load of the tissue [10] (see Fig. 2.9). This causes reduction in tissue stiffness. Lower stiffness causes more strain under load and higher chance of failure.

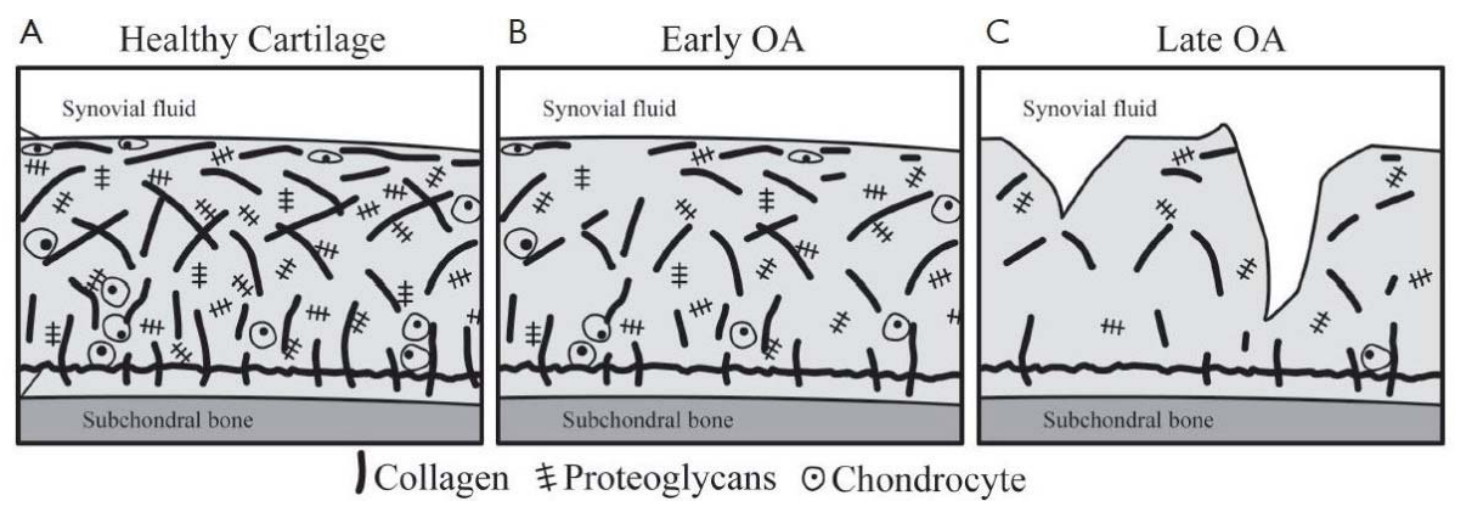

Fig. 2.9: Changes in articular cartilage in early and late osteoarthritis [38].

\subsubsection{Age}

Aging impacts the tissue mechanical properties through different factors of compositional and structural changes. The total content of chondrocytes in the tissue remains unchanged by aging, but its distribution throughout the depth of the tissue and in different layers will be affected [13].

The maximum tensile stress of articular cartilage, which declines in old individuals, is not constant in different locations. For example, tensile strength of articular cartilage in the hip is more affected 
by age than the one in the talus [10]. Fig. 2.10 illustrates the changes in failure tensile stress of the femoral head articular cartilage with respect to age.

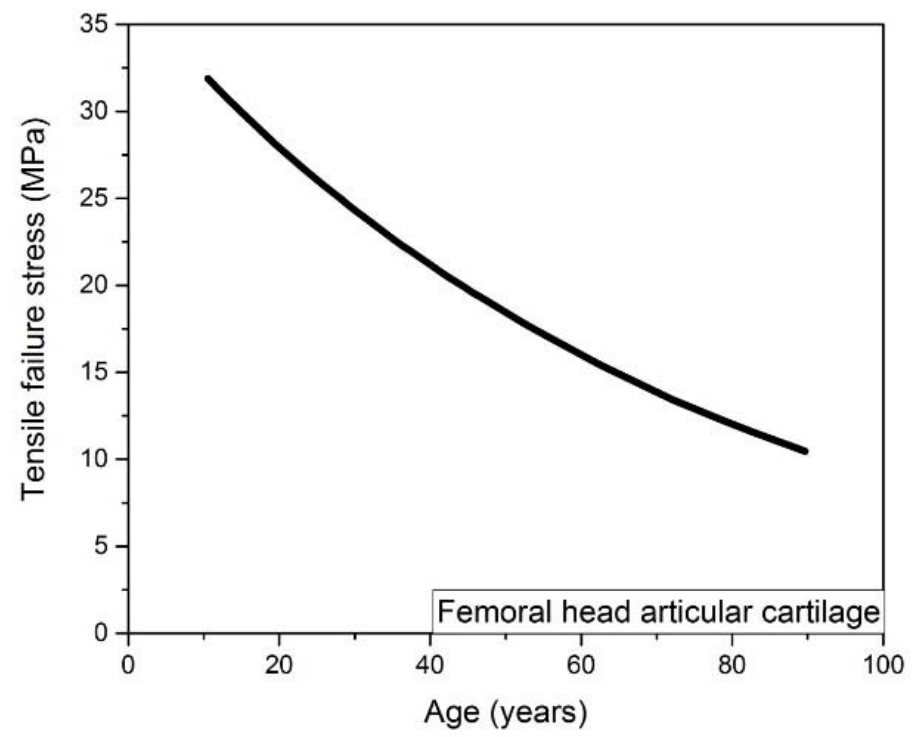

Fig. 2.10: Change in maximum tensile strength of hip articular cartilage by age (data from [10]).

\subsection{Bone}

Bone, as a viscoelastic living tissue, has a complex mechanical behavior. Below, the major influencing factors in mechanical behavior of the cancellous bone are reviewed.

\subsubsection{Bone as a Composite Material}

Bone is considered a composite material consisting of organic and mineral phases and water. The organic part which contributes to the bone's softness is principally made of collagen type I [19]. The mineral phase, mainly composed of calcium phosphate, assists in the bone's stiffness. 
To study mechanical responses of the cancellous bone under force, we start with Hooke's law. For materials with linear elasticity, stress and strain are related through:

$$
\sigma=C . \varepsilon
$$

where term $\sigma$ is the applied stress, $C$ is the elastic matrix, and $\varepsilon$ is the strain caused by the applied stress. For anisotropic materials, the components of Stiffness Matrix are described as (2.2).

$\left[\begin{array}{llllll}C_{11} & C_{12} & C_{13} & C_{14} & C_{15} & C_{16} \\ C_{12} & C_{22} & C_{23} & C_{24} & C_{25} & C_{26} \\ C_{13} & C_{23} & C_{33} & C_{34} & C_{35} & C_{36} \\ C_{14} & C_{24} & C_{34} & C_{44} & C_{45} & C_{46} \\ C_{15} & C_{25} & C_{35} & C_{45} & C_{55} & C_{56} \\ C_{16} & C_{26} & C_{36} & C_{46} & C_{56} & C_{66}\end{array}\right]$

Hooke's law for an anisotropic elastic material is described as below [39]:

$$
\left[\begin{array}{c}
\varepsilon_{11} \\
\varepsilon_{22} \\
\varepsilon_{33} \\
\gamma_{23} \\
\gamma_{13} \\
\gamma_{12}
\end{array}\right]=\left[\begin{array}{c}
\varepsilon_{11} \\
\varepsilon_{22} \\
\varepsilon_{33} \\
2 \varepsilon_{23} \\
2 \varepsilon_{13} \\
2 \varepsilon_{12}
\end{array}\right]=\left[\begin{array}{llllll}
S_{11} & S_{12} & S_{13} & S_{14} & S_{15} & S_{16} \\
S_{21} & S_{22} & S_{23} & S_{24} & S_{25} & S_{26} \\
S_{31} & S_{32} & S_{33} & S_{34} & S_{35} & S_{36} \\
S_{41} & S_{42} & S_{43} & S_{44} & S_{45} & S_{46} \\
S_{51} & S_{52} & S_{53} & S_{54} & S_{55} & S_{56} \\
S_{61} & S_{62} & S_{63} & S_{64} & S_{65} & S_{66}
\end{array}\right]\left[\begin{array}{c}
\sigma_{11} \\
\sigma_{22} \\
\sigma_{33} \\
\sigma_{23} \\
\sigma_{13} \\
\sigma_{12}
\end{array}\right]
$$

The matrix $S$, which is the inverse of the stiffness matrix, is called Compliance Matrix.

Considering the orthotropic property of the trabecular bone and showing all components of the stiffness and strain tensor of the equation (2.1), in the coordinate system, the aforementioned equation can be written as (2.4) and its compliance matrix $S$ as (2.5). 


$$
\begin{aligned}
& \left\{\begin{array}{c}
\sigma_{1} \\
\sigma_{2} \\
\sigma_{3} \\
\tau_{23} \\
\tau_{13} \\
\tau_{12}
\end{array}\right\}=\left[\begin{array}{cccccc}
C_{11} & C_{12} & C_{13} & 0 & 0 & 0 \\
C_{12} & C_{22} & C_{23} & 0 & 0 & 0 \\
C_{13} & C_{23} & C_{33} & 0 & 0 & 0 \\
0 & 0 & 0 & C_{44} & 0 & 0 \\
0 & 0 & 0 & 0 & C_{55} & 0 \\
0 & 0 & 0 & 0 & 0 & C_{66}
\end{array}\right]\left\{\begin{array}{c}
\epsilon_{1} \\
\epsilon_{2} \\
\epsilon_{3} \\
\gamma_{23} \\
\gamma_{13} \\
\gamma_{12}
\end{array}\right\} \\
& {\left[\begin{array}{cccccc}
S_{11} & S_{12} & S_{13} & 0 & 0 & 0 \\
S_{12} & S_{22} & S_{23} & 0 & 0 & 0 \\
S_{13} & S_{23} & S_{33} & 0 & 0 & 0 \\
0 & 0 & 0 & S_{44} & 0 & 0 \\
0 & 0 & 0 & 0 & S_{55} & 0 \\
0 & 0 & 0 & 0 & 0 & S_{66}
\end{array}\right]}
\end{aligned}
$$

The components of the compliance matrix are defined as a relationship between Young's modulus, Poisson's ratio, and shear modulus:

$$
[S]=\left[\begin{array}{rrrrrr}
\frac{1}{E_{1}} & -\frac{v_{12}}{E_{1}} & -\frac{v_{13}}{E_{1}} & 0 & 0 & 0 \\
-\frac{v_{21}}{E_{2}} & \frac{1}{E_{2}} & -\frac{v_{23}}{E_{2}} & 0 & 0 & 0 \\
-\frac{v_{31}}{E_{3}} & -\frac{v_{32}}{E_{3}} & \frac{1}{E_{3}} & 0 & 0 & 0 \\
0 & 0 & 0 & \frac{1}{G_{23}} & 0 & 0 \\
0 & 0 & 0 & 0 & \frac{1}{G_{31}} & 0 \\
0 & 0 & 0 & 0 & 0 & \frac{1}{G_{12}}
\end{array}\right] .
$$

where $E_{i}$ is the Young's modulus of the material in (i) direction, $G_{i j}$ is the shear modulus, and $v_{i j}$ is the Poisson's ratio. 
The trabecular bone, in some cases, can be regarded as transversely isotropic [40]. For orthotropic materials, the number of non-zero components of the compliance matrix is 9 , which will reduce to 5 non-zero components for transversely isotropic materials, as Young's modulus in $\mathrm{x}$ and $\mathrm{y}$ direction is equal. Also, the Poisson's ratio of the tissue in the $\mathrm{XY}$ direction is the same as in the YX direction. Additionally, the Poisson's ratio of the material in XZ, ZX, ZY, and YZ are the same. The shear modulus of the substance in $\mathrm{YZ}$ and $\mathrm{ZX}$ are equal, and that of $\mathrm{XY}$ direction (12) are calculated as:

$$
G_{12}=E_{1} / 2\left(1+v_{12}\right)
$$

Table 2.5 summarizes the elastic modulus, shear modulus, and Poisson's ratio of the trabecular bone of the human distal tibia [41]:

Table 2.5: Elastic properties of trabecular bone form human distal tibia [41].

\begin{tabular}{|c|c|c|c|c|c|c|c|c|c|}
\hline Property & $\begin{array}{c}\mathbf{E}_{\mathbf{1 1}} \\
(G P a)\end{array}$ & $\begin{array}{c}\mathbf{E}_{\mathbf{2 2}} \\
(G P a)\end{array}$ & $\begin{array}{c}\mathbf{E}_{\mathbf{3 3}} \\
(G P a)\end{array}$ & $\begin{array}{c}\mathbf{G}_{\mathbf{1 2}} \\
(G P a)\end{array}$ & $\begin{array}{c}\mathbf{G}_{\mathbf{1 3}} \\
(G P a)\end{array}$ & $\begin{array}{c}\mathbf{G}_{\mathbf{2 3}} \\
(G P a)\end{array}$ & $\boldsymbol{v}_{\mathbf{1 2}}$ & $\boldsymbol{v}_{\mathbf{1 3}}$ & $\boldsymbol{v}_{\mathbf{2 3}}$ \\
\hline \multirow{3}{*}{ In Vivo } & $\begin{array}{c}0.58 \\
\pm 0.10\end{array}$ & $\begin{array}{c}0.45 \\
\pm 0.082\end{array}$ & $\begin{array}{c}0.82 \\
\pm 0.084\end{array}$ & $\begin{array}{c}0.22 \\
\pm 0.022\end{array}$ & $\begin{array}{c}0.25 \\
\pm 0.032\end{array}$ & $\begin{array}{c}0.29 \\
\pm 0.042\end{array}$ & $\begin{array}{c}0.22 \\
\pm 0.034\end{array}$ & $\begin{array}{c}0.15 \\
\pm 0.018\end{array}$ & $\begin{array}{c}0.18 \\
\pm 0.024\end{array}$ \\
\hline
\end{tabular}

\subsubsection{Mechanical Behavior of Trabecular Bone under Static Load}

As an anisotropic mineralized tissue, bone has different responses and properties in different directions. As a viscoelastic material, the response of the bone under load (up to failure) consists of elastic and plastic regions as shown in Fig. 2.11. Like all viscoelastic materials, time dependency, creep, and hysteresis loops are characterizations of the bone. The spongy bone is 
regarded as linear elastic before yielding. It can withstand the strain of about $50 \%$ in compression but yields at $1 \%$ strain [20].

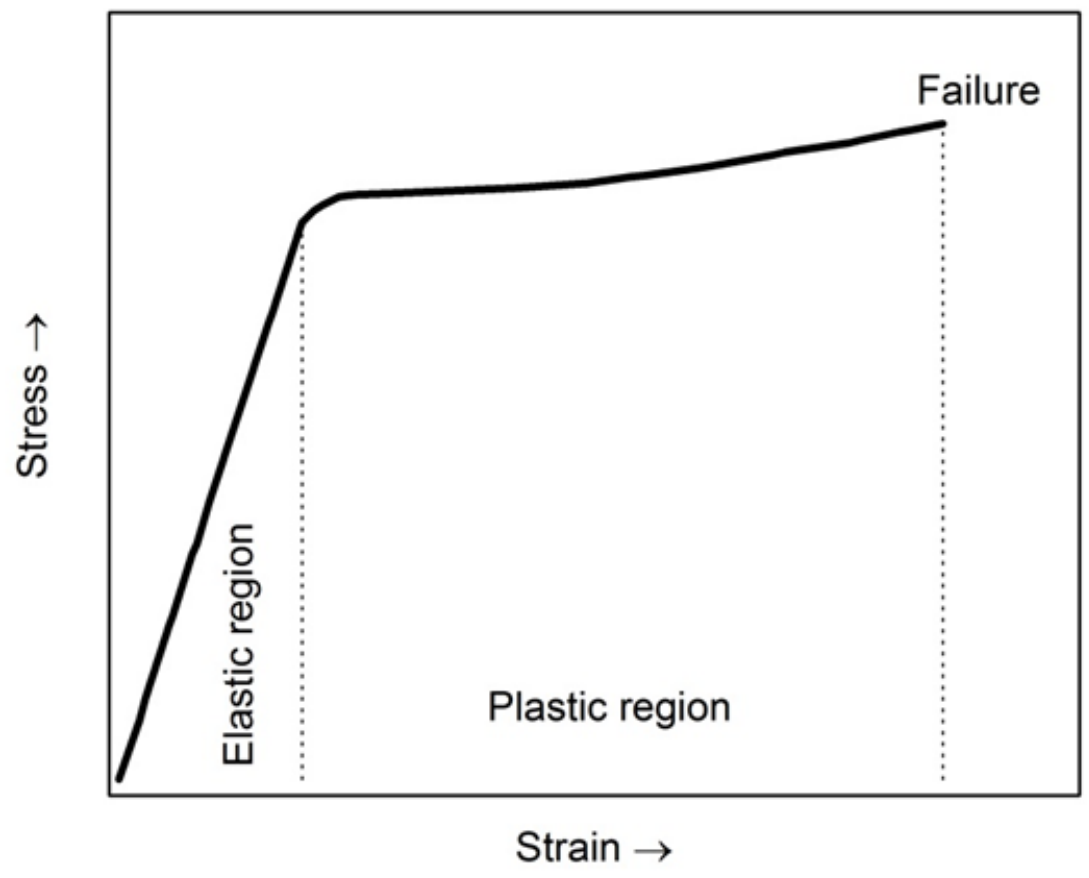

Fig. 2.11: The response of the bone under load.

\subsubsection{Mechanical Behavior of Trabecular Bone under Uniaxial Compression}

Kefalas and Eftaxiopoulos [42] divided the stress-strain curve of trabecular bone under uniaxial compression, into three stages (as shown in Fig. 2.12):

Stage 1: The first part of this stage is a sharp curve, in which a small number of trabeculae experience failure. The next part of this stage is the hardening portion, at which more trabeculae fail. The curve ends up with a softening part resulting in an increase in number of failed trabeculae [42]. 
Stage 2: The stress-strain curve in this stage is almost linear and it seems the tissue has a steady state in this portion of the stress-strain curve [42].

Stage 3: At this stage, force causes densification of the trabecular bone [42].

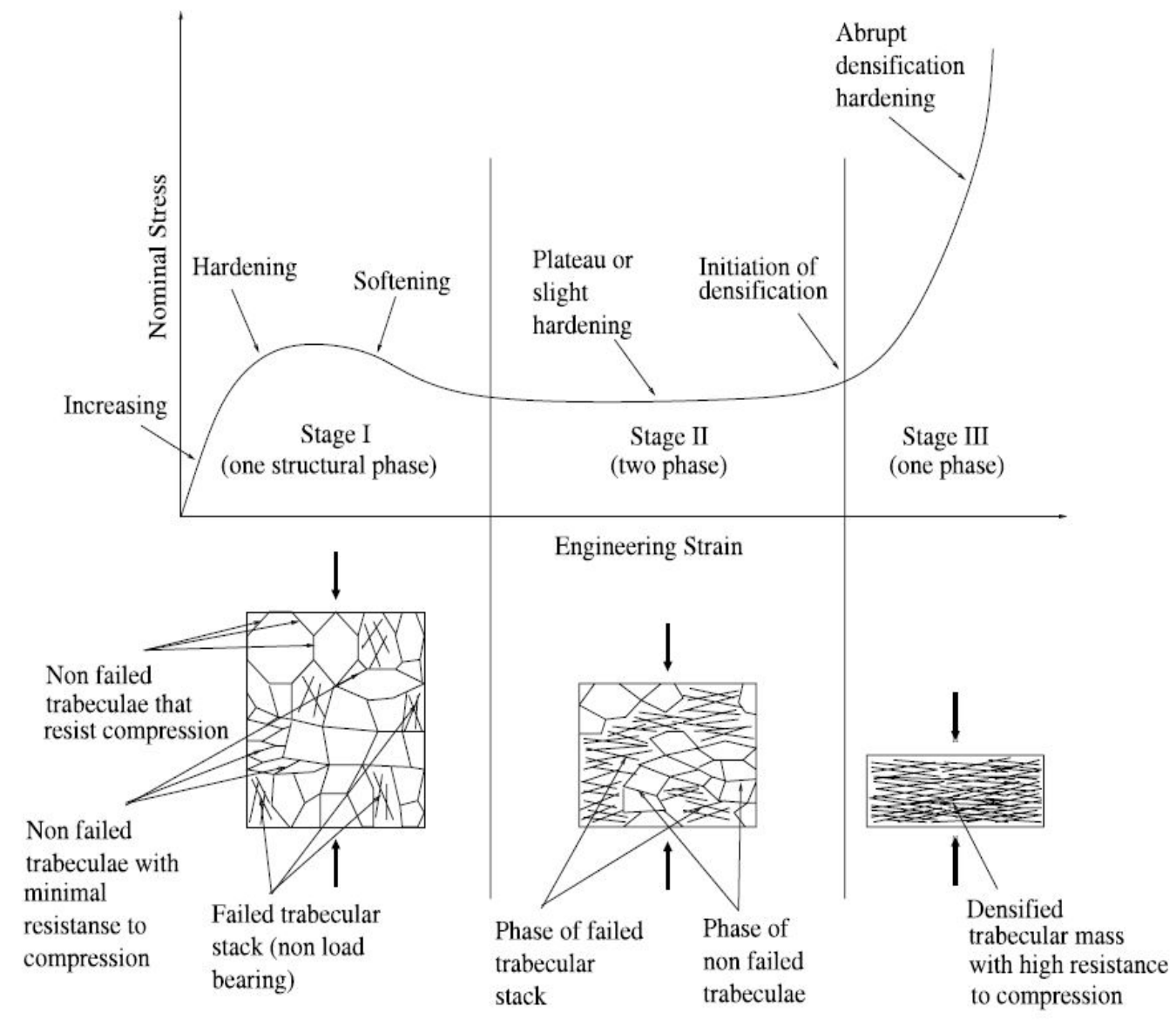

Fig. 2.12: Different stages of stress-strain curve of the spongy bone under uniaxial compression [42].

\subsubsection{Mechanical Response of the Trabecular Bone under Uniaxial Tension}

Applying uniaxial tension stress, the stress-strain curve of the spongy bone, as shown in Fig. 2.13, starts with an increasing part similar to the hard tissue response on compression, followed by a 
hardening portion, and finally a softening portion of the curve, which ends up in failure of the tissue [42].
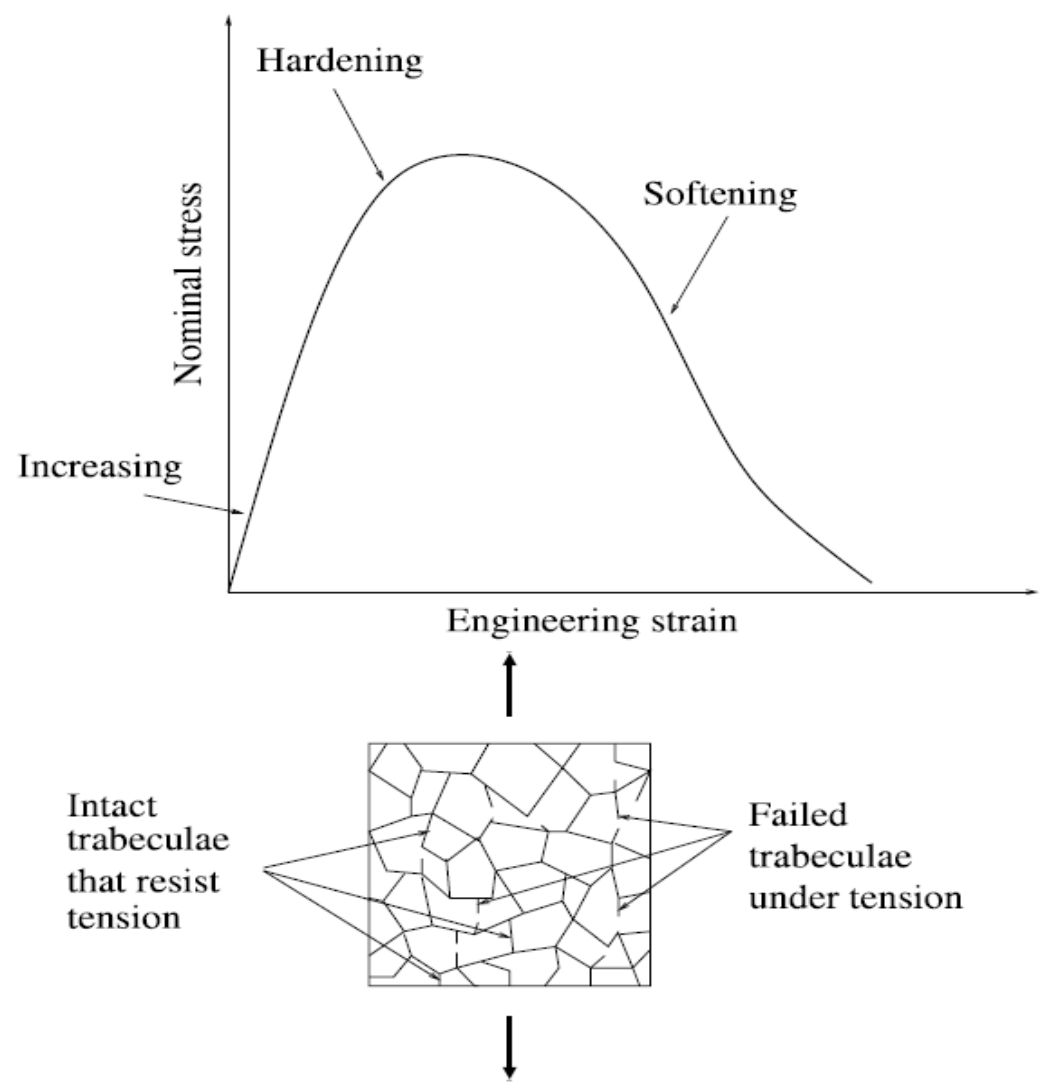

Fig. 2.13: Different stages of stress-strain curve of cancellous bone under tension [42].

\subsubsection{Factors Influencing Mechanical Behavior of the Trabecular Bone}

Several factors influence the bone's mechanical responses. In this section some factors will be discussed.

\subsubsection{Bone Density}

Tissue density is calculated through dividing its mass by the volume of the bone tissue, while, bone apparent density is equal to the ratio of the bone's mass to the bone's bulk volume (after 
removal of bone marrow) [20]. The tissue density value for both compact and spongy bone is approximately the same $\left(2 \mathrm{~g} / \mathrm{cm}^{3}\right)$. However, apparent density varies in cortical and cancellous bones [20]. The relationship between apparent density, tissue density, and volume fraction is defined [20] as:

$$
\rho_{\text {app }}=\rho_{\text {tissue }} \cdot V_{f}
$$

where $\rho_{a p p}$ is the apparent density, $\rho_{\text {tissue }}$ is the tissue density, and $V_{f}$ is the volume fraction.

Apparent density affects yield stress of the bone in longitudinal, transverse and shear directions. As is shown in Fig. 2.14, apparent density has a positive correlation with yield stress. Modulus and strength are also influenced by the apparent density [20]. Osteoporosis, regardless of its cause (disease or age) decreases the bone density and consequently increases the risk of bone fracture.

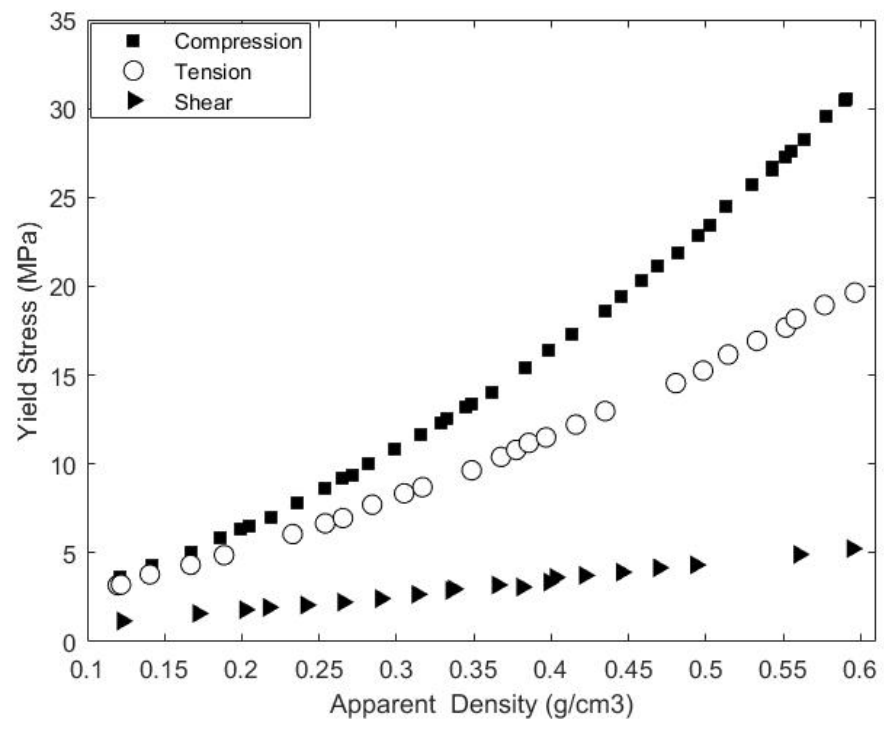

Fig. 2.14: Relationship between yield stress and apparent density in longitudinal direction in trabecular bone (data from [43]). 


\subsubsection{Degree of Anisotropy}

Another important factor that exerts an influence over the risk of fracture in spongy bone is the degree of the anisotropy. Kreider and Goldstein [44] found that this characteristic of cancellous bone in patients with hip fracture was higher than comparable bones. Spongy bone is highly anisotropic, thus, according to Wolff's law, to increase the bone strength in old people, more bone formation happens at the sites and in the direction of the habitual loads. This leads to a higher degree of anisotropy in the bone and consequently, a higher risk of fracture in other directions $[44,45]$. The load direction, age, and genetics have direct influences on the degree of anisotropy in the cancellous bone [44].

\subsubsection{Age}

As discussed before, age through impact on the bone density causes changes in the bone yield stress. However, its effect is not limited to the yield stress, as ultimate stress and Young's modulus also decrease with age. The compressive strength of the trabecular bone declines by $8.5 \%$ every ten years [46]. The amount of bone loss caused by age is not constant throughout the tissue. Bone density loss is higher at sites with low-strain and less in high-strain locations. Additionally, its effect on mechanical performance of the bone differs location-wise. In low-strain sites, even minor bone loss results in high degradation in mechanical properties. Nevertheless, in high-strain locations, large amounts of bone loss have little effect on the mechanical response of the trabecular bone [47]. 


\subsection{Summary}

Meniscus, articular cartilage and bone like all viscoelastic materials have time dependent behavior under load. Meniscus and articular cartilage are biphasic materials with dry and wet phases. Permeability and aggregate modulus are two important factors in the tissue mechanical response to the load. Different factors such as strain rate, number of applied stress cycles, osteoarthritis, and age can affect mechanical properties and the responses of the meniscus and articular cartilage. Bone, as a composite material, contains organic, inorganic phases. Any changes in its components from a healthy state affect bone performance under load such as diseases and age. 


\section{Chapter 3}

\section{Ratcheting of Biological Tissues}

Material substitution or repairing for a defective biological tissue has been of major interest. With advances in tissue engineering and implants, the designers endeavor to mimic the mechanical response of the tissue through studying and understanding their mechanical behaviors. An important response of biological tissues to the load is accumulation of plastic deformation over asymmetric stress cycles referred as ratcheting.

In this chapter a brief definition of ratcheting in biological tissues, its calculation, and examples of such phenomenon will be discussed. Ratcheting, which is defined as the built-up strain of a material under non-zero mean cyclic load $[48,49,50]$, is more investigated in metals. Due to their time dependency behavior and characterization ratcheting behavior of a biological tissue differs from metals. Ratcheting strain of each cycle is defined as the mean of the minimum and maximum strain values produced by that stress cycle:

$$
\varepsilon_{r}=\frac{\varepsilon_{\max }+\varepsilon_{\min }}{2}
$$

Fig. 3.1 presents a typical peak-valley strain values for the 20 th cycle for a bovine meniscus tested at load cycles $5.5 \pm 4.5 \mathrm{MPa}$ respectively 0.37 and $0.27 \mathrm{~mm} / \mathrm{mm}$. Substituting these values in equation (3.1), the ratcheting strain of the tissue in cycle 20 is calculated as 0.32 for the corresponding cycle. 


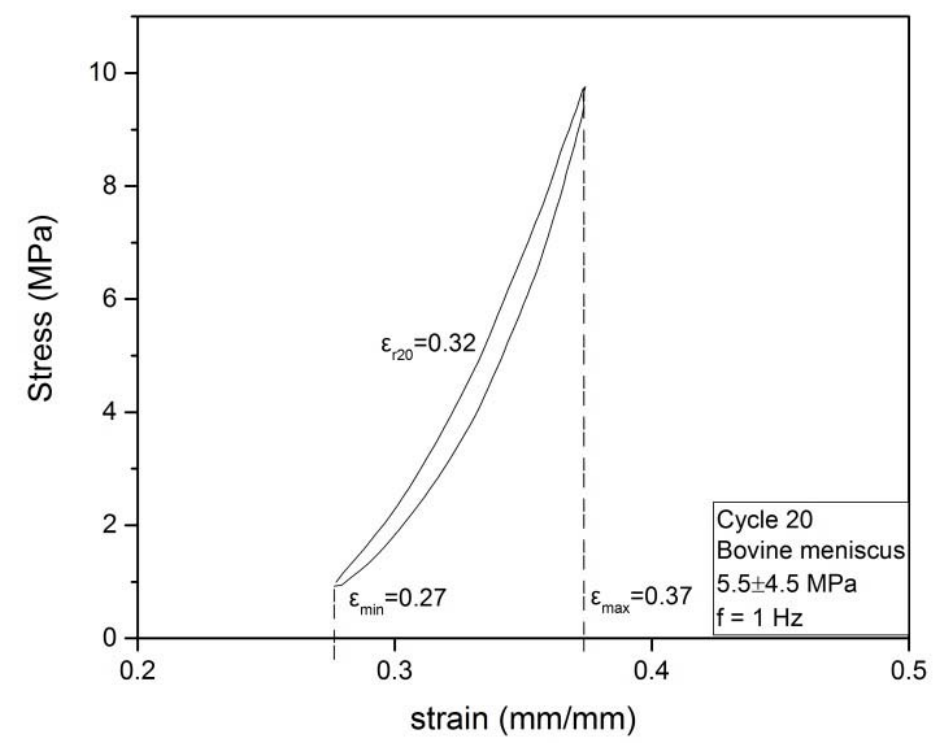

Fig. 3.1: Typical $20^{\text {th }}$ hysteresis loop to calculate ratcheting strain in bovine meniscus.

In the following sections, responses of the meniscus, articular cartilage, trabecular bone, cortical bone, skin, and tendon and corresponding stress-strain hysteresis loops will be briefly discussed.

\subsection{Meniscus}

In an experiment done by Miller et al. [48], the response of bovine meniscus under cyclic compression was studied. This test was performed on stress range between 1-10 $\mathrm{MPa}$ and at frequencies of $1 \mathrm{~Hz}$ and $10 \mathrm{~Hz}$. Fig. 3.2 presents hysteresis loops of bovine meniscus tissue at both frequencies as plastic strain is accumulated. Ratcheting strain and its rate in tissues are highly time and frequency dependent, which will be discussed in Chapter 6. 

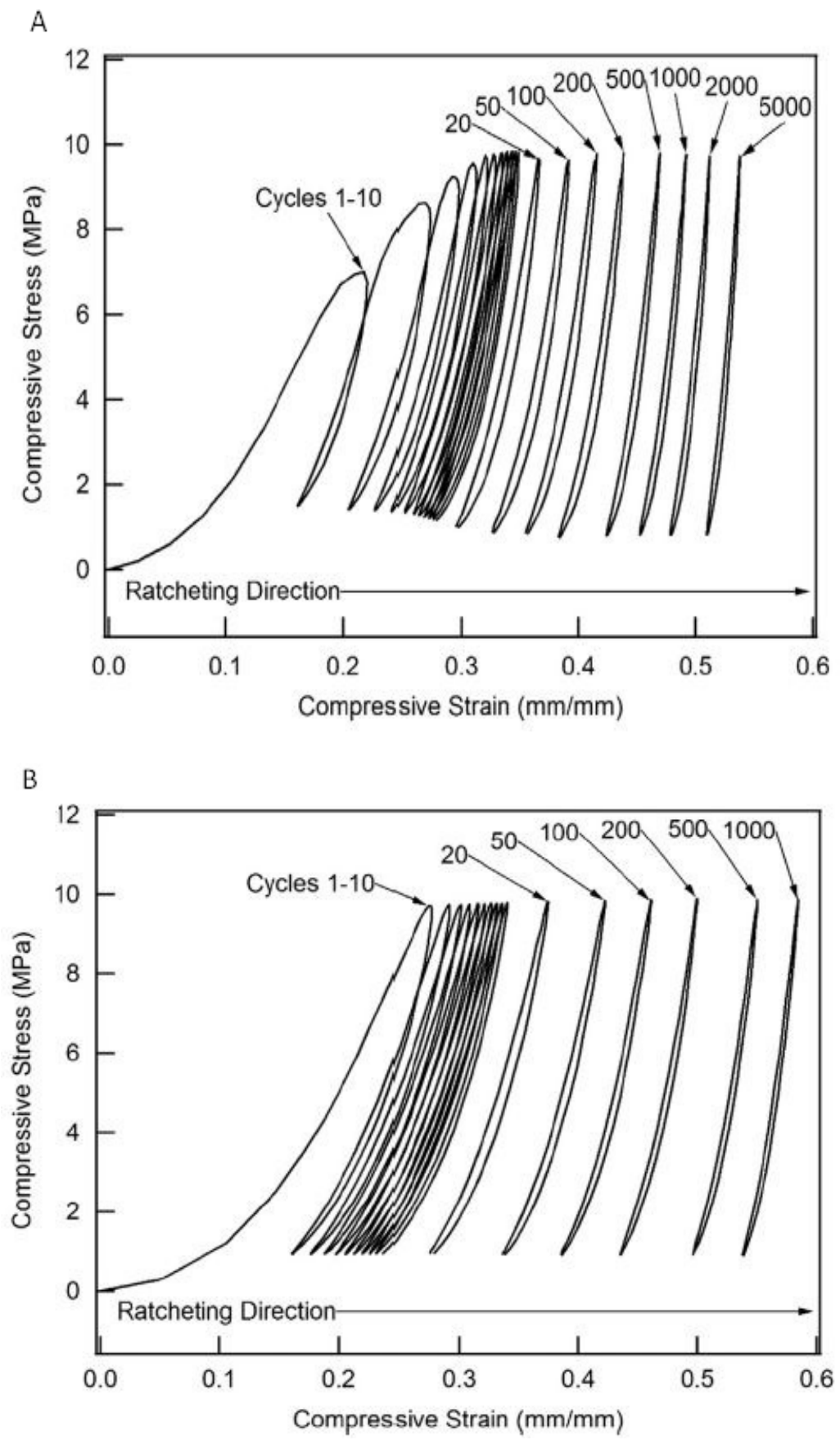

Fig. 3.2: Stress-strain curves of bovine meniscus (A) $10 \mathrm{~Hz}$ (B) $1 \mathrm{~Hz}$ [48].

Ratcheting strains of bovine meniscus tissue at two frequencies are calculated through equation (3.1) and is presented in Fig. 3.3. Ratcheting strain data rapidly increase in magnitude at first few cycles followed by a steady growth afterwards. 

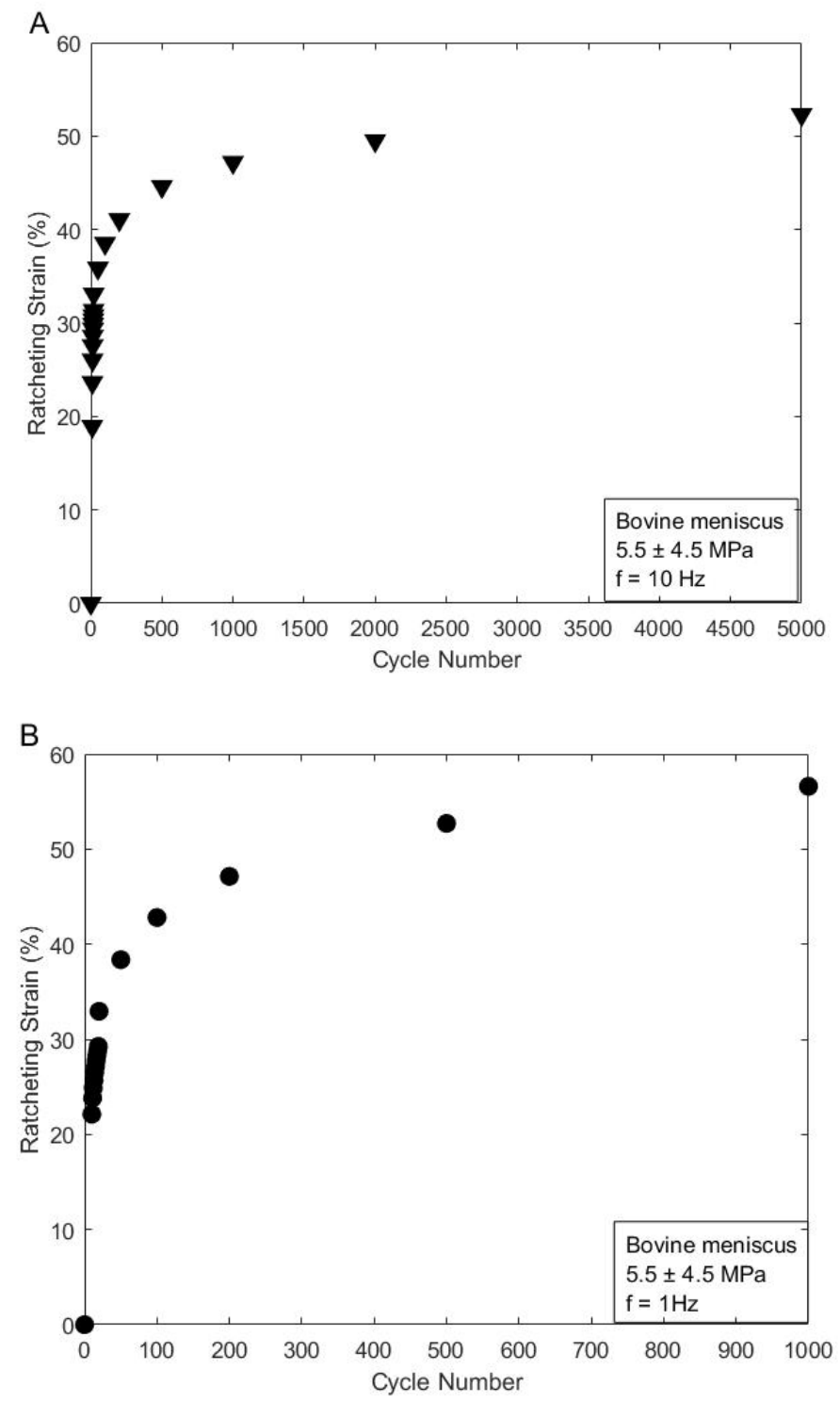

Fig. 3.3: Ratcheting strain of the meniscus under cyclic compression (A) $10 \mathrm{~Hz}$ (B) $1 \mathrm{~Hz}$.

\subsection{Articular Cartilage}

Porcine articular cartilage was tested under different stress variations and stress rates to investigate the ratcheting behavior of the tissue under cyclic compression [49]. As illustrated in Fig. 3.4A, like meniscus, there is a positive correlation between the strain of the connective tissue and the stress cycles. Additionally, the test environment and stress levels were changed to investigate 
dependency of the ratcheting on the stress variation, stress rate, tissue depth, and biological environment, which will be further detailed in Chapter 6. The ratcheting curve developed for articular cartilage over 200 loading cycles is presented in Fig. 3.4B.
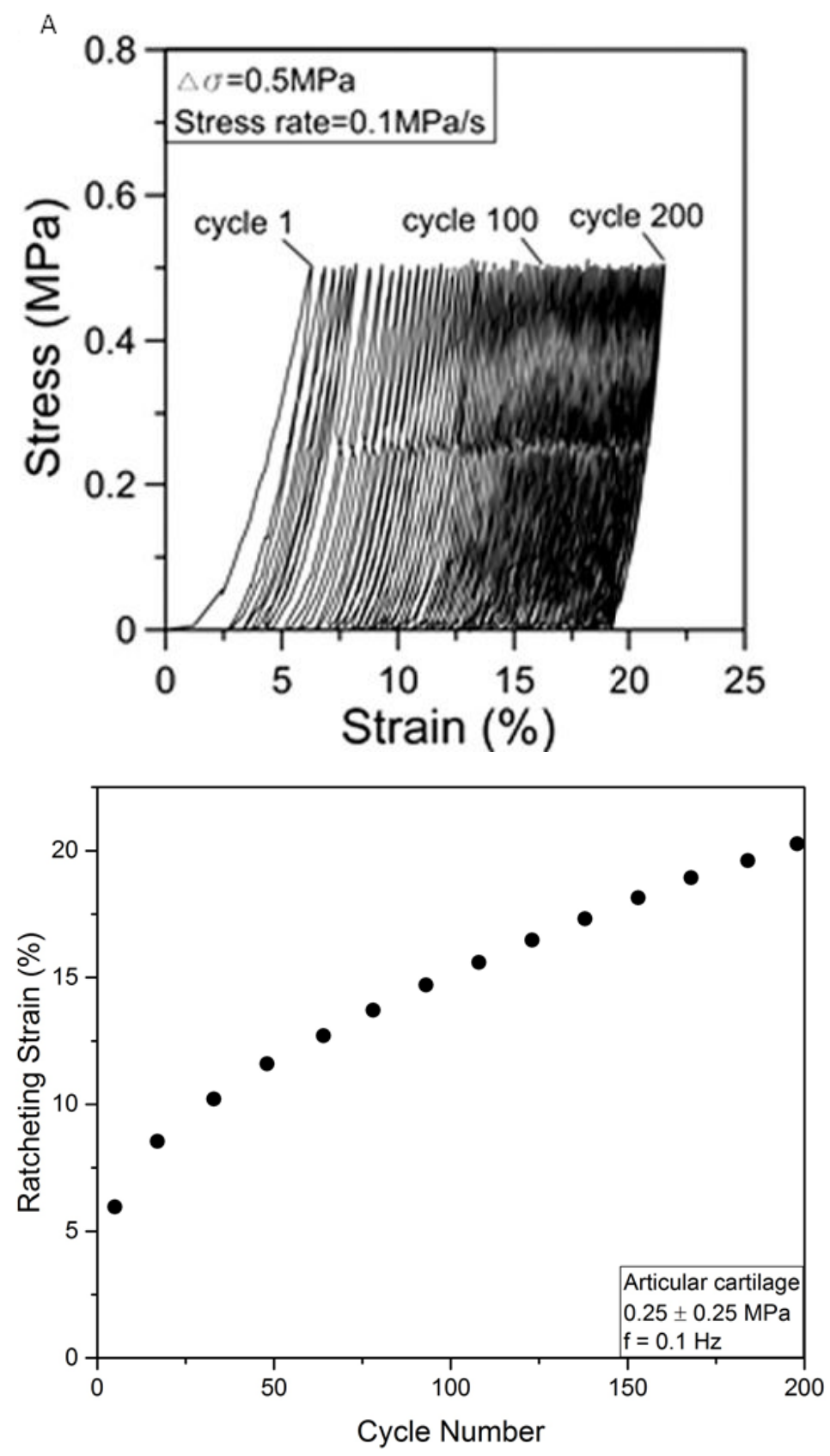

Fig. 3.4: Articular cartilage under cyclic load (A) Stress-strain curve [49]

(B) Ratcheting strain curve (data from [49]). 


\subsection{Trabecular Bone}

Wei et al. [50] investigated the ratcheting response of trabecular bone under cyclic compression. The experiment was performed under compression of $0-1.56 \mathrm{MPa}$. The response of porcine spongy bone to plastic strain accumulation over asymmetrically compressive cycles and their related hysteresis loops are plotted in Fig. 3.5. Fig. 3.5B shows the increase in the strain of the hard tissue under cyclic load. Ratcheting response of trabecular bone shows a high rate at initial cycles, but after cycle 100 , steady state was achieved.

A

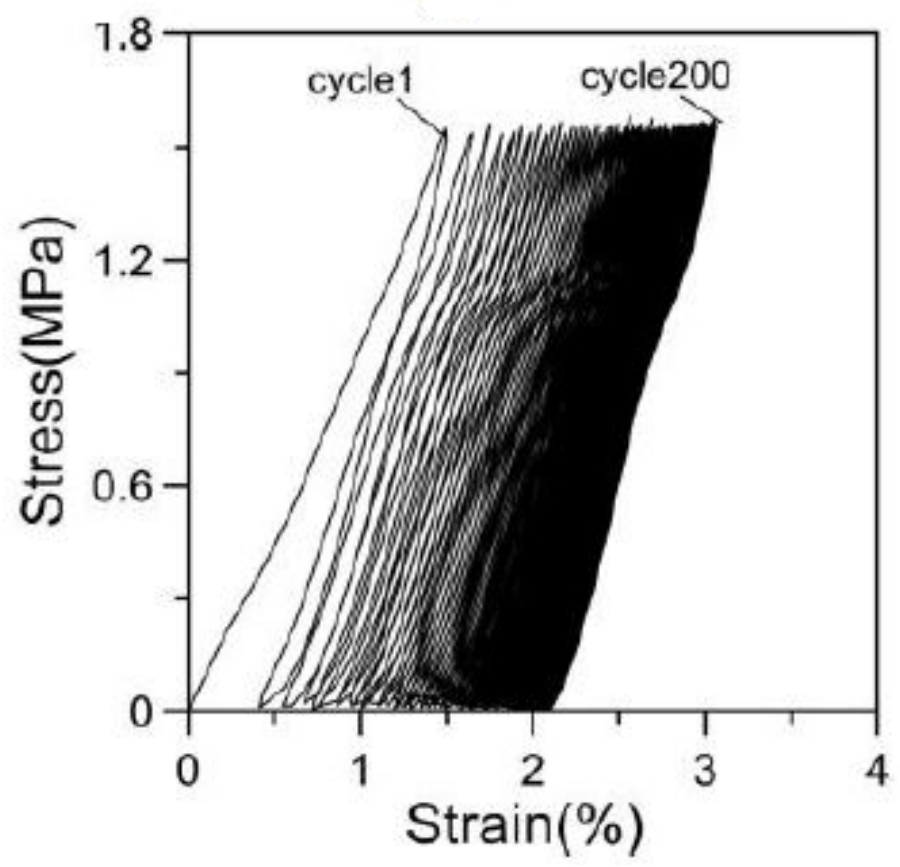

Fig. 3.5: Trabecular bone under cyclic load (A) Stress-strain curve [50] (B) Ratcheting strain curve (data from [50]) 


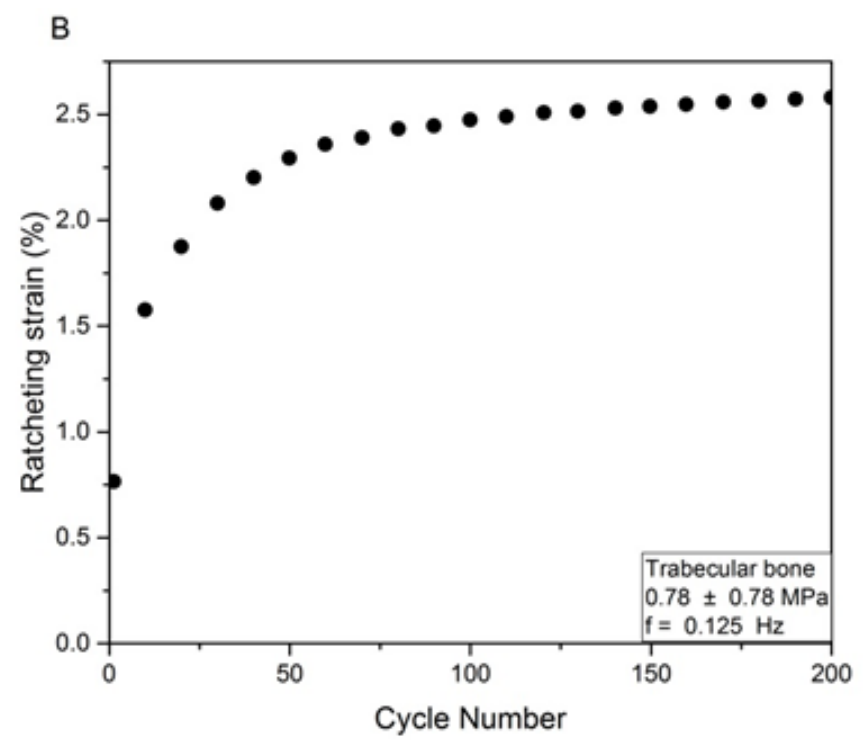

Fig. 3.5: (continued)

\subsection{Cortical Bone}

Pattin et al. [51] studied the fatigue behavior of human cortical midshaft under cyclic loads. Samples of the cortical bone were tested under tensile and compressive cyclic loads. The hysteresis loops of cortical bone under tensile and compressive stress cycles are presented in Fig. 3.6A, which illustrates that more stress cycles result in increments in width and decreases in the slope of the loops. Fig. 3.6B and 3.6C plot ratcheting strains of cortical bone tissues versus compressive and tensile cycles, respectively. The magnitude and trend of increase in ratcheting strain in these figures were found different at two load types. When the cortical bone is subjected to tension, higher ratcheting strain growth happens at the first 1,000 cycles, while during compression, this ratcheting progress occurred after the $1,000^{\text {th }}$ cycle. 

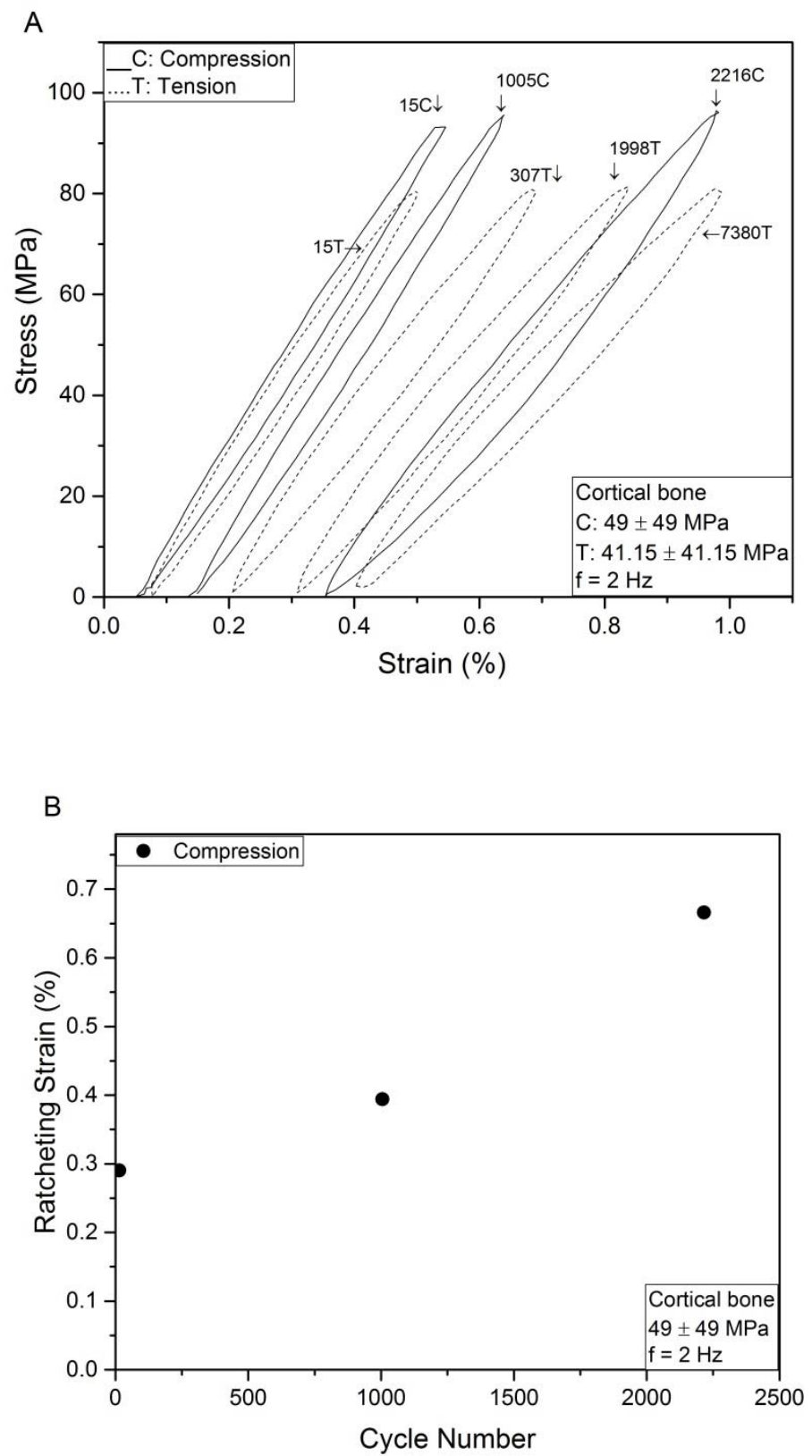

Fig. 3.6: Cortical bone under cyclic tension and compression (A) Stress-strain curve (data from [51]) (B) Compressive ratcheting strain (C) Tensile ratcheting strain. 


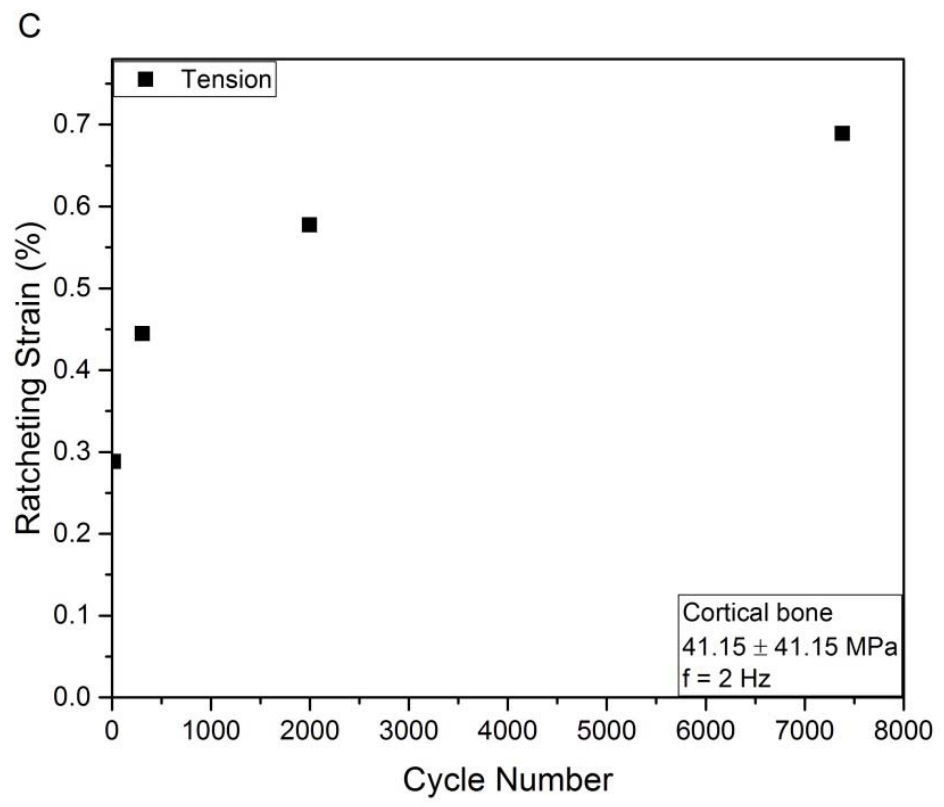

Fig. 3.6: (Continued)

\subsection{Skin}

Kang and $\mathrm{Wu}$ [52] studied ratcheting behavior of porcine skin. Stress-strain hysteresis loops for loading cycles 1, 50 and 100 are plotted in Fig. 3.7A. Ratcheting response in skin tissue shows that tensile stress cycles promoted plastic strain accumulation in Fig. 3.7B. Experimental results prove dependency of ratcheting strain on loading direction, force amplitude, mean force, displacement rate, and mode of loading [52]. 

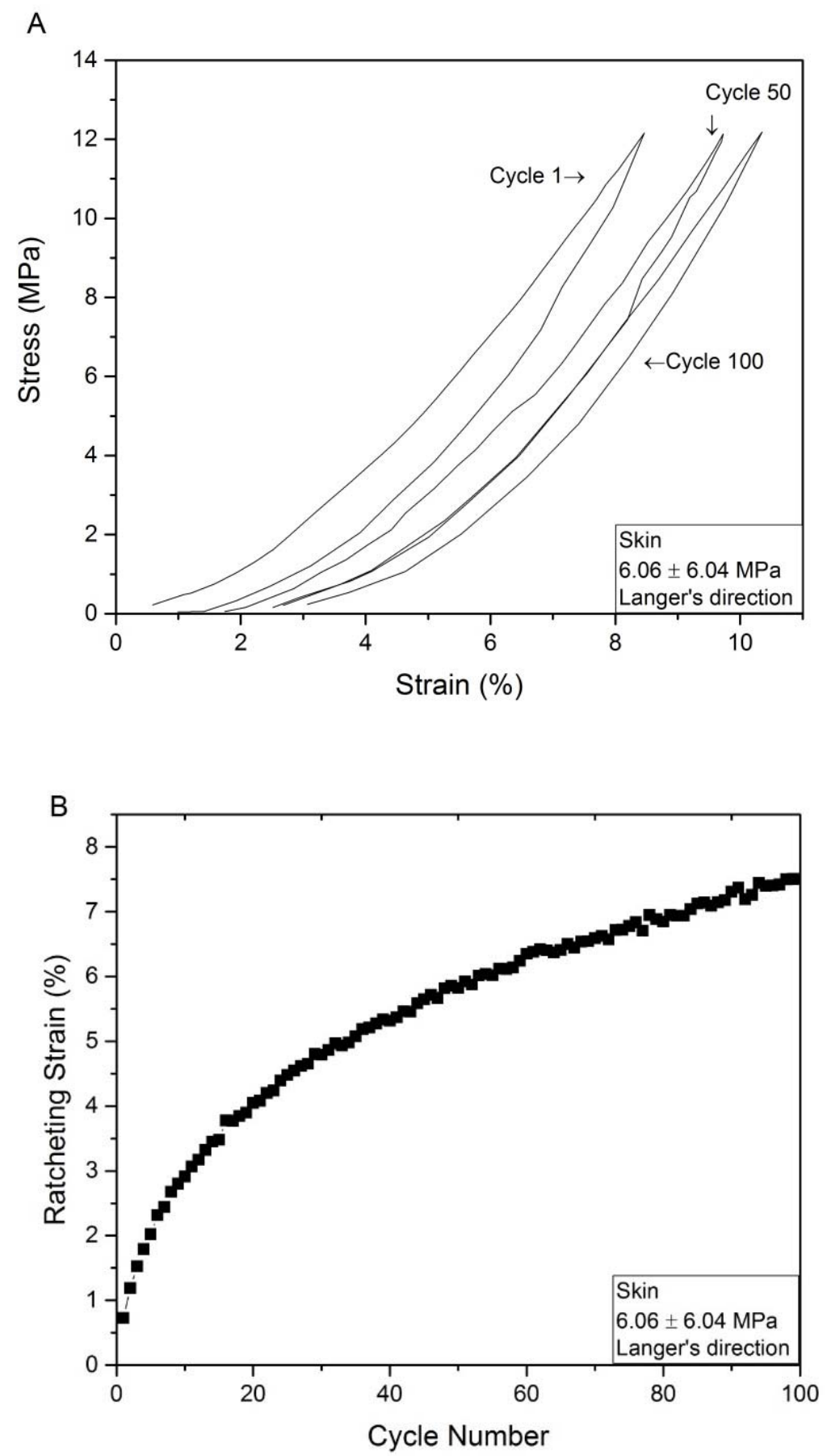

Fig. 3.7: Porcine skin under cyclic tension (A) Stress- strain diagram (data from [52]) (B)

Ratcheting strain. 


\subsection{Tendon}

Wren et al. [53] studied the behavior of human Achilles tendon under cyclic load. Three loops representing cycles corresponding to $0.01,0.5$ and 0.99 of the tendon's life are shown in Fig. 3.8A. Analogous to other tissues that have been discussed, human tendon undergo ratcheting deformation over stress cycles as presented in Fig. 3.8B.

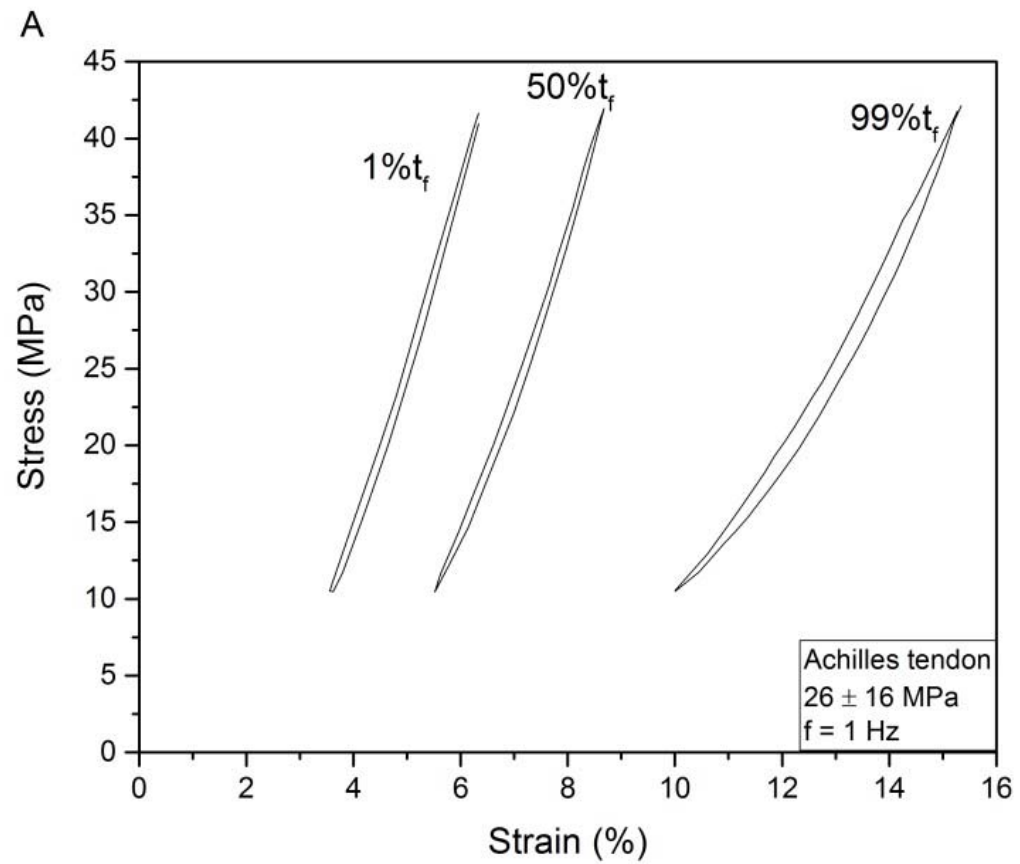

Fig. 3.8: Human Achilles tendons (A) Stress-strain diagram (data from [53])

(B) Ratcheting strain. 


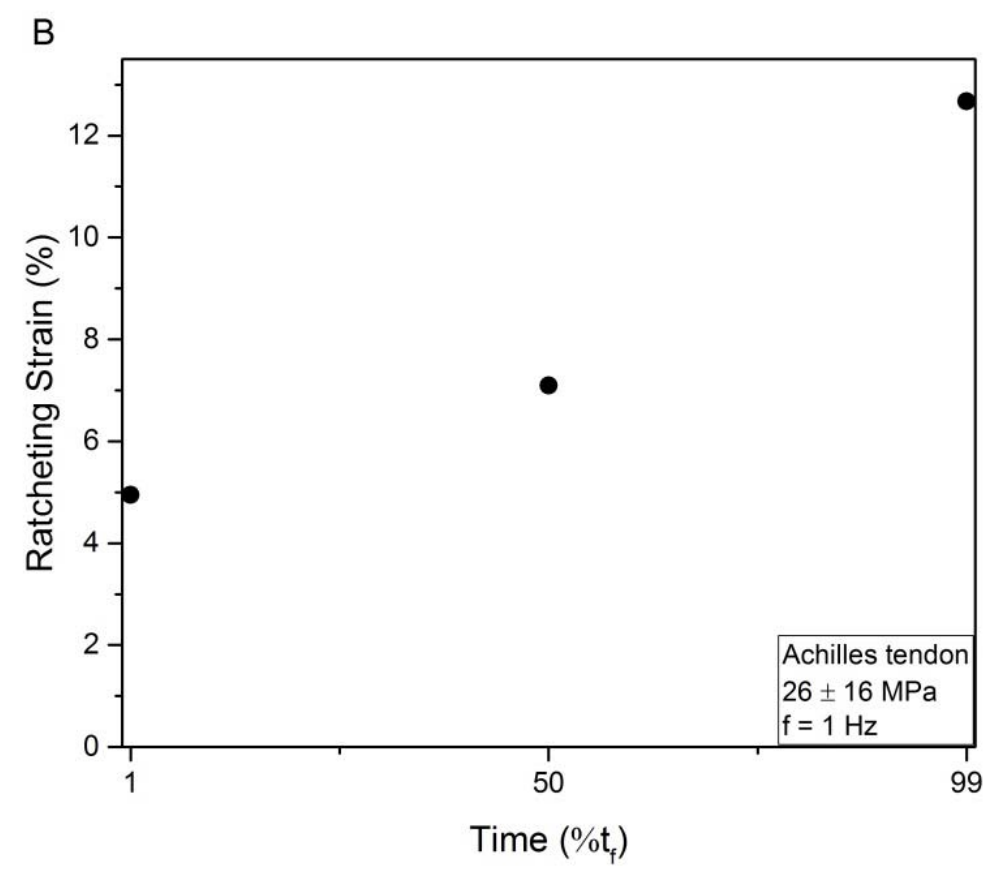

Fig. 3.8: (Continued)

\subsection{Summary}

The ratcheting response of meniscus over cyclic compression, at frequencies of 1 and $10 \mathrm{~Hz}$ was studied. Under cyclic compression, hysteresis loops for articular cartilage and trabecular bone tissues were not closed at 200 cycles, and the tissues showed ratcheting strain progress over stress cycles. The ratcheting response of cortical bone tissue under both tensile and compressive stress cycles has resulted in different trends. The hysteresis loops in skin tissue showed a similar response to the tension-unloading cycles. Tendon tissue experienced ratcheting strain progress under cyclic loads and resulted different rates and magnitudes as number of cycles increased. 


\section{Chapter 4}

\section{Models for Strain Calculation}

Ratcheting progress over loading cycles in various tissues of trabecular and cortical bones, meniscus, articular cartilage, and skin was discussed in Chapter 3. The magnitude of strain and predictability of this phenomenon is beneficial in preventing failure and determining the average life cycle of tissues. In this chapter, two models to assess ratcheting will be discussed.

\subsection{NVC Model for Trabecular Bone}

Li-Lan et al. [54] developed a mathematical model for predicting creep and ratcheting strain of the cancellous bone under cyclic compression. This model adopted Onaran and Findley [55] and Lai and Findley [56] models to be applicable for trabecular bone. The base model is defined as:

$$
\begin{aligned}
\varepsilon(t)=\int_{0}^{t} K_{1}( & \left.-t_{1}\right) \sigma^{\prime}\left(t_{1}\right) d t_{1} \\
& +\int_{0}^{t} \int_{0}^{t} K_{2}\left(t-t_{1}, t\right. \\
& \left.-t_{2}\right) \sigma^{\prime}\left(t_{1}\right) \sigma^{\prime}\left(t_{2}\right) d t_{1} d t_{2} \\
& +\int_{0}^{t} \int_{0}^{t} \int_{0}^{t} K_{3}\left(t-t_{1}, t-t_{2}, t\right. \\
& \left.-t_{3}\right) \sigma^{\prime}\left(t_{1}\right) \sigma^{\prime}\left(t_{2}\right) \sigma^{\prime}\left(t_{3}\right) d t_{1} d t_{2} d t_{3}
\end{aligned}
$$

where $K_{i}$ is a material function, $\varepsilon$ and $\sigma$ are strain and stress values. In equation (4.1), $K_{i}(\mathrm{i}=1,2$, $3)$ is defined as [54]: 


$$
K_{i}(t)=\mu_{i}+\gamma_{i} t^{n}
$$

where $\mu_{i}$ in equation (4.1) is material constant and $\gamma_{i}$ is a material parameter associated with the stack of trabecular deformation under compression.

Substituting $K_{1}, K_{2}$ and $K_{3}$ into equation (4.2) is written as:

$$
\begin{aligned}
\varepsilon(t)=\int_{0}^{t}\left[\mu_{1}\right. & \left.+\gamma_{1}\left(t-t_{1}\right)^{n}\right] \sigma^{\prime}\left(t_{1}\right) d t_{1} \\
& +\int_{0}^{t} \int_{0}^{t}\left[\mu_{2}\right. \\
& \left.+\gamma_{2}\left(t-t_{1}\right)^{\frac{n}{2}}\left(t-t_{2}\right)^{\frac{n}{2}}\right] \sigma^{\prime}\left(t_{1}\right) \sigma^{\prime}\left(t_{2}\right) d t_{1} d t_{2} \\
& +\int_{0}^{t} \int_{0}^{t} \int_{0}^{t}\left[\mu_{3}\right. \\
& +\gamma_{3}\left(t-t_{1}\right)^{n / 3}\left(t-t_{2}\right)^{n / 3}(t \\
& \left.\left.-t_{3}\right)^{n / 3}\right] \sigma^{\prime}\left(t_{1}\right) \sigma^{\prime}\left(t_{2}\right) \sigma^{\prime}\left(t_{3}\right) d t_{1} d t_{2} d t_{3}
\end{aligned}
$$

This equation describes creep deformation. Since the stress rate in creep is constant, the equation (4.1) will be written as:

$$
\varepsilon(t)=K_{1}(t) \sigma+K_{2}(t) \sigma^{2}+K_{3}(t) \sigma^{3}
$$

For uniaxial compressive stress, the stress is written as:

$$
\sigma^{\prime}(\mathrm{t})=\sigma^{\prime}{ }_{0} \mathrm{t}
$$

where $\sigma^{\prime} 0$ denotes stress rate. Substituting $\sigma^{\prime}(t)$ from (4.5) in (4.3), the nonlinear viscoelastic model for trabecular bone under uniaxial compressive stress will be obtained. The value of $\mu_{i}$ in uniaxial compressive model is the same as for the creep test. Term $\gamma_{i}$ will be changed and replaced with $\gamma^{\prime} i$ as [54]: 


$$
\gamma^{\prime}{ }_{i}=\alpha_{i} \cdot \gamma_{i}
$$

where $\alpha_{i}$ is damage factor, $\gamma_{i}^{\prime}$ is a new parameter defined under compressive load, and $\alpha_{i}$ is dependent on the stress rate and is calculated through least square method [54]. Figure 4.1 plots the $\sigma-\varepsilon$ results predicted through non-linear viscoelastic (NVC) model versus experimental data.

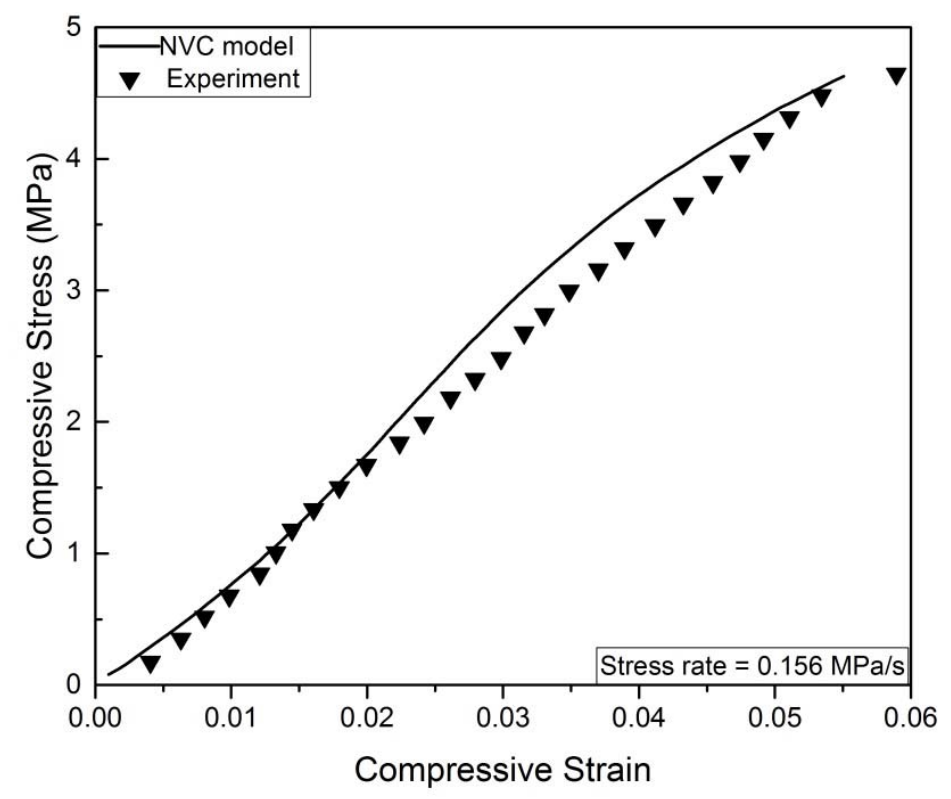

Fig. 4.1: Comparison of experimental data and nonlinear viscoelastic model in trabecular bone under compressive stress (data from [54]).

\subsection{Kafalas' Model}

As explained before in section (2.3.3) of chapter 2, the stress-strain curve of the spongy bone under uniaxial compression is divided into three stages [42] (see Fig. 2.12) and the bone responses in each stage, as well as the number of failed trabeculae in each stage, are different.

Based on three stages of the stress-strain curve of the bone under compression, Kefalas and Eftaxiopoulos [42] developed a model to predict the ratcheting strain of the trabecular bone. The 
macroscopic stress in stages 1, 2, and 3 is introduced by the second Piola-Kirchoff stress tensor $S$ as [42]:

$$
S=S^{(t s)}+S^{(t m)}
$$

where superscripts ${ }^{(t s)}$ and ${ }^{(t m)}$ respectively correspond to trabecular structure, and compact trabecular mass. Equation (4.7) accumulates the effect of the trabecular structure in the first two stages of the stress-strain curve, $S^{(t s)}$, and the contribution of compact tissue mass, $S^{(t m)}$, in the last stage of the curve (Fig. 2.12). Using the relationship between stress and strain for stages 1 and 2 of the stress-strain curve, the equation (4.8) is defined as:

$$
S^{(t s)}=E^{(s)} \eta
$$

where $E^{(s)}$ is a material parameter related to the trabecular structure, and $\eta$ is the Lagrangian normal strain component in the direction of load.

Material stiffness of the spongy bone at any stage of the stress-strain curve is relevant to the trabecular structure as well as the tissue compacting mass, and it can be calculated by:

$$
E=E^{(t s)}+E^{(t m)}
$$

Through substitution of equations (4.7) and (4.8), equation (4.10) is defined as:

$$
S=S^{(t s)}+S^{(t m)}=E^{(t s)} \eta+E^{(t m)} \eta=E \eta=1 / 2 E\left(\lambda^{2}-1\right)
$$

where $S$ is the overall stress of the spongy bone, and $\lambda$ is the stretch ratio along the direction of compression. In the direction of uniaxial loading the nominal normal stress $P$ is calculated as:

$$
P=S \lambda
$$

and $\lambda$ is calculated as:

$$
\lambda=\sqrt{2 \mu+1}
$$


Material parameters were calculated through stress-strain curve derived from the equation and corresponding experimental data. The stress-strain curve of the cancellous bone under compression along with Kefalas' model is presented in Fig. 4.2.

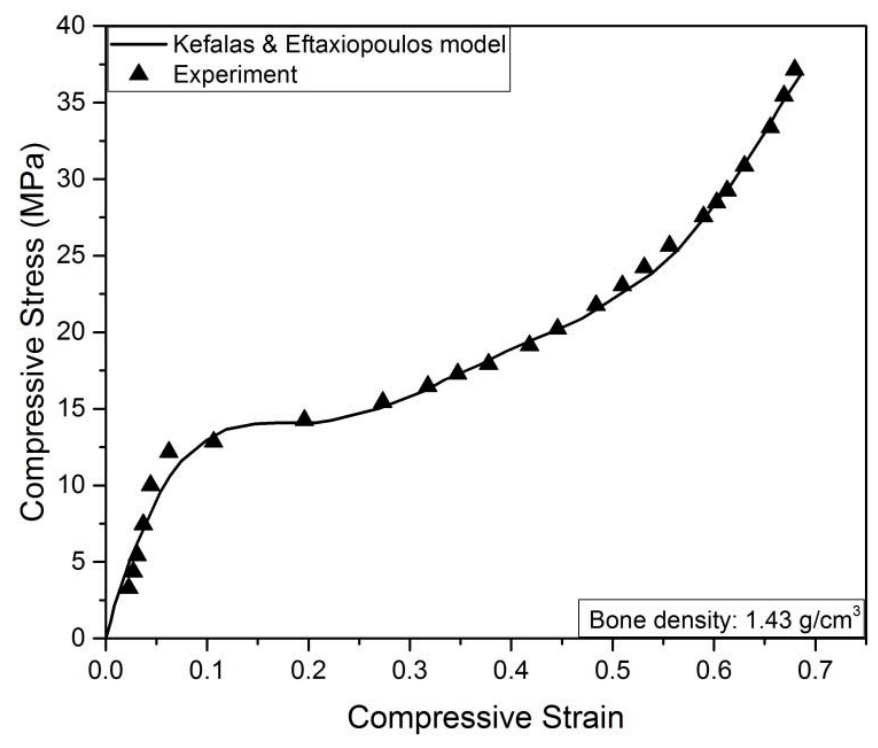

Fig. 4.2: Trabecular bone stress-strain curve from Kefalas \& Eftaxiopoulos' model against the experimental data in a bone density of $1.43\left(\mathrm{~g} / \mathrm{cm}^{3}\right)$ (data from [42]).

\subsection{Summary}

In this chapter, two models of NVC and Kefalas and Eftaxiopoulos to compute strain of the trabecular bone were discussed. Trabecular bone behaved non-liner viscoelastic response under cyclic loads. The NVC [54] model was developed based on viscoelastic constitutive equations. Kefalas and Eftaxiopoulos model [42] utilizes three different stages of the stress-strain curve of the trabecular bone under cyclic compression and develops a model to calculate strain on the trabecular bone at any stage of the stress-strain diagram. 


\section{Chapter 5}

\section{Parametric Ratcheting Model and}

\section{Formulation}

Prediction of ratcheting in biological tissues involves biological and mechanical parameters to describe tissue deformation over stress cycles, and consequently prevention of damage and destructive strain accumulation in the tissue. The present thesis employs an earlier developed ratcheting model [57] to evaluate ratcheting response of biological tissues examined in this study.

In 2012, Ahmadzadeh and Varvani-Farahani [57] introduced an equation to calculate ratcheting strain in steel alloys. The backbone of this model is developed on the basis of mechanical parameters including applied stress, life span, yield stress, and ultimate strength to anticipate the strain accumulation in the materials due to asymmetric cyclic loads. The model is built to physically address three stages of ratcheting phenomenon as schematically presented in Fig. 5.1. This diagram includes the first stage on which strain rate grows rapidly during initial loading cycles, followed by a gradual and slow increment in ratcheting strain that builds up a steady ratcheting rate, and ends up with a sudden increase in ratcheting strain rate leading to failure of materials [57]. The phenomenological model for strain accumulation under asymmetric cyclic loading [57] is given as: 
$\varepsilon_{r}=\alpha^{*}\left(A\left(\frac{\ln N}{\ln N_{f}}+C\left(\frac{N}{N_{f}}-\frac{\ln N}{\ln N_{f}}\right)\right)+B^{2} \frac{\ln \left(1-\frac{N}{N_{f}}\right)}{\ln \frac{1}{N_{f}}}\right)$

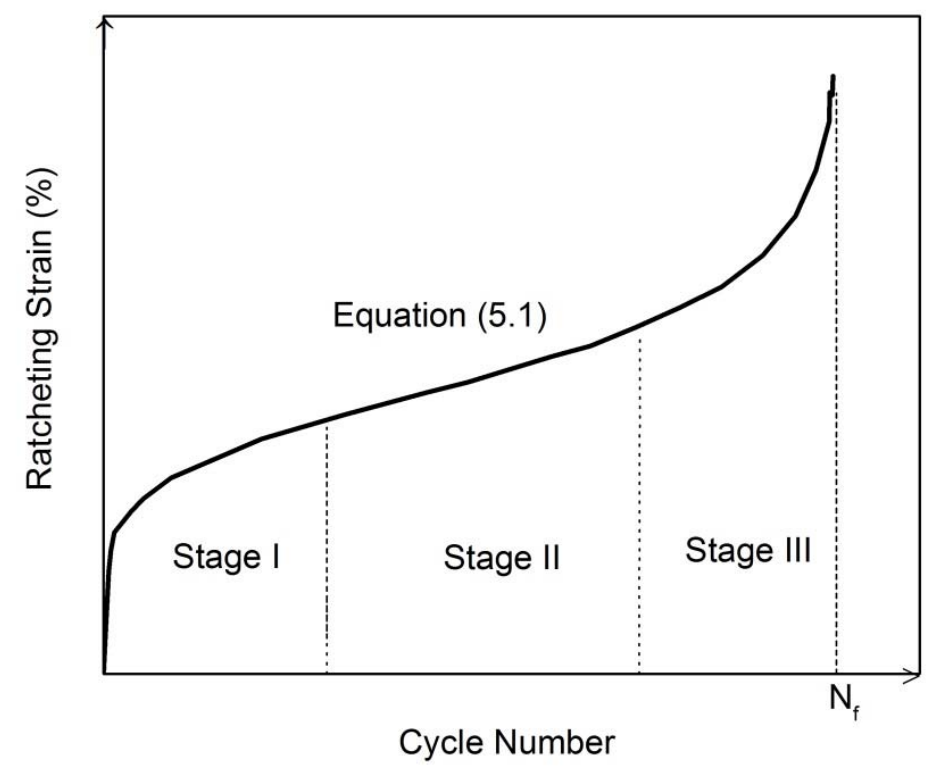

Fig. 5.1: Different stages of ratcheting strain in metals and associated equation (data from [57]).

In equation (5.1), parameters $A, B$ and $C$ are defined as [57]:

$$
\begin{aligned}
& A=2 \ln \left(\frac{\sigma_{\mathrm{y}}}{E}\right)^{-1} \\
& B=\ln \left(\frac{\Delta \sigma}{E}\right) \\
& C=\frac{1}{2}\left(1-\frac{\sigma_{m}}{\Delta \sigma}\right)^{\frac{1}{2 n}}
\end{aligned}
$$


where $\alpha=\left(\sigma_{u l t} / \sigma_{y}\right)^{n}, \Delta \sigma$ is stress variation $=2 \sigma_{a}=\sigma_{\max }-\sigma_{\min }$, In this study, $\mathrm{N}$ is number of stress cycle, $N_{f}$ is number of life cycles, $\sigma_{m}$ is mean stress $=\frac{\sigma_{\max }+\sigma_{\min }}{2}, \sigma_{y}$ is yield stress,$\sigma_{u l t}$ is ultimate strength, $E$ is the Young's modulus, and $n$ is the cyclic strain hardening exponent. The phenomenological model is adopted to predict the ratcheting strain of bovine meniscus, porcine articular cartilage, porcine trabecular bone, and porcine skin tissues.

\subsection{Bovine Meniscus}

The experimental data used in this study was obtained from tests on bovine meniscal tissue [48]. The average modulus of bovine meniscal tissue from the slope of the linear portion of the strainstress curve (monotonic test) is reported as $37 \mathrm{MPa}$ [48]. Calculating the slope of the toe region of the stress-strain curve during cyclic compression test (Fig. 3.2) provided with a modulus of 31.02 and 31.82 at $1 \mathrm{~Hz}$ and $10 \mathrm{~Hz}$ respectively. Cyclic strain hardening exponent $(n)$ was defined equal to 1 for life cycles 50,000 (at $10 \mathrm{~Hz}$ ) and 5,000 (at $1 \mathrm{~Hz}$ ). Number of life cycles for tests conducted at stress fluctuating between 1 and $10 \mathrm{MPa}$ with frequencies of $10 \mathrm{~Hz}$ and $1 \mathrm{~Hz}$ was found to be 50,000 and 5,000 respectively. Thus, the life span at $10 \mathrm{~Hz}$ is greater than that of $1 \mathrm{~Hz}$ which is comparable with experiment results reported in reference [48] and indicates that tissue undergoes more cycles at $10 \mathrm{~Hz}$ (compared to $1 \mathrm{~Hz}$ ) to achieve the same strain. In other words, by increasing the frequency, the ratcheting strain declines which explicitly correspond to longer number of cycles to failure. The life span in this experiment was regarded as 5,000 and 1,000 cycles at $10 \mathrm{~Hz}$ and $1 \mathrm{~Hz}$ respectively [48]. Considering the fact that ratcheting experiment was performed until failure (which was defined as $10 \%$ increase in the strain from the initial value), the cyclic loading was stopped at 5,000 cycles at $10 \mathrm{~Hz}$, and 1,000 cycles at $1 \mathrm{~Hz}$. Reaching the failure strain criteria

provided by the paper [48] does not imply the meniscus can merely withstand the said number of 
stress cycles. As evidence, Creechley [58] reported cycles to failure of bovine meniscal tissue under tensile cyclic loads (at stress level up to $60 \%$ of ultimate strength and at frequency of $2 \mathrm{~Hz}$ ) as 2,424 \pm ,551 in longitudinal direction and $10,598 \pm 11,974$ in transverse directions, respectively.

Table 5.1 lists the material properties for bovine meniscus tissue.

Table 5.1: Material properties for bovine meniscus tissue.

\begin{tabular}{|c|c|c|c|c|c|}
\hline $\begin{array}{c}\text { Modulus of } \\
\text { Elasticity } \\
(\mathrm{MPa})\end{array}$ & $\begin{array}{c}\text { Yield } \\
\text { Stress } \\
(\mathrm{MPa})\end{array}$ & $\begin{array}{c}\text { Ultimate } \\
\text { Strength } \\
(\mathrm{MPa})\end{array}$ & $\begin{array}{c}\text { Life Cycles } \\
(\text { Cycles })\end{array}$ & $\begin{array}{c}\text { Cyclic Strain } \\
\text { Hardening } \\
\text { Exponent }\end{array}$ & $\boldsymbol{\alpha}^{*}$ \\
\hline $31.02(1 \mathrm{~Hz})$ & $16.6[27]$ & $18.9[27]$ & $5,000(1 \mathrm{~Hz})$ & 1 & $\begin{array}{c}10 \alpha \\
(\text { derived } \\
\text { from the } \\
\text { original } \\
\text { equation })\end{array}$ \\
\hline
\end{tabular}

Fig. 5.2 compares the experimental and calculated ratcheting results based on equation (5.1) over loading cycles 5.5 $\pm 4.5 \mathrm{MPa}$ for different loading frequencies. Ratcheting data for bovine meniscus tissue in this figure shows how influential is the testing frequency on calculated results. 

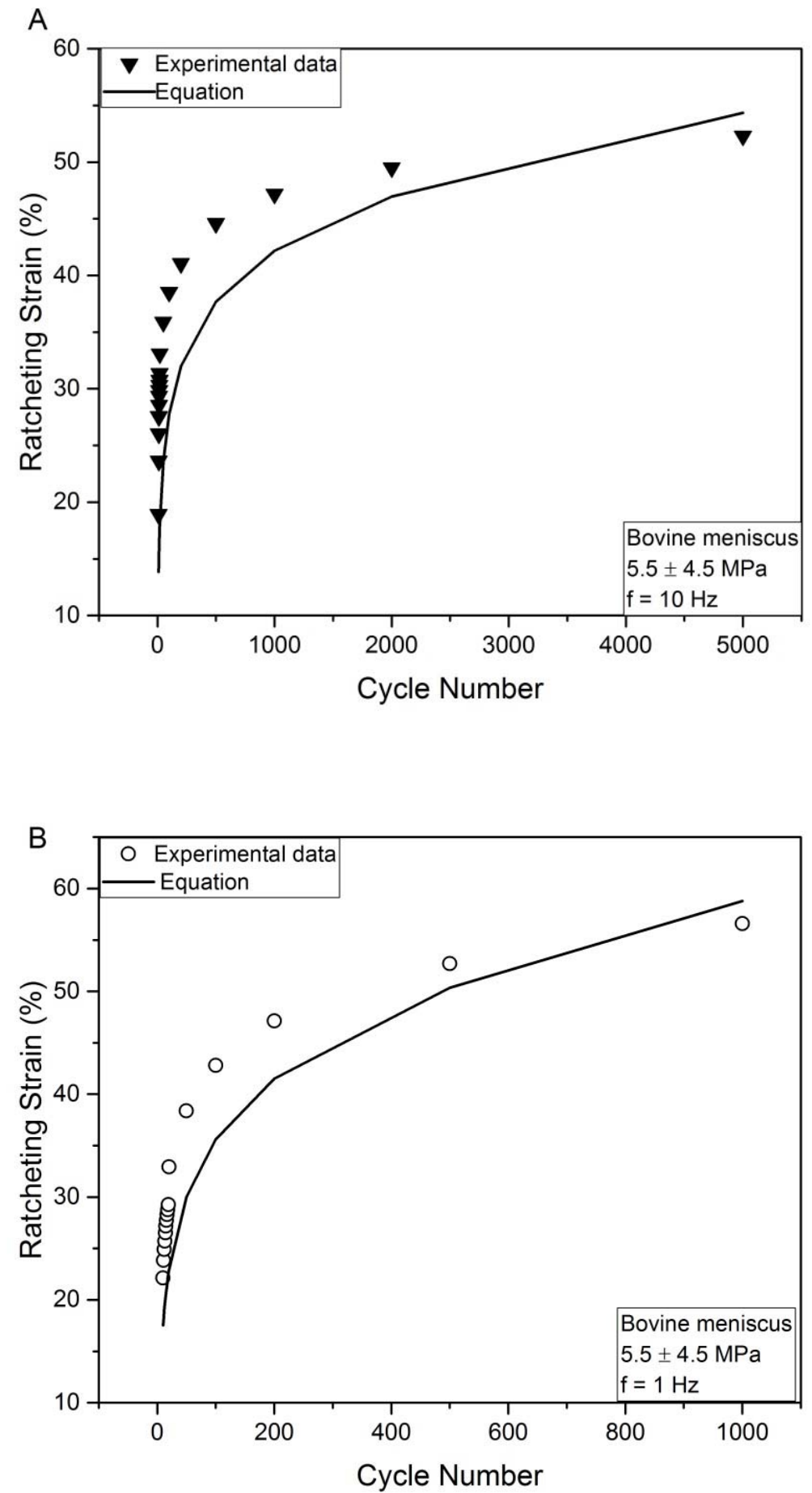

Fig. 5.2: Experimental data [48] and predicted ratcheting curves by equation (5.1) for meniscal tissue at (A) $10 \mathrm{~Hz}$ (B) $1 \mathrm{~Hz}$. 
Fig. 5.2 shows a closer agreement of the predicted curve with ratcheting data achieved at lower testing frequency. The maximum deviation of experimental and calculated ratcheting strain excluding the first 50 cycles was found as low as $34 \%$ and $22 \%$ at frequencies of $10 \mathrm{~Hz}$ and $1 \mathrm{~Hz}$ respectively.

\subsection{Porcine Articular Cartilage}

The experimental data used in this study was collected from cyclic compressive tests on porcine articular cartilage [49]. Danso et al. [27] reported the Young's modulus of the bovine articular cartilage $6.00 \pm 1.95 \mathrm{MPa}$. The storage modulus of the porcine articular cartilage was reported 18 $\mathrm{MPa}$ and its loss modulus equal to $5 \mathrm{MPa}[59]$.

The slope of the toe region of the stress-strain curve for porcine articular cartilage (as shown in Fig. 5.3) is calculated as 4.02 MPa and 5.2 MPa for the first and second cycles, respectively.

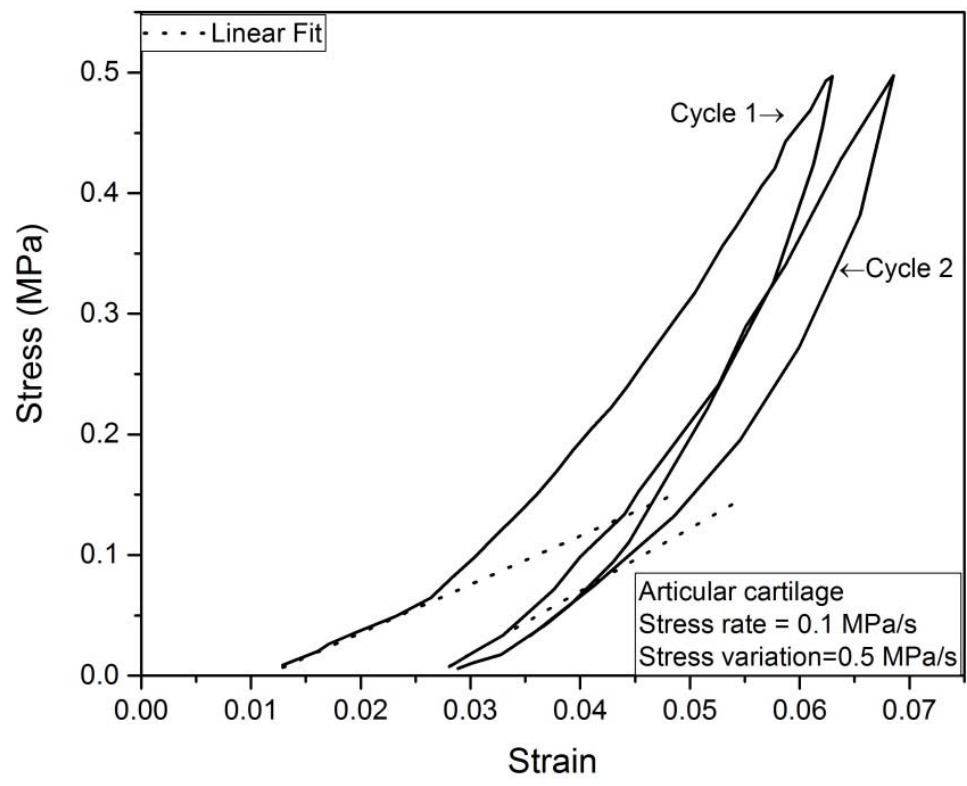

Fig. 5.3: Slope of the toe region of $1^{\text {st }}$ and $2^{\text {nd }}$ cycles of the porcine articular cartilage. 
Variations in Young's modulus of different zones of the cartilage as the number of cycles increase are plotted in Fig. 5.4A. To calculate Young's modulus of cartilage tissue, the best fitted curve for Young's modulus of each layer was first determined as of Fig. 5.4B, C, D. The rule of mixture was then employed to achieve cartilage modulus over 100 cycles as of Fig. 5.4E. The median of the fitted curve for the whole tissue was designated as the modulus of the cartilage, regardless of the cycle number and tissue depth. The modulus of porcine articular cartilage in the stress variation of $0.5 \mathrm{MPa}$ and stress rate of $0.1 \mathrm{MPa} / \mathrm{s}$ was computed as $5 \mathrm{MPa}$. This value is consistent with the slope of the toe region of the stress-strain curve and is considered as Young's modulus of the articular cartilage.

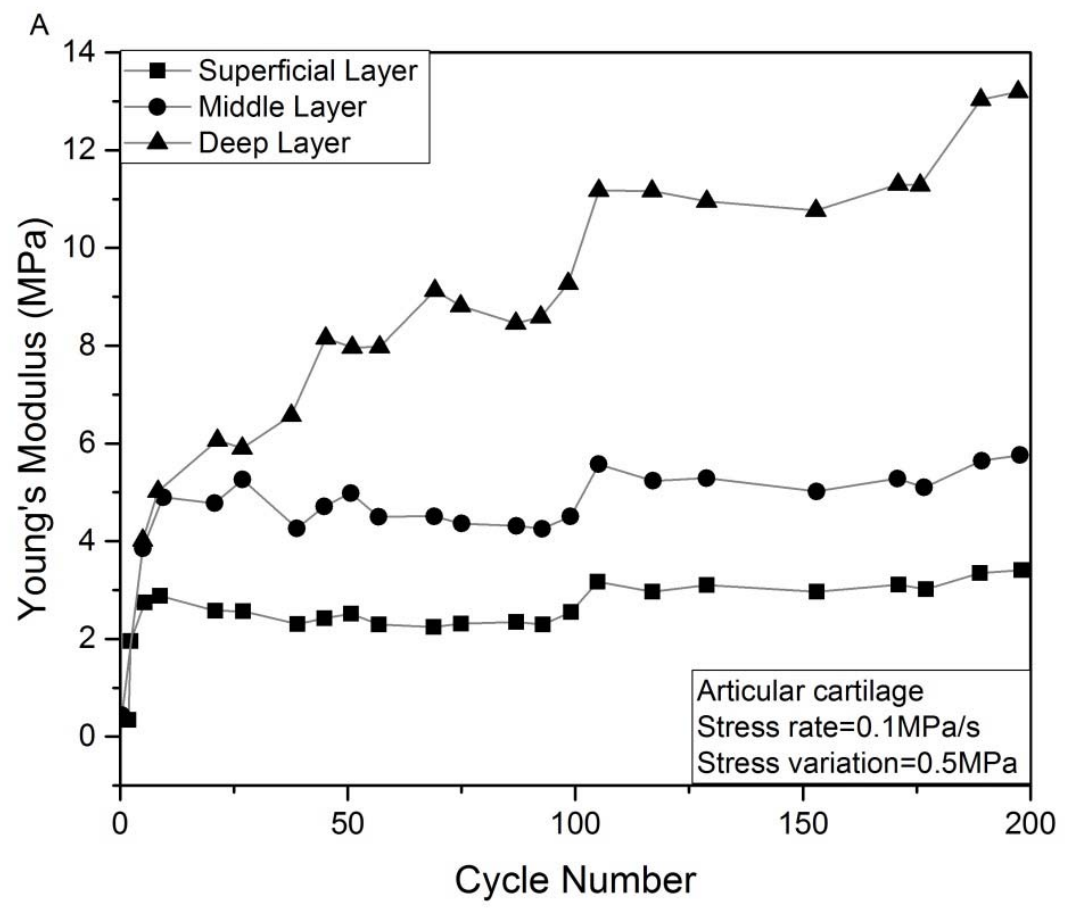

Fig. 5.4: (A) Young's modulus of different layers of the articular cartilage (data from [49]), (B), (C), (D) The best fitted curves for different layers of the articular cartilage (E) Young's modulus of the articular cartilage tissue. 

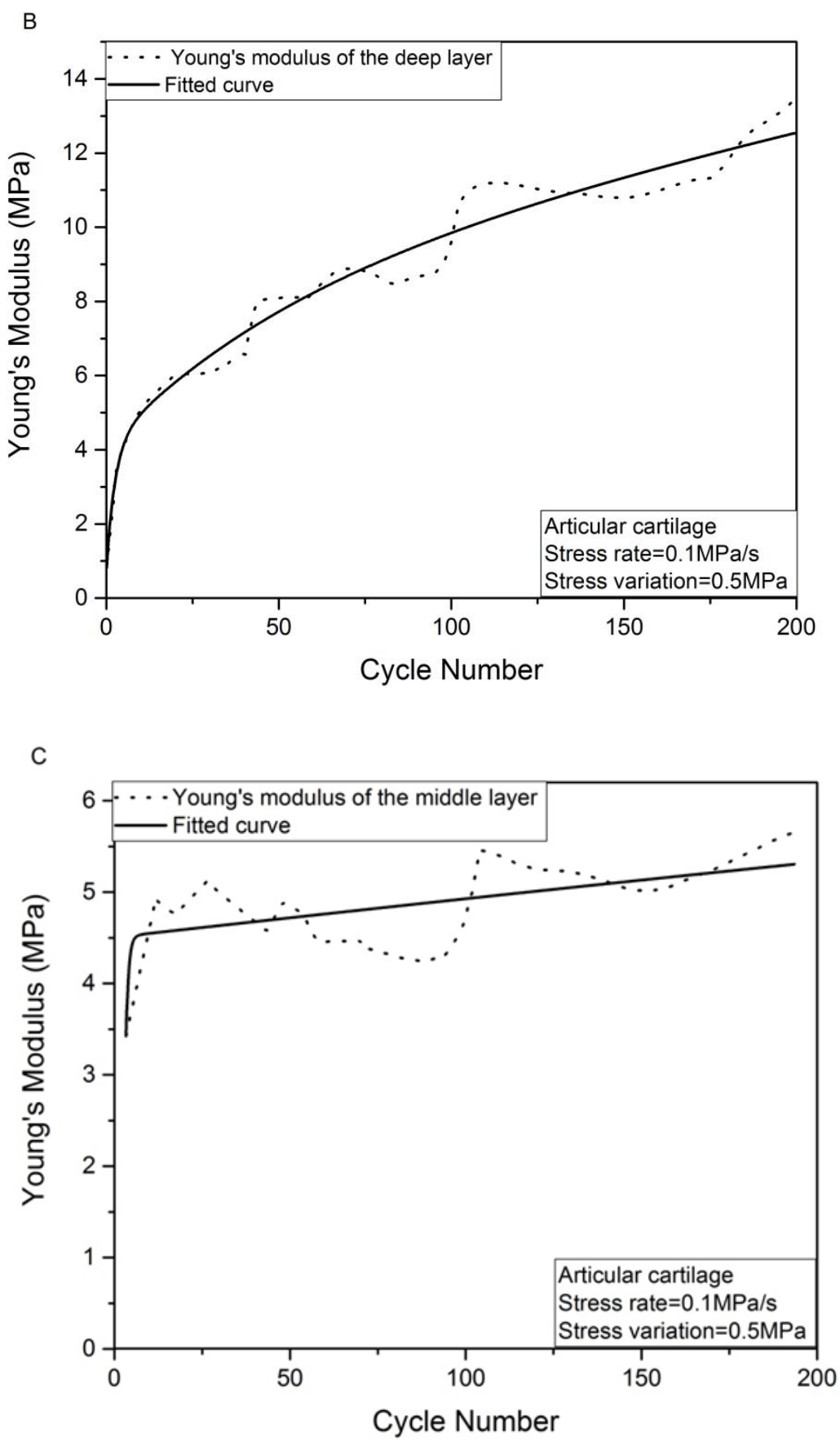

Fig. 5.4: (Continued) 

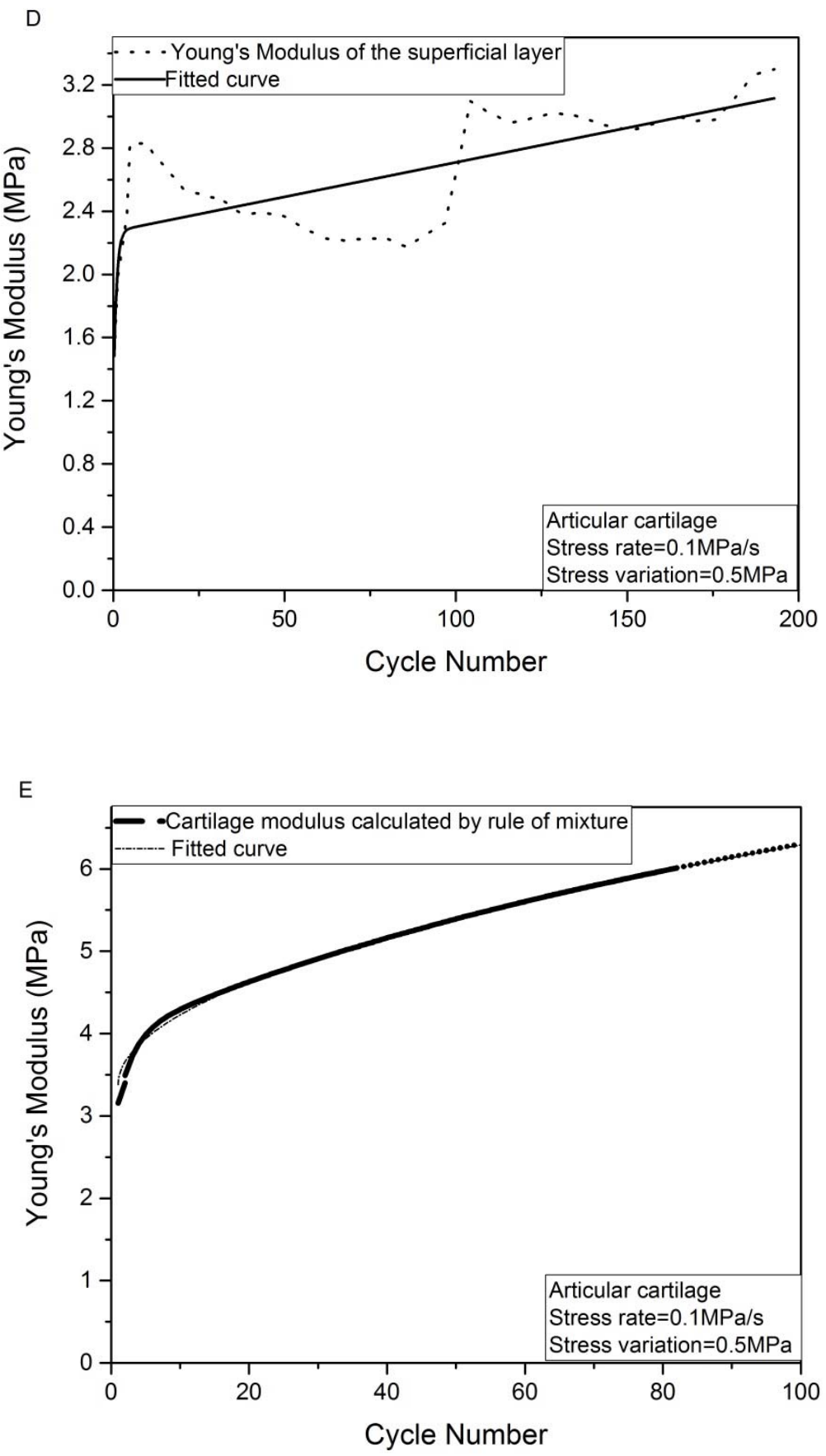

Fig. 5.4: (Continued)

The mechanical properties of the soft tissue employed to assess ratcheting are listed in Table 5.2. 
Table 5.2: Material properties for porcine articular cartilage.

\begin{tabular}{|c|c|c|c|c|c|}
\hline $\begin{array}{c}\text { Modulus of } \\
\text { Elasticity } \\
(\mathrm{MPa})\end{array}$ & $\begin{array}{c}\text { Yield } \\
\text { Stress } \\
(\mathrm{MPa})\end{array}$ & $\begin{array}{c}\text { Ultimate } \\
\text { Strength } \\
(\mathrm{MPa})\end{array}$ & $\begin{array}{c}\text { Life Cycles } \\
(\text { Cycles })\end{array}$ & $\begin{array}{c}\text { Cyclic Strain } \\
\text { Hardening } \\
\text { Exponent }\end{array}$ & $\alpha^{*}$ \\
\hline 5 & $4.8[27]$ & $4.7[27]$ & $200-300,000$ & 5 & $\begin{array}{c}10 \alpha \text { (derived } \\
\text { from the } \\
\text { original } \\
\text { equation) }\end{array}$ \\
\hline
\end{tabular}

The predicted ratcheting results for cartilage tissue through use of equation (5.1) over loading cycles are compared with those of experimentally measured in Fig. 5.5. Predicted ratcheting data for various stress levels of 1 , and 1.5 MPa tested with various frequencies of $0.1,0.05,0.033$, and $0.2 \mathrm{~Hz}$ are found in close agreement with the experimental data in Fig. 5.5. In this figure, sample tested at $\Delta \sigma=0.5 \mathrm{MPa}$ and stress rate of $0.1 \mathrm{MPa} / \mathrm{s}$, showed some over-prediction of ratcheting values as compared with experimental data. This sample possessed the highest life cycles of 300,000 cycles. The maximum deviation of experimental and calculated ratcheting strain for this sample was found about $50 \%$. At the stress rate of $0.1 \mathrm{MPa} / \mathrm{s}$, the deviation of the model, excluding initial five cycles, for $\Delta \sigma=1.5 \mathrm{MPa}$ and $\Delta \sigma=1 \mathrm{MPa}$ is equal to $5.6 \%$ and $6.4 \%$, respectively. At stress variation of $1 \mathrm{MPa}$, the model deviation after $20^{\text {th }}$ cycle at stress rates of 0.4 and $0.2 \mathrm{MPa} / \mathrm{s}$ was found $14.5 \%$ and $18 \%$, respectively. 


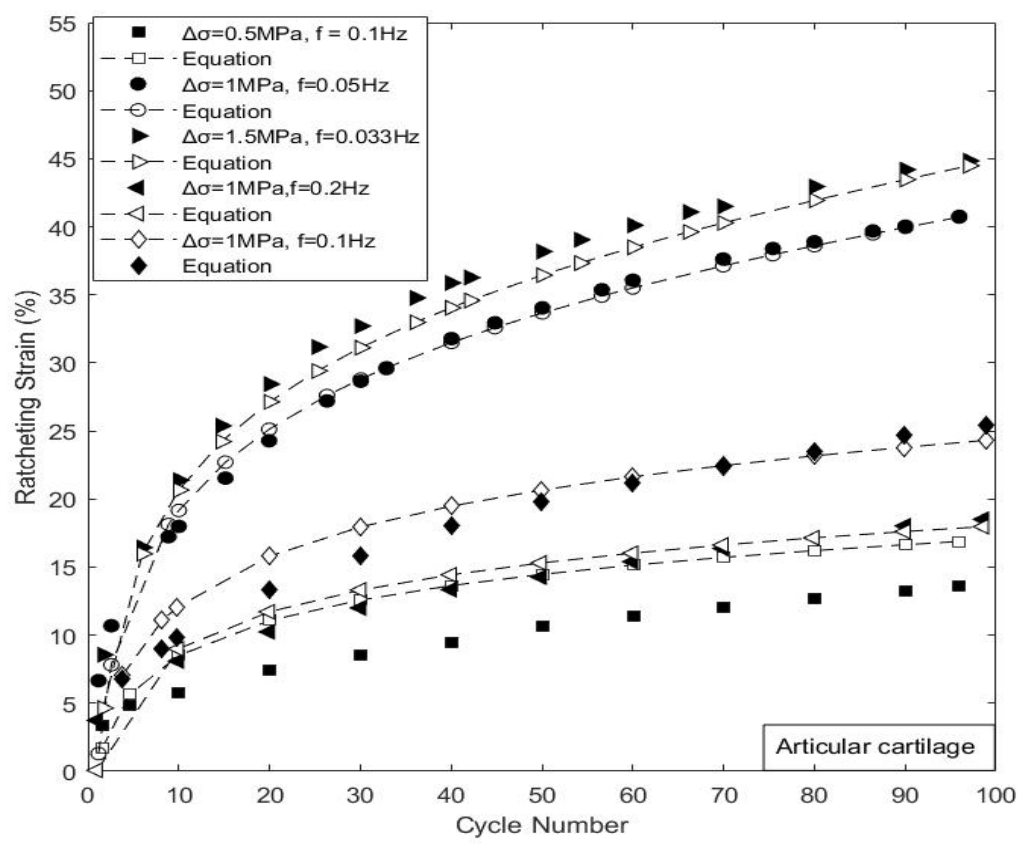

Fig. 5.5: Experimental [49] and predicted ratcheting curves by equation (5.1) for cartilage tissue.

The life cycles for tested cartilage samples are listed in Table 5.3.

Table 5.3: Experimental data of tested cartilage samples and their life cycles.

\begin{tabular}{|c|c|c|c|c|}
\hline Sample & $\boldsymbol{\Delta} \mathbf{6}(\mathrm{MPa})$ & Stress Rate $(\mathrm{MPa} / \mathrm{s})$ & Frequency $(\mathrm{Hz})$ & Life Cycles \\
\hline $\mathbf{1}$ & 0.5 & 0.1 & 0.1 & 300,000 \\
\hline $\mathbf{2}$ & 1 & 0.1 & 0.05 & 300 \\
\hline $\mathbf{3}$ & 1.5 & 0.1 & 0.033 & 200 \\
\hline $\mathbf{4}$ & 1 & 0.4 & 0.2 & 150,000 \\
\hline $\mathbf{5}$ & 1 & 0.2 & 0.1 & 7,000 \\
\hline
\end{tabular}

Table 5.3 presents the number of cycles to failure for a wide range, from 300,000 cycles in sample 1 to 200 cycles in sample 3 . The highest ratcheting magnitude was achieved in test sample 3 with stress level of 1.5 MPa leading to lower number of cycles to failure ( $\mathrm{N}=200$ cycles). 


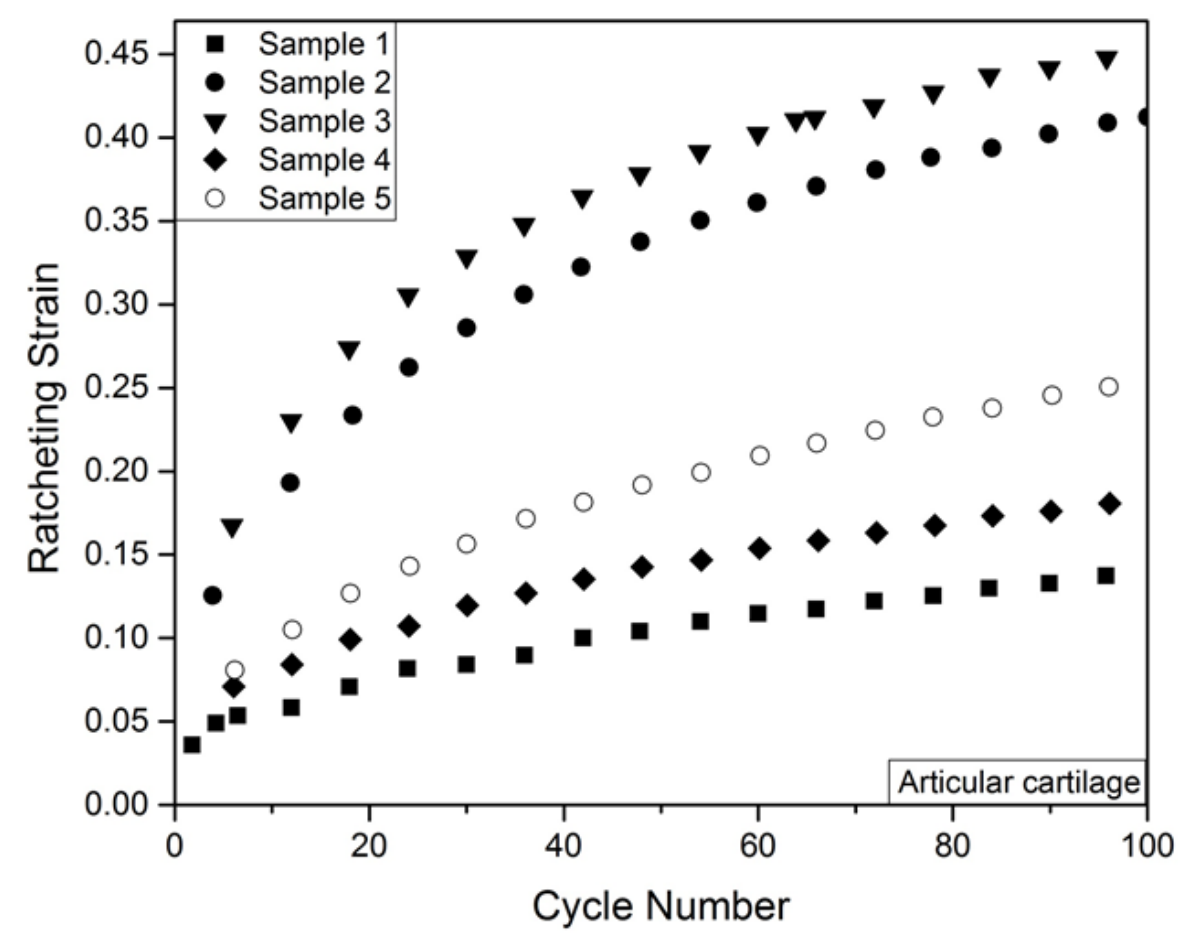

Fig. 5.6: Ratcheting strain of tested articular cartilage samples at different loading conditions (data from [49]).

Test samples 1-3 listed in Table 5.3 are performed at the same stress rate $(0.1 \mathrm{MPa} / \mathrm{s})$. An increase in peak stress of these tests results in the reduction of life cycles to failure.

Also, another study [53] performed tests on tendon samples at various maximum stress levels while minimum stress was kept constant and equal to $10 \mathrm{MPa}$ with loading frequency of $1 \mathrm{~Hz}$. Fig. 5.7 further shows as applied maximum stress increases the cycles to failure in tendon tissue drop [53]. In this figure a large data scatter is reported. 


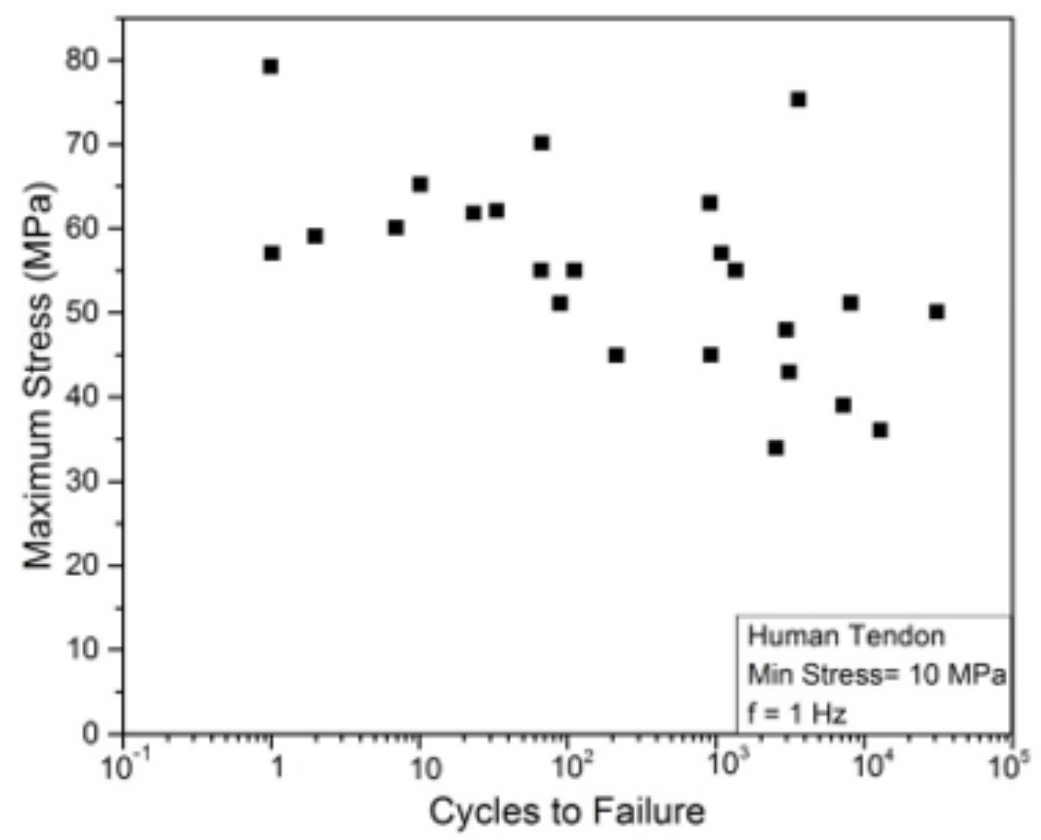

Fig. 5.7: Life cycles at various maximum stress while minimum stress kept constant (data from [53]).

\subsection{Porcine Trabecular Bone}

Wei et al. [50] performed ratcheting tests in trabecular bone samples under compressive cycles. The cyclic compression of $0-1.56 \mathrm{MPa}$ on the hard bone tissue leaded the samples to progressive plastic strain accumulation. The stress-strain curve of the tissue under load was previously shown in chapter 3 (Fig. 3.5A). Young's modulus of bovine trabecular bone was reported 117.49 \pm 61.53 MPa [60]. Calculating the slope of the toe region of the stress-strain curve (Fig. 3.5A) resulted in a stiffness of 102.61 MPa for the spongy bone. Mechanical properties of human trabecular bone were however reported by Matsuura et al. [61]. The ultimate strength of the trabecular bone tissue was found approximately $27 \%$ greater than the tissue yield stress. The yield stress fell between 0.05-14.6 MPa [61] while ultimate strength of bovine's trabecular bone dropped to $8.5 \pm 4.2 \mathrm{MPa}$ 
[60]. Material properties employed for trabecular bone to assess ratcheting over loading cycles are listed in Table 5.4.

Table 5.4: Material properties for trabecular bone tissue.

\begin{tabular}{|c|c|c|c|c|c|}
\hline $\begin{array}{c}\text { Modulus of } \\
\text { Elasticity } \\
(M P a)\end{array}$ & $\begin{array}{c}\text { Yield } \\
\text { Stress } \\
(M P a)\end{array}$ & $\begin{array}{c}\text { Ultimate } \\
\text { Strength } \\
(M P a)\end{array}$ & $\begin{array}{c}\text { Life Cycles } \\
(\text { Cycles })\end{array}$ & $\begin{array}{c}\text { Cyclic Strain } \\
\text { Hardening } \\
\text { Exponent }\end{array}$ & $\boldsymbol{\alpha}^{*}$ \\
\hline $117[60]$ & $7.08[61]$ & $\begin{array}{c}8.5 \\
{[60,61]}\end{array}$ & 6,000 & 1 & $\begin{array}{c}\alpha \text { (derived } \\
\text { from the } \\
\text { original } \\
\text { equation) }\end{array}$ \\
\hline
\end{tabular}

Ratcheting strain values for trabecular bone tissue were calculated through equation 5.1 and plotted in Fig. 5.8 along with those of experimental values. The predicted and experimental ratcheting data fall in close agreement. The maximum deviation of experimental and calculated ratcheting strain for trabecular bone after cycle $40^{\text {th }}$ was found about $15 \%$. Extension of loading cycles in this figure leads to life cycles in the trabecular bone tissue of 6,000 cycles which closely conforms to previous findings reported for life of human vertebral trabecular bone at 6,888 cycles [62]. 


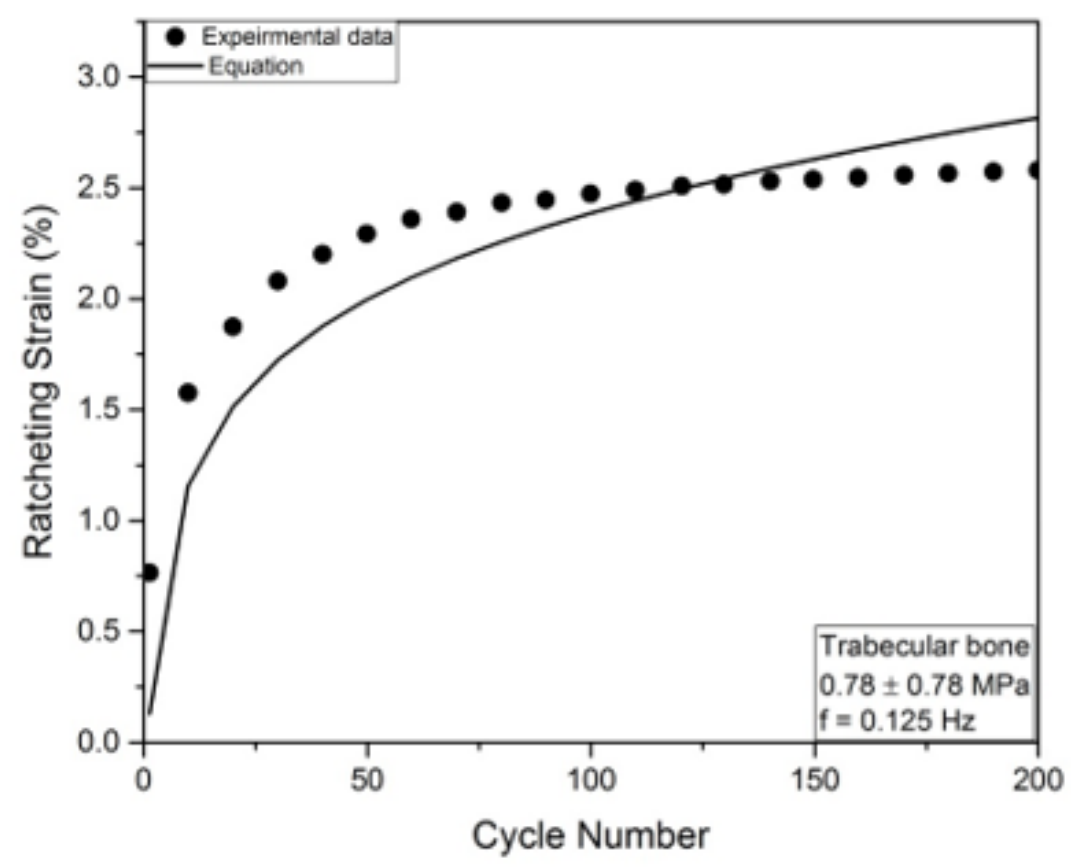

Fig. 5.8: Experimental [50] and predicted ratcheting values by equation (5.1) for trabecular bone tissue.

\subsection{Porcine Skin}

Soft tissue of porcine skin tested at asymmetric cyclic tension of 0.02-12.1 MPa has undergone ratcheting deformation. Fig. 5.9 presents experimentally obtained stress-strain hysteresis loops of the tissue [52]. 


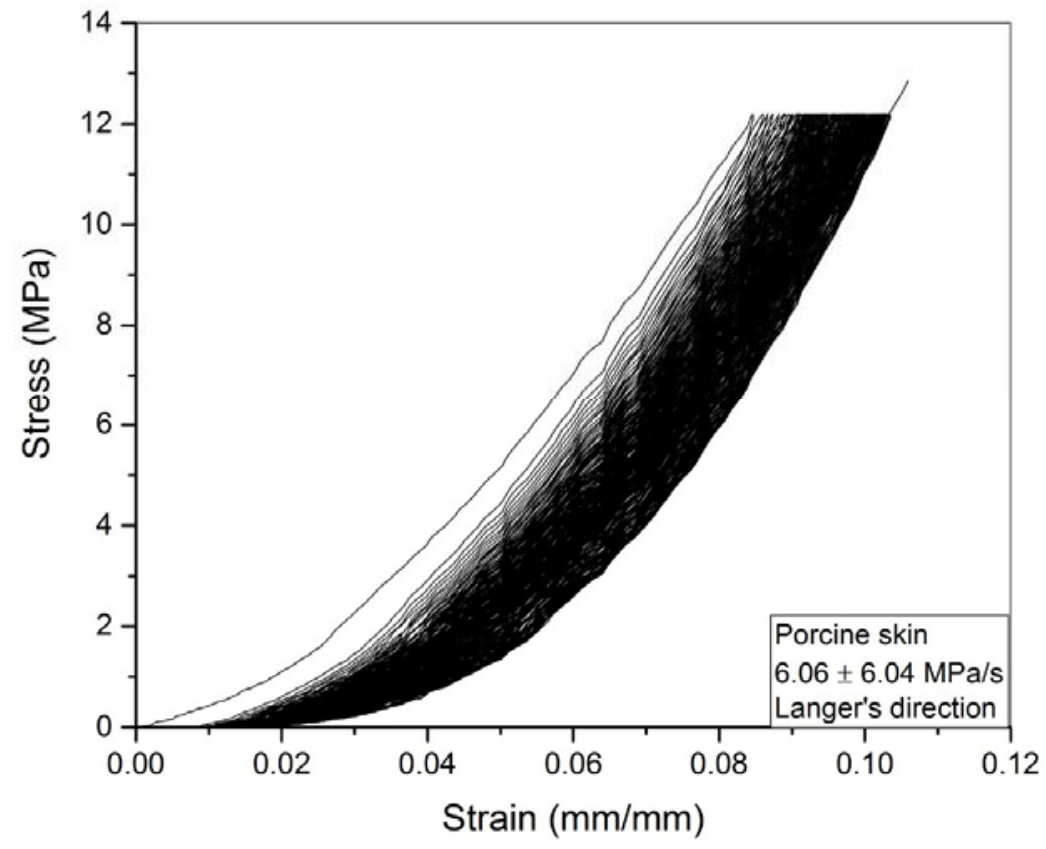

Fig. 5.9: The stress-strain hysteresis loops obtained for porcine skin tissue (through communication from author [52]).

The pig skin of the dorsal area was used as the sample to run ratcheting test. Porcine skin sample tested at $6.06 \pm 6.04 \mathrm{MPa}$ were evaluated to fail at 100,000 cycles. Elastic modulus of the porcine skin was reported 150.53 $\mathrm{MPa}$ [63]. The ultimate tensile strength was reported as 39.5 [52] and yield stress from monotonic stress-strain curve in Langer's direction was computed as 37.75 MPa.

Table 5.5: Material properties assigned to the porcine skin.

\begin{tabular}{|c|c|c|c|c|c|}
\hline $\begin{array}{c}\text { Modulus of } \\
\text { Elasticity } \\
(M P a)\end{array}$ & $\begin{array}{c}\text { Yield } \\
\text { Stress } \\
(M P a)\end{array}$ & $\begin{array}{c}\text { Ultimate } \\
\text { Strength } \\
(M P a)\end{array}$ & $\begin{array}{c}\text { Life } \\
\text { Cycles } \\
(\text { Cycles })\end{array}$ & $\begin{array}{c}\text { Cyclic Strain } \\
\text { Hardening } \\
\text { Exponent }\end{array}$ & $\boldsymbol{\alpha}^{*}$ \\
\hline $150.53[63]$ & 37.75 & $39.5[52]$ & 100,000 & 1 & $\begin{array}{c}10 \alpha \text { (derived from } \\
\text { the original } \\
\text { equation) }\end{array}$ \\
\hline
\end{tabular}


Through mechanical properties adapted for swine skin in equation (5.1), predicted ratcheting values were found in close agreement with those measured values in Fig. 5.10. After initial 30 cycles, maximum deviation of the predicted curve from experimental data was found about $16 \%$.

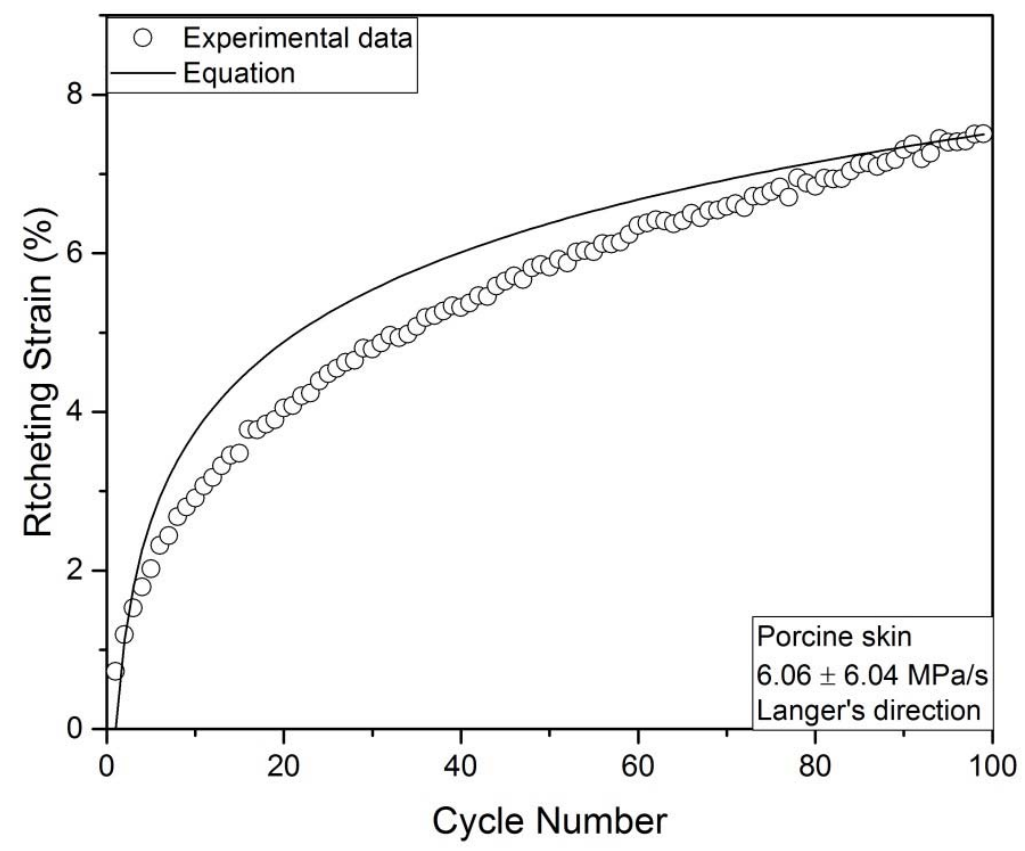

Fig. 5.10: Experimental [52] and predicted ratcheting values by equation (5.1) for porcine skin.

\subsection{Summary}

In this chapter, the triphasic ratcheting model [57] was modified and employed to assess ratcheting strain of the meniscus, articular cartilage, trabecular bone and porcine skin tissues. The phenomenological model through its parameters and coefficients enables a successful ratcheting assessment of biological tissues as compared with experimental data achieved at different loading conditions. The outcomes of predicted ratcheting values closely agreed with the measured values. 


\section{Chapter 6}

\section{Results and Discussion}

In daily activities, human body organs undergo cyclic loads in different stress variations and frequencies. For instance, articular cartilage bears about $1 \mathrm{MPa}$ stress at $1 \mathrm{~Hz}$ frequency during walking $[64,65]$ which can be increased to more than $10 \mathrm{MPa}$ in other activities [34]. These repetitive cyclic loads cause excess of strain, tissue deformation, and crack propagation resulting in progressive damage and failure. A critical part of the knee is the meniscus, which transmits the loads. Articular cartilage, another load transmitter tissue in the knee joint, is susceptible to degeneration and deformation. Unfortunately, unlike bone, these tissues are not very efficient in the self-repairing and healing process $[12,48]$. Therefore, applying intense or repetitive cyclic loads may lead to unhealable damages, and consequently pain and malfunction of the tissue. In many cases, damaged tissue needs to be replaced by an engineering material. Developing a substance to mimic the realistic tissue functionality, material response under physiological activities are of great interest to study. Having sufficient knowledge and thorough understanding about the tissue mechanical properties and its responses in different load conditions is crucial for designing and substitution within frame of tissue engineering that highly mimics the functionality of the original tissue. An important phenomenon that occurs when tissue is under repetitive cyclic loads is Ratcheting, at which plastic strain is accumulated over asymmetric cyclic loads. This phenomenon is mostly investigated in metals and rarely studied in biological tissues. With limited available experiments and research about ratcheting of biological tissues, this study will investigate and discuss ratcheting behavior of the meniscal tissue, articular cartilage, and trabecular bone 
through applying mechanical and biological concepts. In order to better understand the response of soft and hard tissues under cyclic loads and ratcheting, various parameters including tissue mechanical and biological properties, applied stress amplitude, stress rate, composition, and structure of the tissue are to consider in the analysis.

\subsection{Ratcheting of Meniscus and Influential Parameters}

Miller et al. [48] tested the ratcheting behavior of bovine meniscus under cyclic stress loads. This experiment was performed utilizing the MTS Bionix machine under stress range of 1-10 MPa, at two different frequencies of $1 \mathrm{~Hz}$ and $10 \mathrm{~Hz}$ and at room temperature. The samples were customized for use in cyclic compressive loads with a diameter of $10 \mathrm{~mm}$ and height of $8 \mathrm{~mm}$.

\subsubsection{Loading Frequency and Water Content}

Measured strains values through ratcheting tests conducted on bovine meniscus tissue samples at different frequencies, Miller [48] found that frequency of testing has a noticeable influence on ratcheting magnitude and rate. Load cycles $5.5 \pm 4.5 \mathrm{MPa}$ at lower frequency of $1 \mathrm{~Hz}$ promoted ratcheting to higher magnitude and higher rate than those tests with higher frequency of $10 \mathrm{~Hz}$. The ratcheting test at $1 \mathrm{~Hz}$ frequency achieved $20 \%$ higher in strains as compared with test of 10 $\mathrm{Hz}$ in frequency as shown in Fig. 6.1. 


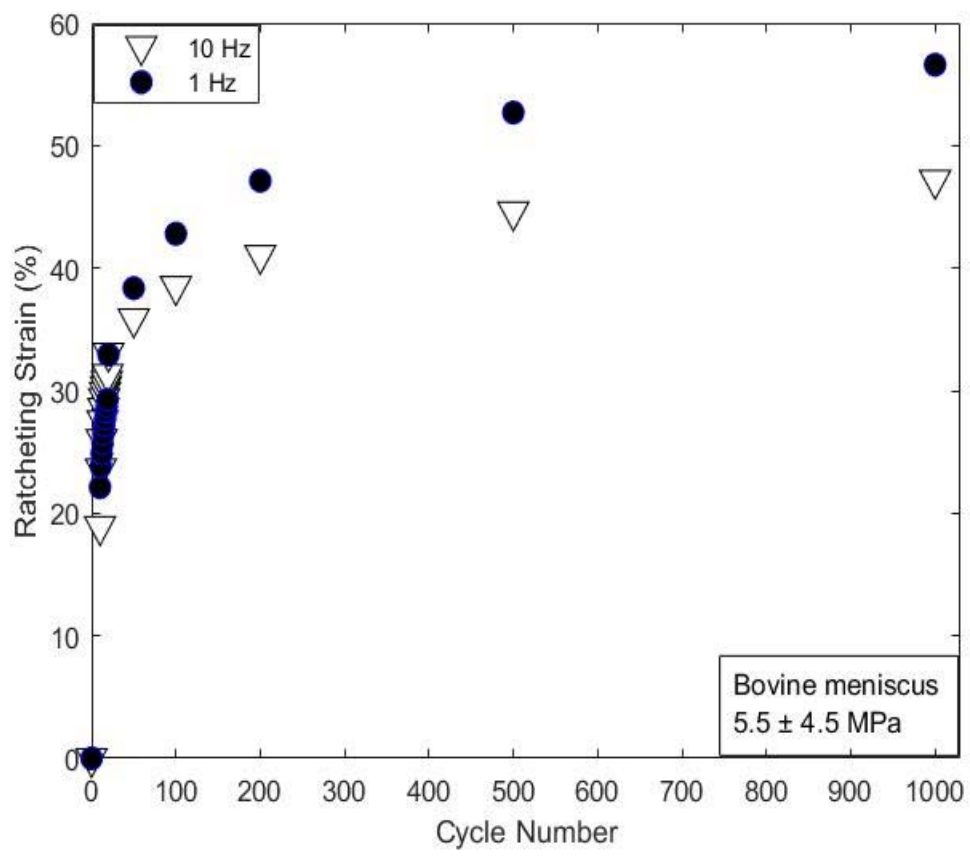

Fig. 6.1: Experimental ratcheting data for bovine meniscus tissue samples tested at $1 \mathrm{~Hz}$ and 10 $\mathrm{Hz}$.

The difference in ratcheting rate and magnitude at various frequencies in meniscus tissue is attributed to the water content as high as $72 \%$ [3]. Under compression and at low testing frequency of $1 \mathrm{~Hz}$, liquid is discharged from the tissue over longer time period and cycles, resulting in a higher ratcheting strain [48].

\subsubsection{Time dependency and Ratcheting}

The soft tissue of bovine meniscus deforms visco-elastically under loading cycles. The viscoelastic response of this tissue is well described through loading frequency and time dependency. Fig. 6.2 presents ratcheting data in vertical axis plotted versus time period for two meniscus samples tested at different frequencies. The noticeable difference in ratcheting magnitude in this figure is where two sets of data deviate from each other for cycles below 200 seconds at two 
different frequencies. Ratcheting of meniscus sample tested at $10 \mathrm{~Hz}$ possesses higher magnitude in strain. Beyond 200 seconds, ratcheting data for both tests are unified regardless of timedependency. Ratcheting becomes the same at the 500 seconds, which is equal to 5,000 cycles at $10 \mathrm{~Hz}$ and 500 cycles at $1 \mathrm{~Hz}$.

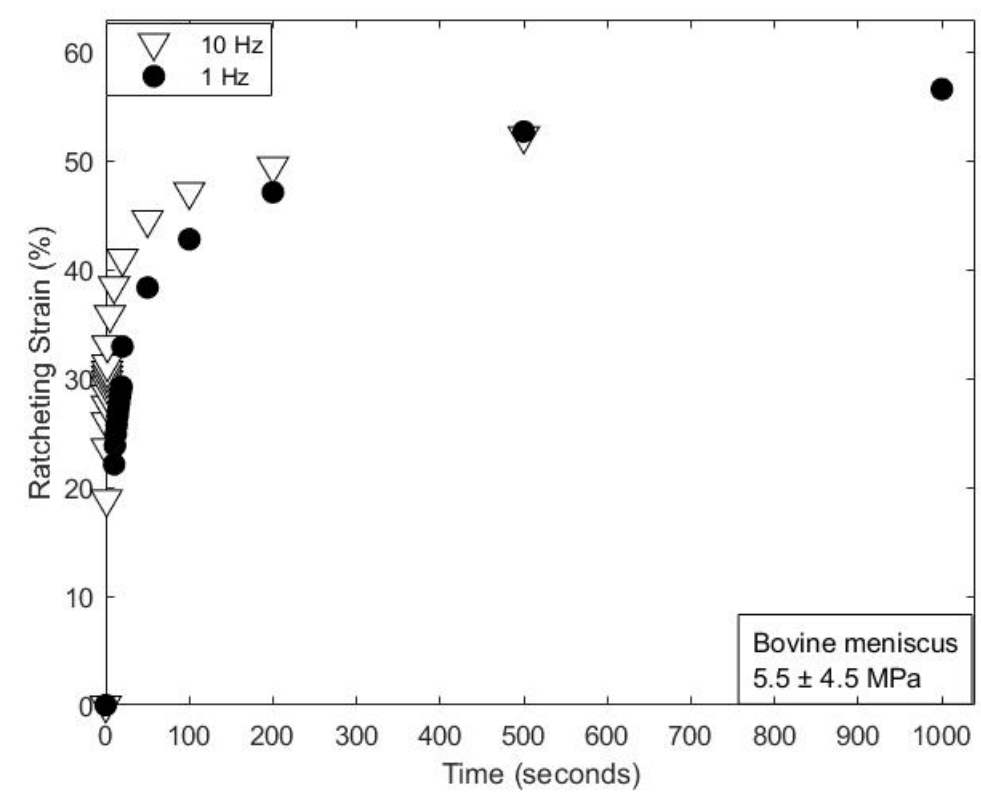

Fig. 6.2: Ratcheting strain data at different frequency plotted versus time.

\subsubsection{Stress-Strain Hysteresis Loops and Ratcheting}

Selected loops of the stress-strain curve of the meniscal tissue under cyclic loads (1-10 MPa) are presented in Fig. 6.3. 

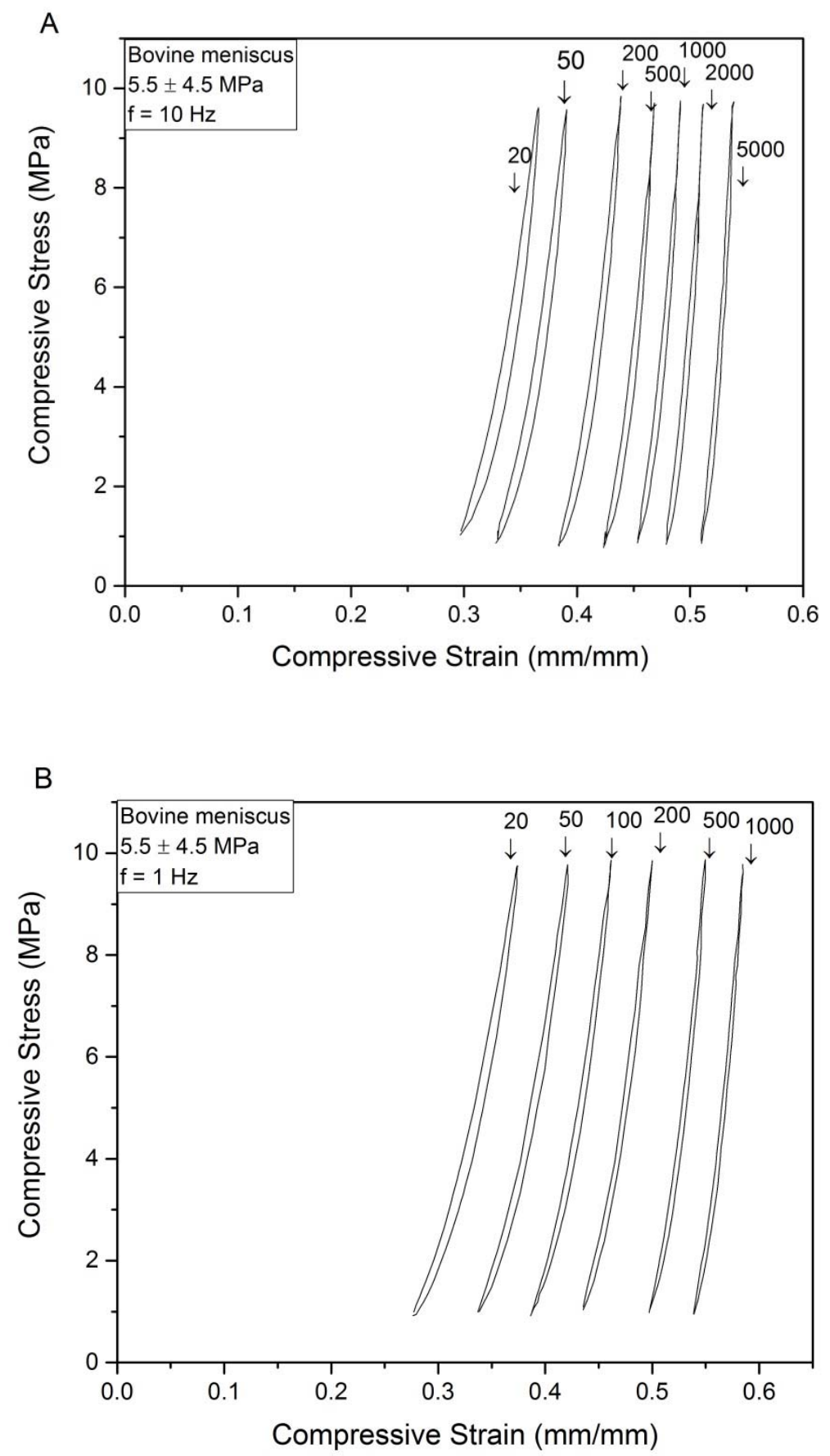

Fig. 6.3: Experimental hysteresis loops of tested meniscus sample at (A) $10 \mathrm{~Hz}$ and (B) $1 \mathrm{~Hz}$ (data from [48]). 
At both frequencies, hysteresis loops rise in slope incrementally as the number of cycles increases. In other words, as tissue bears more stress cycles, the meniscus becomes stiffer. Fig. 6.4 shows hysteresis loops at various cycles of 20, 100, 500, and 1,000 for both frequencies of 1 and $10 \mathrm{~Hz}$. Loops generated through testing at $1 \mathrm{~Hz}$ and $10 \mathrm{~Hz}$ are respectively presented in solid and dashed curves.

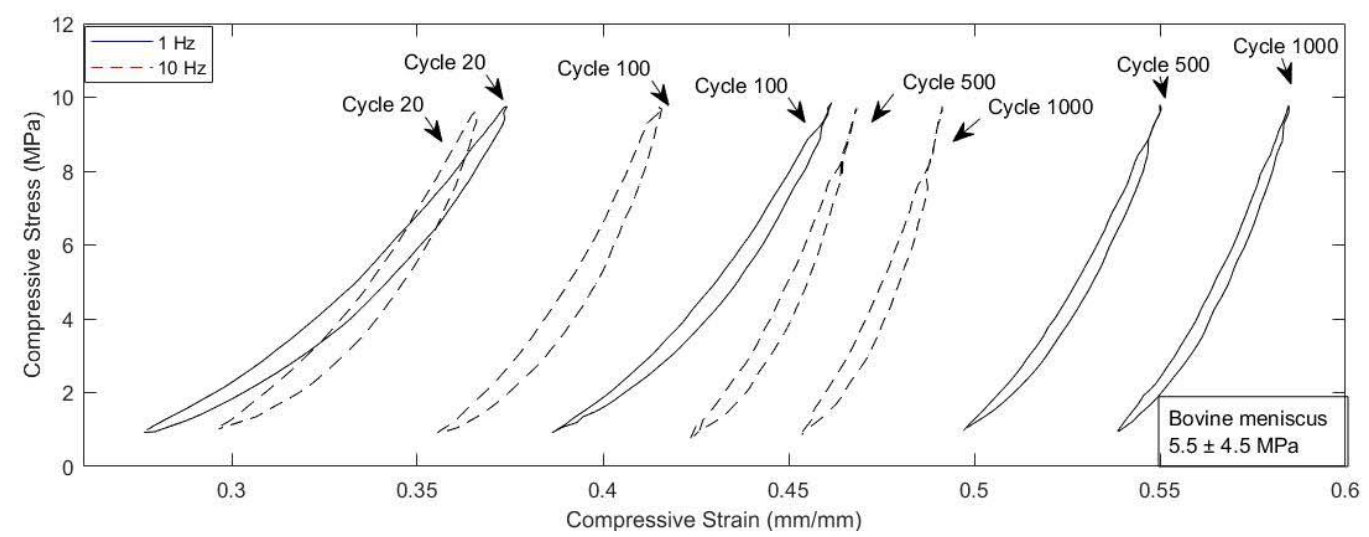

Fig. 6.4: Hysteresis loops of cycles 20, 100, 500, and 1,000 for meniscus tissue samples tested at $10 \mathrm{~Hz}$ and $1 \mathrm{~Hz}$ (data from [48]).

Regardless of cycle number, loops at frequency of $1 \mathrm{~Hz}$ consistently have lower slopes compared to that of $10 \mathrm{~Hz}$, which indicates more ratcheting strain. Hysteresis loops generated under $1 \mathrm{~Hz}$ possessed lower stiffness than those tested at $10 \mathrm{~Hz}$. This clearly shows how influential the time dependency and testing frequency is on the stiffness and ratcheting response of bovine meniscal tissue. At the initial cycles (1-20), valley strain of the tissue at $1 \mathrm{~Hz}$ is lower than the corresponding strain for the same cycles at $10 \mathrm{~Hz}$; however, at higher cycles, both minimum and maximum strains are greater at the frequency of $1 \mathrm{~Hz}$. By applying more compressive loads, the loops at both frequencies move further away from each other. For instance, as shown in Fig. 6.5, the valley strain occurred at $1 \mathrm{~Hz}$ during cycle 20 is $2 \%$ less than corresponding strain at $10 \mathrm{~Hz}$. While throughout 
the $1,000^{\text {th }}$ cycle, the minimum strain at $1 \mathrm{~Hz}$ surpasses $10 \mathrm{~Hz}$ by over $8.5 \%$. These changes in the minimum and maximum strains over cycles result in an increase in the ratcheting strain.

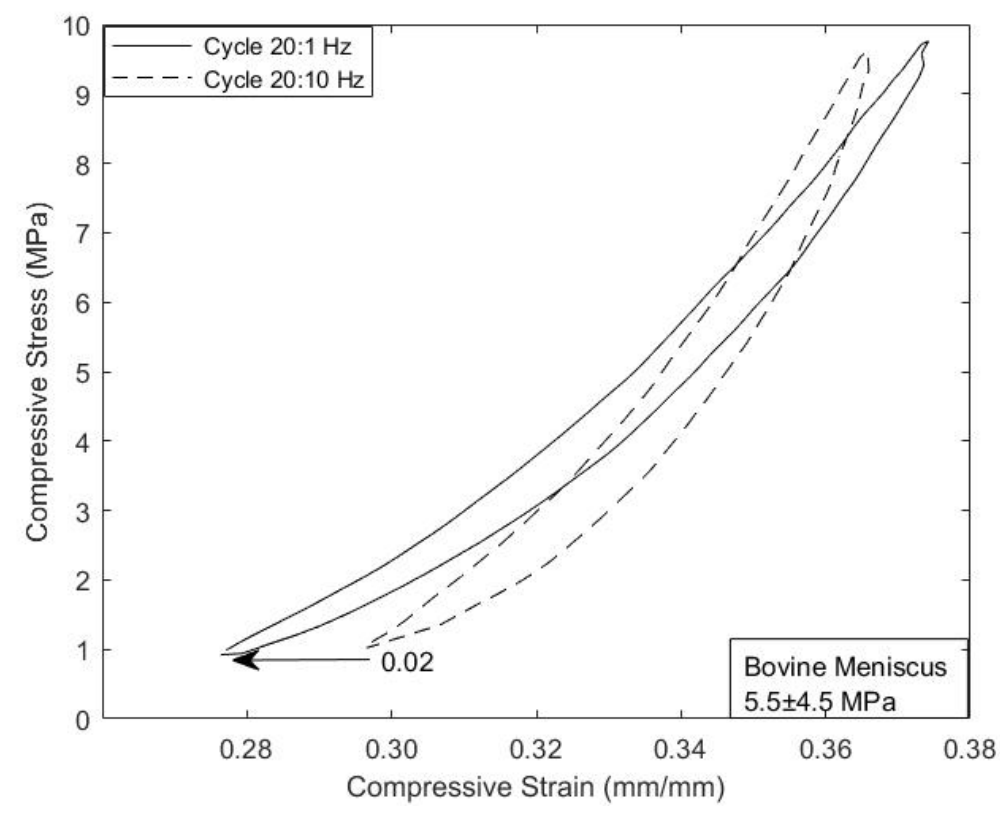

Fig. 6.5: Minimum strains at $20^{\text {th }}$ cycle at two frequencies of $1 \mathrm{~Hz}$ and $10 \mathrm{~Hz}$.

\subsubsection{Effect of Ratcheting on Modulus}

Meniscus tissue is a viscoelastic material and possesses a non-linear stress-strain curve. A stressstrain curve for meniscus is schematically presented in Fig. 6.6 holding three different regions of toe, linear, and failure. These regions consist of three tangents/ moduli representing stiffness values. 


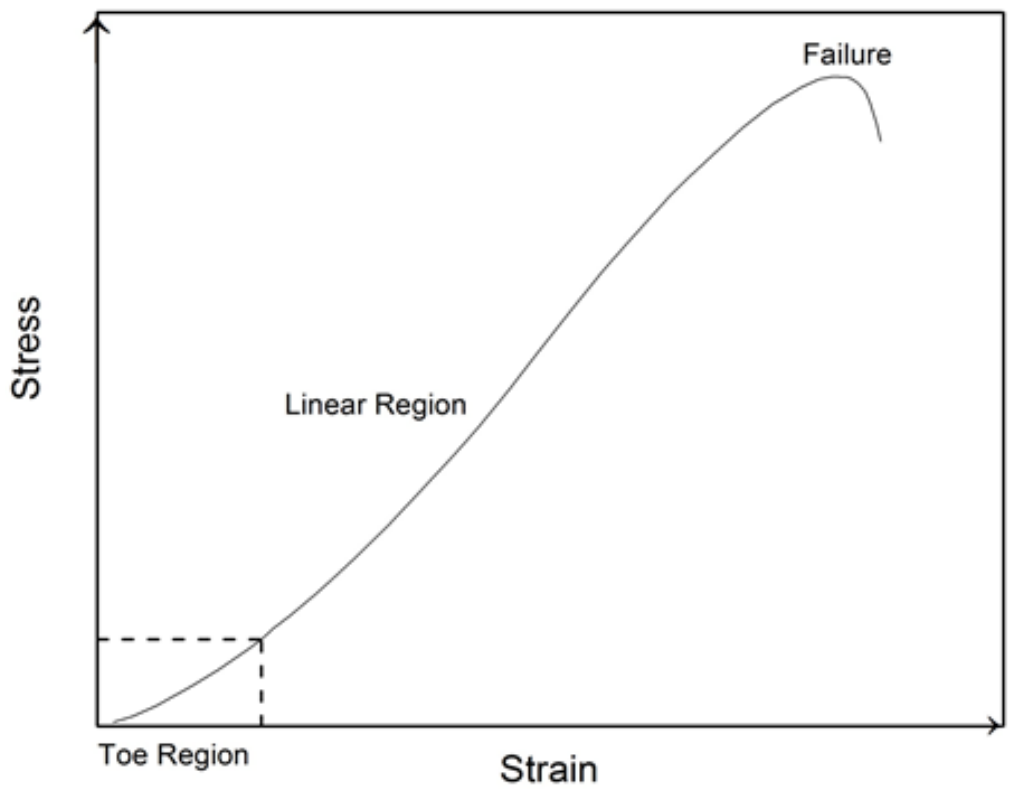

Fig. 6.6: Schematic presentation of stress-strain curve of a viscoelastic material.

Fig. 6.7 presents stress-strain curve for meniscus tissue. In the first region of the stress-strain curve, the "toe region", the collagen fibrils are not aligned with the direction of the load, therefore, the tissue has limited stiffness. The slope of the toe region is called $E_{1}$. In the next part of the curve, the "linear region", collagen fibrils are in line with the load direction, which results in higher resistance of the material. The slope of this part is termed $E_{2}$. The slope of the last region of the curve which is followed by failure is defined as $\beta$. This slope is defined through use of $E_{1}$ and $E_{2}$ as [66]:

$$
\beta=\frac{1}{E_{1}}+\frac{1}{E_{2}}
$$




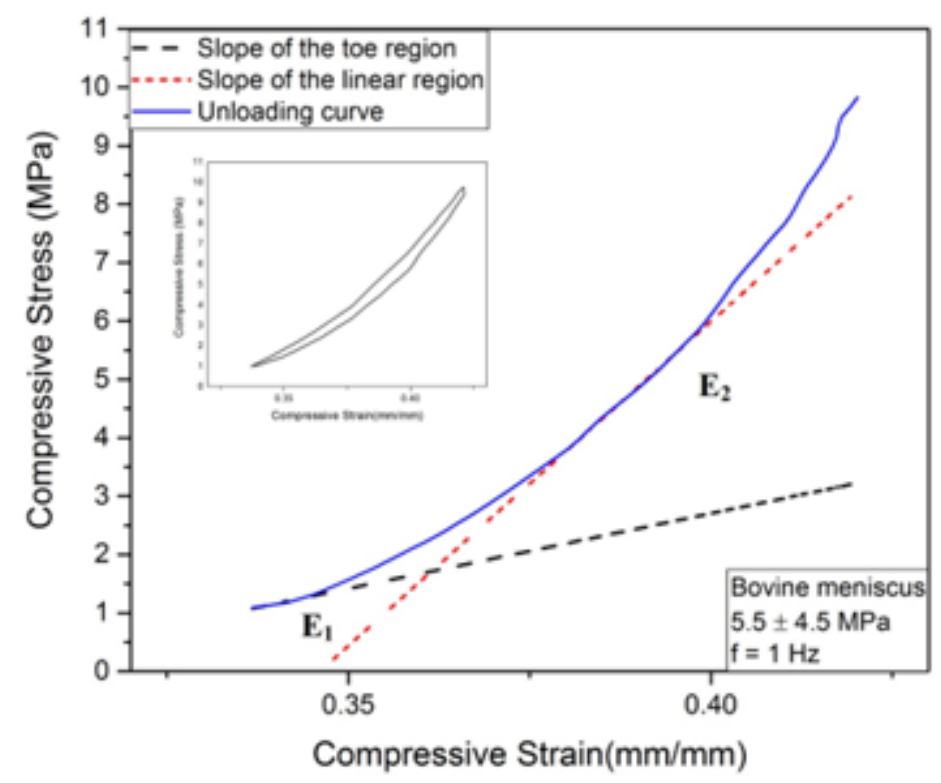

Fig. 6.7: Typical stress-strain curve of the meniscus and the slope of the two regions.

The hysteresis loops of bovine meniscal tissue were employed to calculate of the moduli. In each loop, the slopes of the toe and linear regions $\left(E_{1}\right.$ and $\left.E_{2}\right)$ were computed and are shown in Fig. 6.8A, B. Substituting $E_{1}$ and $E_{2}$ in equation (6.1), the failure modulus was calculated. $E_{1}, E_{2}$, and $\beta$, at both frequencies are plotted in Fig. 6.8C.

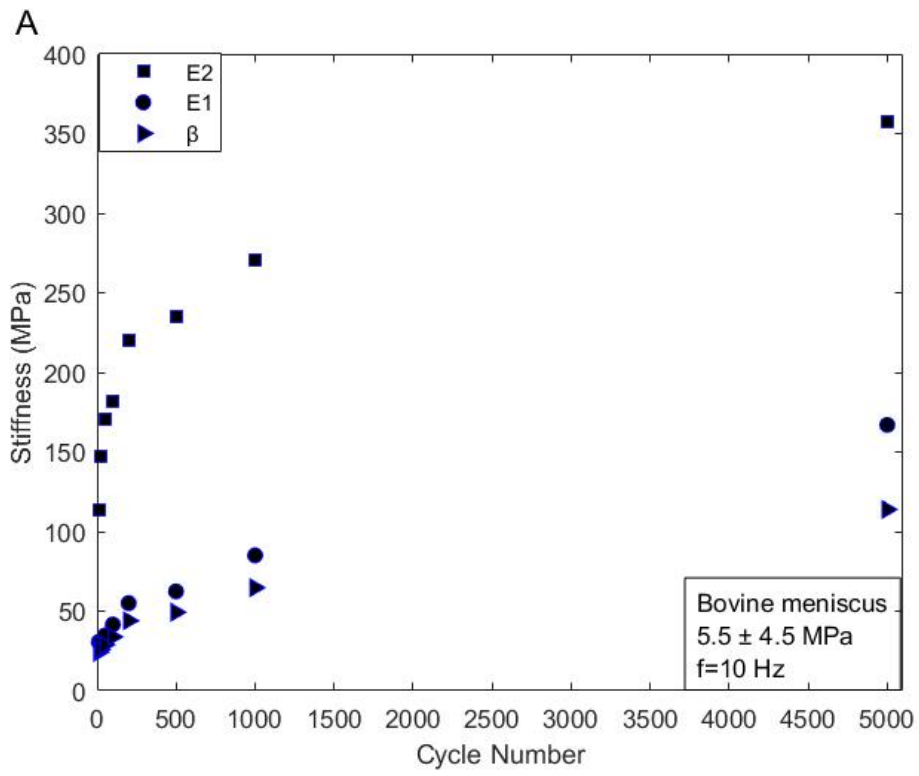

Fig. 6.8: Slopes of three regions of stress-strain curves of the meniscus at (A) $10 \mathrm{~Hz}$, (B) $1 \mathrm{~Hz}$, and $(\mathrm{C})$ both frequencies. 

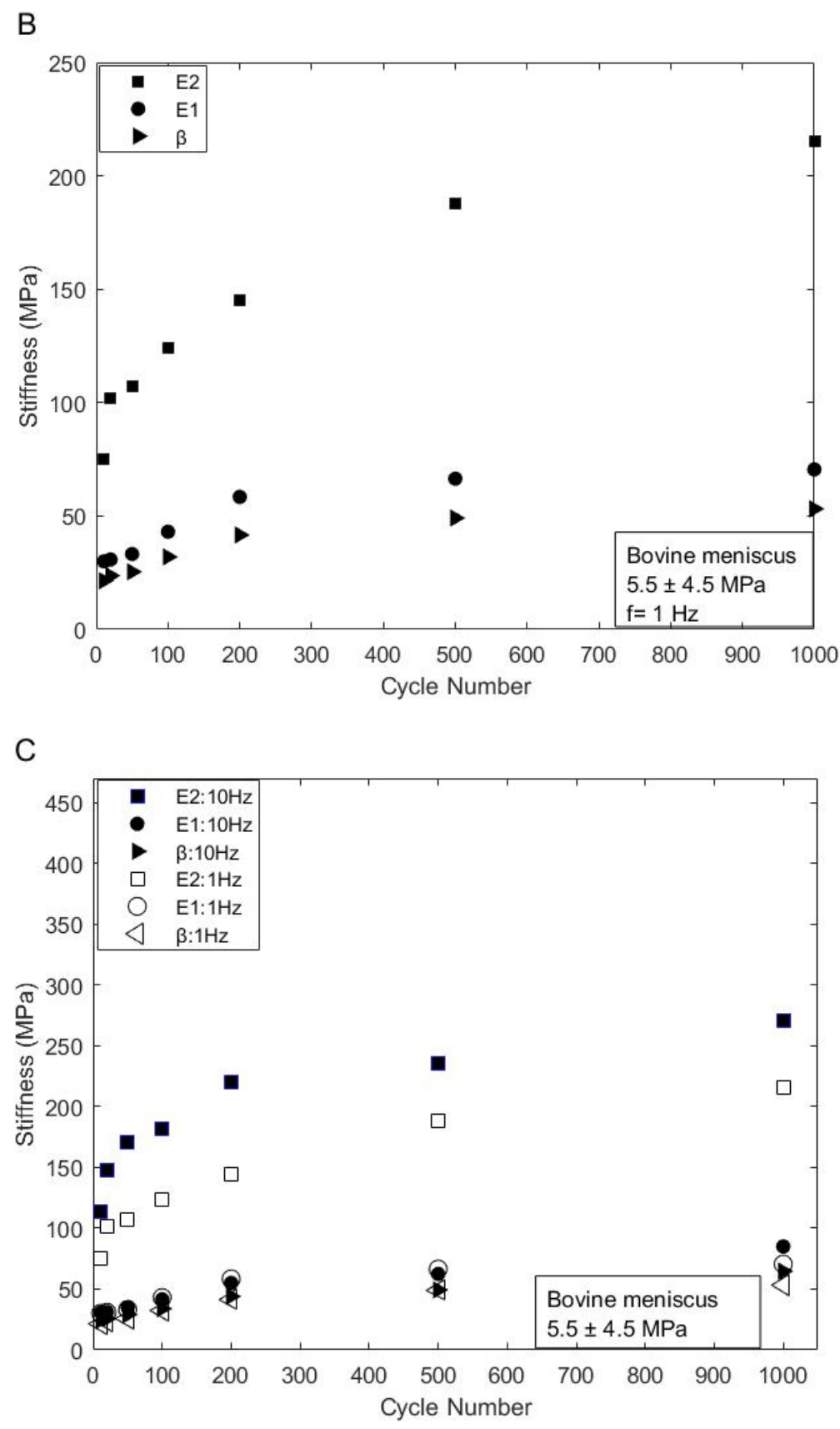

Fig. 6.8: (continued)

The slopes of the three regions of the stress-strain curve in Fig. 6.8, indicates that regardless of frequency, the slope of the linear region $\left(E_{2}\right)$ is the highest. This is due to the alignment of the collagen fibrils with orientation of the applied load, and subsequently, the stiffness of the biological material in this region is at the highest. $\beta$ the slope of the failure region, has the smallest 
value which represents the weakest portion of the curve that yields failure. Moduli $E_{1}, E_{2}$ and $\beta$ at frequency of $10 \mathrm{~Hz}$ are always greater than corresponding values at $1 \mathrm{~Hz}$. Therefore, less strain is expected at higher frequencies. This is in harmony with the results achieved in section (6.1.1) through comparing ratcheting strain of the bovine meniscal tissue at frequencies of $1 \mathrm{~Hz}$ and 10 $\mathrm{Hz}$ (shown in Fig. 6.1). Unlike $E_{2}$, values of $E_{1}$ and $\beta$ at $1 \mathrm{~Hz}$ and $10 \mathrm{~Hz}$ frequencies have minor changes and very close values.

\subsubsection{Energy Dissipation During Ratcheting Phenomenon}

As a viscoelastic material, meniscus - unlike elastic substances - does not build symmetric loading and unloading curves under cyclic loads. Constructing hysteresis loops and the area inside the loops correspond to the energy loss during cycles of loading and unloading [22]. To track variation of energy dissipation in the meniscus and its relation to the ratcheting, the area of each hysteresis loop was calculated and plotted in Fig. 6.9. In this figure, energy loss in meniscus tissue begins with approximately the same initial value during the first cycle at both frequencies of $1 \mathrm{~Hz}$ and 10 Hz. However, as more cyclic loads are applied, more energy was dissipated during stress cycles at the higher frequency as compared to corresponding cycle at the lower frequency. The energy dissipation curve at $1 \mathrm{~Hz}$ dropped sharper before cycle 200 followed by a slower decrease. Nonetheless, the same phenomenon happens at cycle 500 when the tissue undergoes cyclic stress at $10 \mathrm{~Hz}$. Higher energy loss resulted in less ratcheting strain of the material. The amount of energy dissipated between cycles 20 and 50 (Fig. 6.9) at $1 \mathrm{~Hz}$ is about 2.15 times greater than the corresponding cycles at $10 \mathrm{~Hz}$ and it decreases to about 0.91 between cycles 500 and 1,000 . As the number of cycles proceeded, the amount of energy loss decreased the loops became narrower 
and the loading and unloading paths got closer. This also explains the decrease in ratcheting strain rate at higher cycles.

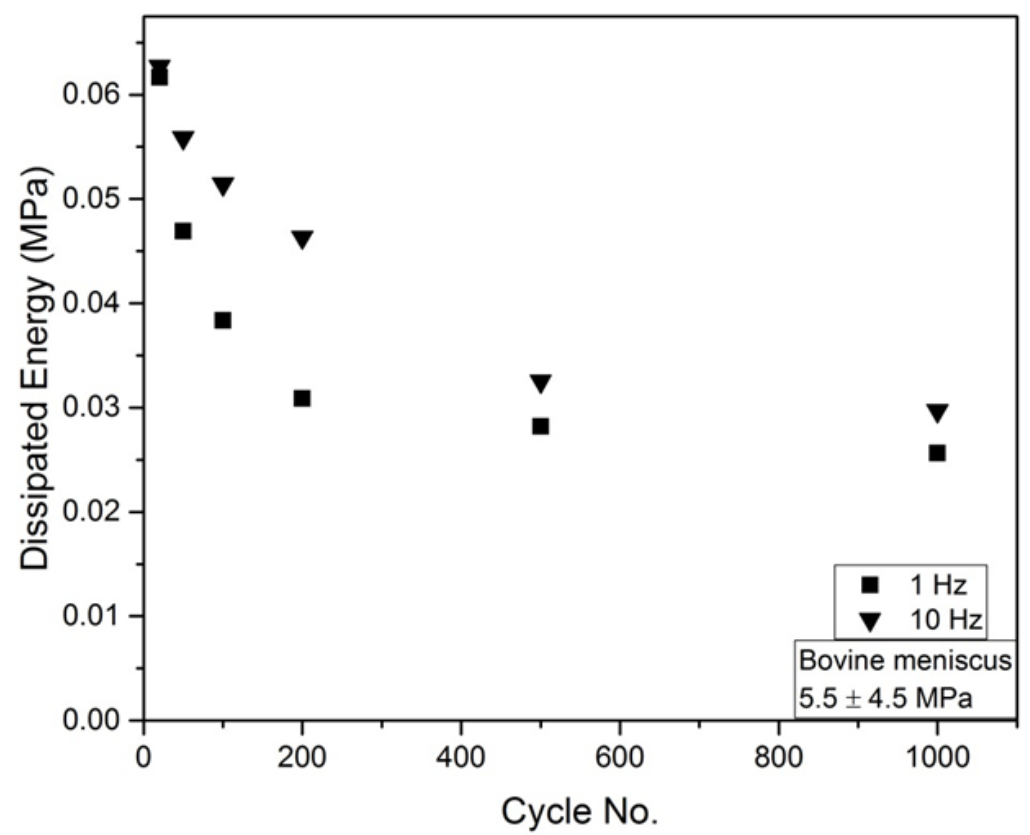

Fig. 6.9: Dissipated energy during different cycles at two frequencies for meniscus tissue.

\subsection{Ratcheting of Articular Cartilage and Influential}

\section{Parameters}

Gao et al. [49] examined ratcheting behavior of porcine articular cartilage under compressive cyclic loads. Articular cartilage samples attached to bone, with dimensions of $5.5 \times 4.5 \times 12 \mathrm{~mm}$ were studied under different stress conditions to investigate ratcheting phenomenon in the tissue. Experiment was conducted on soaked samples (in saline) and unsoaked specimen to investigate the effect of environment on the tissue responses to cyclic loads. Samples were tested on stress variations of $0.5,1$ and $1.5 \mathrm{MPa}$ and stress rates of $0.1,0.2$ and $0.4 \mathrm{MPa} / \mathrm{s}$. Compressive cyclic tests were performed utilizing the Electronic Universal Fatigue Testing System (EUF-1020) [49]. The 
stress-strain diagram, hysteresis loops, and ratcheting strain curve of the articular cartilage subjected to compressive cyclic loads (0.0-0.5 MPa) was presented in Fig. 3.4 in Chapter 3. Fig. 3.4A showed that as the tissue withstands more stress cycles, the slope of the hysteresis loops increases and the articular cartilage becomes stiffer. Hysteresis loops became thinner which indicates the ratcheting rate, as well as, lost in energy were declined.

\subsubsection{Effect of Frequency and Stress Rate on Ratcheting}

Articular cartilage tested at three different frequencies of $0.05,0.1$ and $0.2 \mathrm{~Hz}$ while stress level kept constant. Fig. 6.10 shows how influential the testing frequency on the ratcheting results of the cartilage samples are. An increase in loading frequency dropped the ratcheting magnitude in cartilage over loading cycles. At stress variation of $1 \mathrm{MPa}$, as testing frequency increased from 0.05 to $0.1 \mathrm{~Hz}$ and 0.05 to $0.2 \mathrm{~Hz}$, the magnitude of ratcheting strain decreased about $40 \%$ and $57 \%$ respectively.

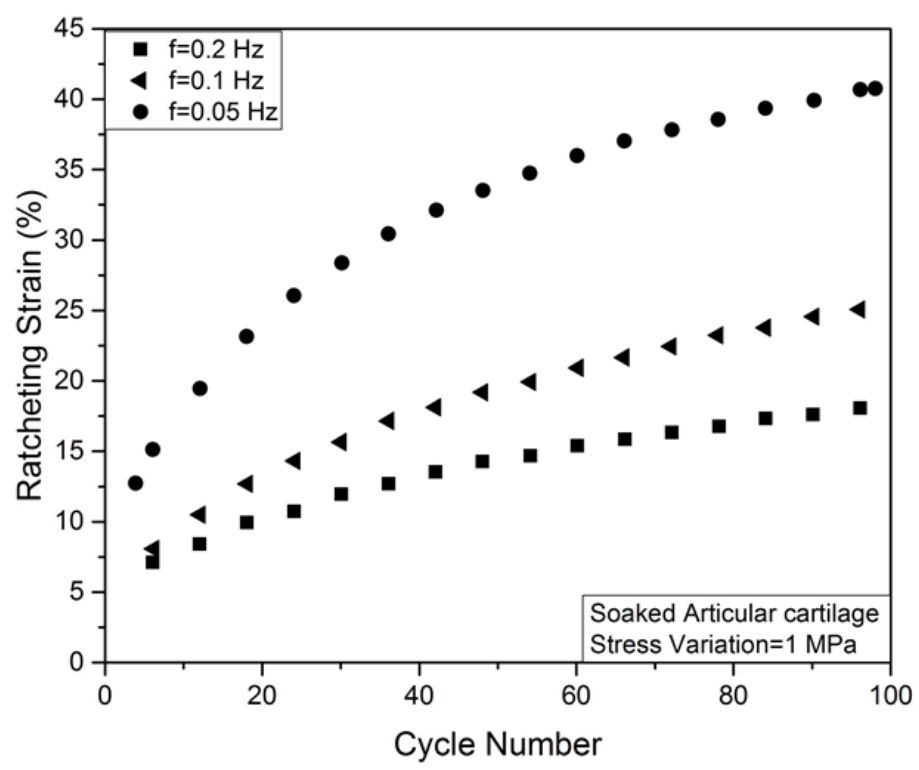

Fig. 6.10: Ratcheting strain of the porcine articular cartilage at different frequencies (data from [49]). 
This change in ratcheting magnitude is related to the water content in cartilage tissue. The water content of the articular cartilage is $70-85 \%[10,67]$. About $70 \%$ of water freely moves through the tissue matrix [1]. When cartilage is subjected to loading, under less frequency, the moisture has more time to flow out of the tissue, which leads to an increase in strain accumulation. The same relationship between ratcheting strain and stress rate exists (Fig. 6.11). At a constant stress variation, the higher stress rate results in less ratcheting strain.

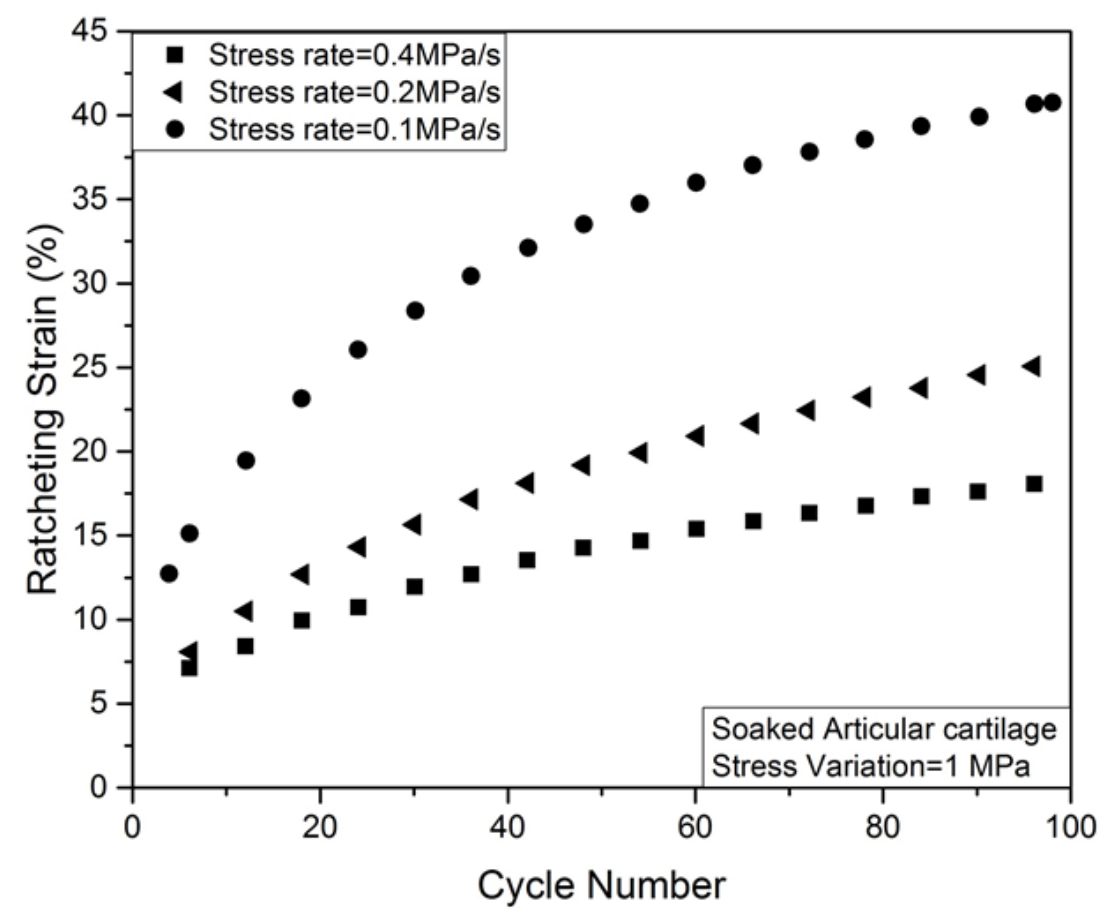

Fig. 6.11: Ratcheting strain of the porcine articular cartilage at different stress rates (data from [49]).

\subsubsection{Effect of Stress Variation on Ratcheting}

Unlike stress rate, stress level directly influences the magnitude of ratcheting strain. Test results indicated that at a constant loading rate an increase in stress amplitude increases the ratcheting strain (Fig. 6.12). More compressive force yields a higher ratcheting strain, although, this increase 
is not linear. For instance, increasing stress amplitude by $0.5 \mathrm{MPa}$ (from 0.5 to $1 \mathrm{MPa}$ ) causes a rise in the ratcheting strain as high as 3.2 times, but the same increment from 1 to $1.5 \mathrm{MPa}$ has a smaller boost in ratcheting of $12 \%$ in Fig. 6.12. This can be explained as the effect of maximum stress on strain accumulation.
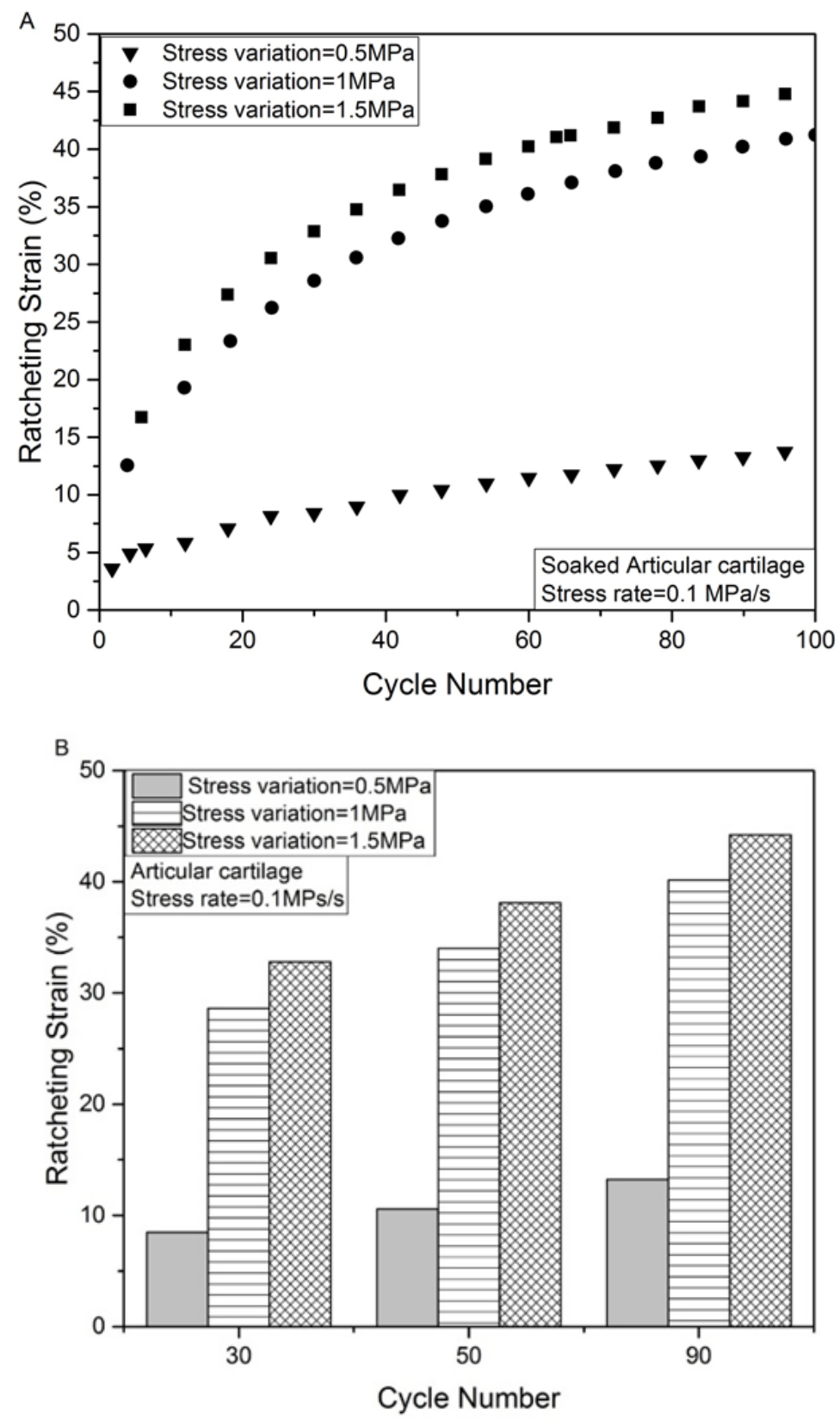

Fig. 6.12: Ratcheting strain of articular cartilage at different stress levels (A) all cycles, (B) cycles 30, 50, 90 (data from [49]). 
The effect of stress level and loading frequency on ratcheting of articular cartilage is presented in Fig. 6.13. The highest ratcheting strain belongs to the tissue sample tested at stress level of 1.5 $\mathrm{MPa}$ and frequency of $0.033 \mathrm{~Hz}$. Ratcheting data achieved at cycle 95 and at applied stress levels of $0.5 \mathrm{MPa}$ and $1 \mathrm{MPa}$ at loading frequencies of $0.1 \mathrm{~Hz}$ and $0.2 \mathrm{~Hz}$ respectively, boost about $36 \%$ in magnitude, as both stress level and frequency are doubled. This suggests that less stress variation results in lower ratcheting strain. It can be postulated that the effect of stress level on ratcheting strain is significantly higher than the loading frequency.

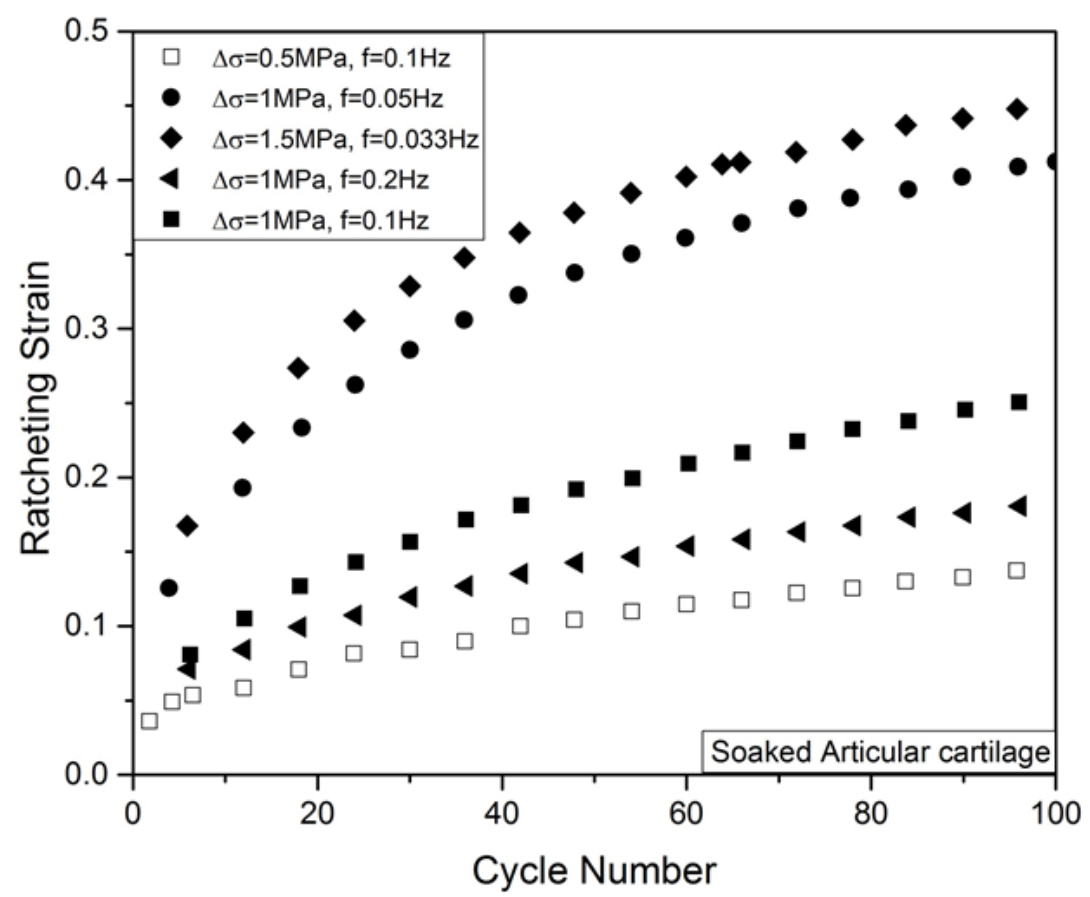

Fig. 6.13: Ratcheting strain values at different stress levels and frequencies (data from [49]).

\subsubsection{Effect of Physiological and Testing Environment on Ratcheting}

The ratcheting strain experiment was done on two sets of samples, soaked in saline and unsoaked [49]. Saline soaked samples were tested maintaining the physiological environment of the tissue.

The outcomes indicated that at the same load conditions, unsoaked samples ratchet faster than 
soaked samples, yet, this difference declines with increase in cycle number as presented in Fig. 6.14. This phenomenon is also related to the fluid phase of the material. Articular cartilage contained a high volume of water which is discharged from tissue under compression. At the first cycles, part of discharged moisture returns to the tissue during unloading which results in less ratcheting strain. Nonetheless, at larger cycle numbers or when cartilage strain is high, the fluid supply of the tissue decreases, and the fibril network bears load which causes more ratcheting strain of soaked samples, reaching to the same level as unsoaked samples [49].

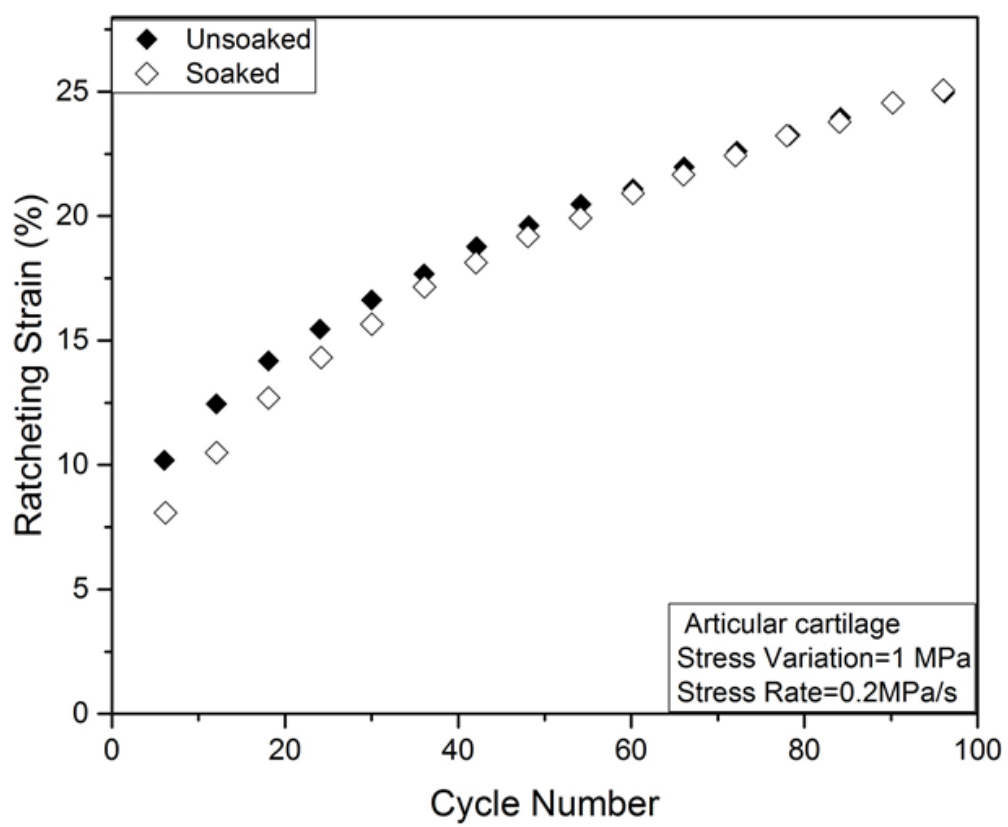

Fig. 6.14: Ratcheting strain of soaked and unsoaked articular cartilage tissue samples (data from [49]).

\subsubsection{Dependency of Ratcheting Strain on Depth of the Tissue}

Articular cartilage is a load resistant tissue composed of three zones and a tidemark. The superficial layer, called "tangential zone", is located at the tissue surface and composes $10-20 \%$ of the 
articular cartilage's thickness. The thickness of the mid (transitional) zone is $40-60 \%$ [11]. Each zone has its unique structure and content as shown in Fig. 1.4. Since the composition in each zone is different, dissimilarity is expected in the tissue's mechanical response as well. The response of the different depths of the articular cartilage under stress variation of $0.5 \mathrm{MPa}$ and frequency of $0.1 \mathrm{~Hz}$ is shown in Fig. 6.15. As it is noticeable, the deep layer develops the lowest ratcheting strain value. This can be explained by the water content and permeability of the tissue. Permeability is a factor of fluid flow in the matrix [10], which is not constant throughout tissue depth. It is minimal in the deep zone since the moisture is unable to move as freely as the two other regions [10]. Considering variations in both permeability and water content of the tissue through its depth, through superficial layer to deep layer, less ratcheting strain is expected as of Fig. 6.15. As the stress cycles advance, the curves of the three zones move apart and the difference in ratcheting strain between them increases [49].

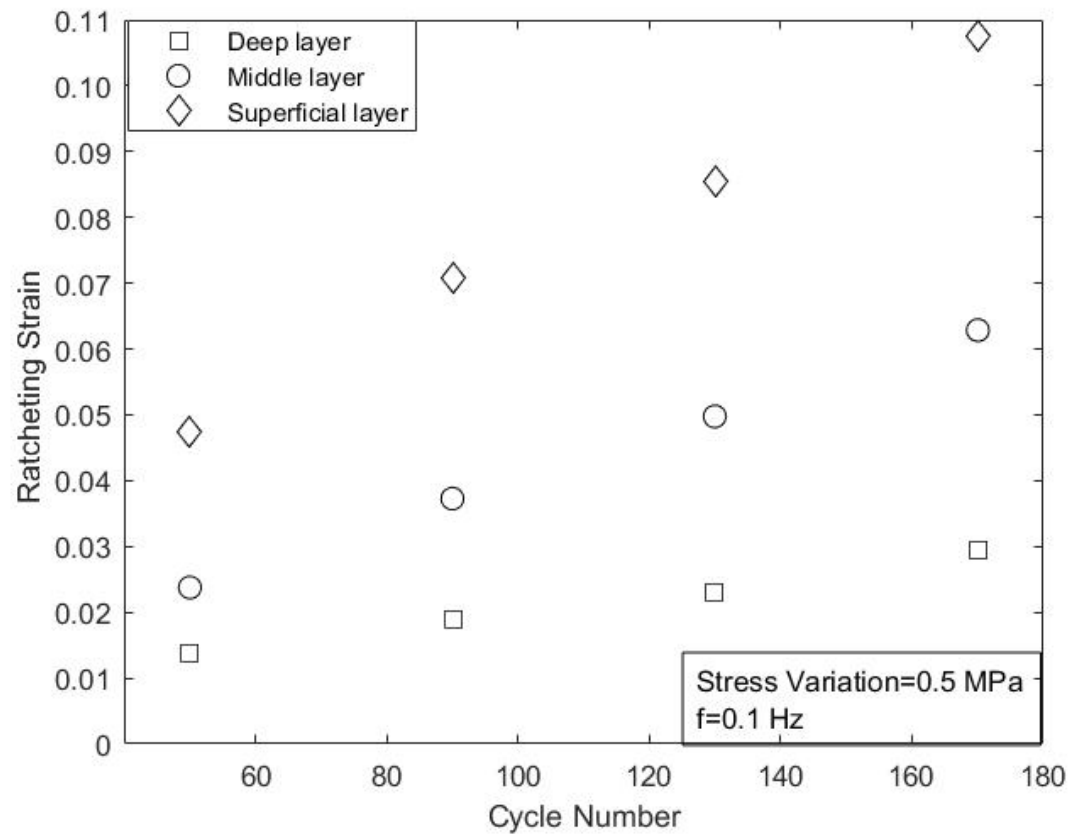

Fig. 6.15: Ratcheting strain of different zones of the cartilage under cyclic compression (data from [49]). 


\subsubsection{Young's Modulus Dependency on Depth of the Cartilage}

In accord with the depth dependency behavior of the articular cartilage ratcheting strain, Young's modulus of the tissue is not constant in the three zones. The superficial layer makes the least modulus, while the deep layer with the highest modulus produces the least ratcheting strain. As plotted in Fig. 6.16, the difference in modulus increases as the tissue bears more cyclic stresses. At cycle 2, the modulus of the superficial layer is $2 \mathrm{MPa}$, while the middle and deep layers have approximately the same stiffness (2.8-2.9 MPa). However, in cycle 98, the superficial, middle and deep layers perform stiffness of 3.4, 5.7 and 13.2 MPa respectively. Among all individual layers, the stiffness of the deep layer grows faster compared to two other regions.

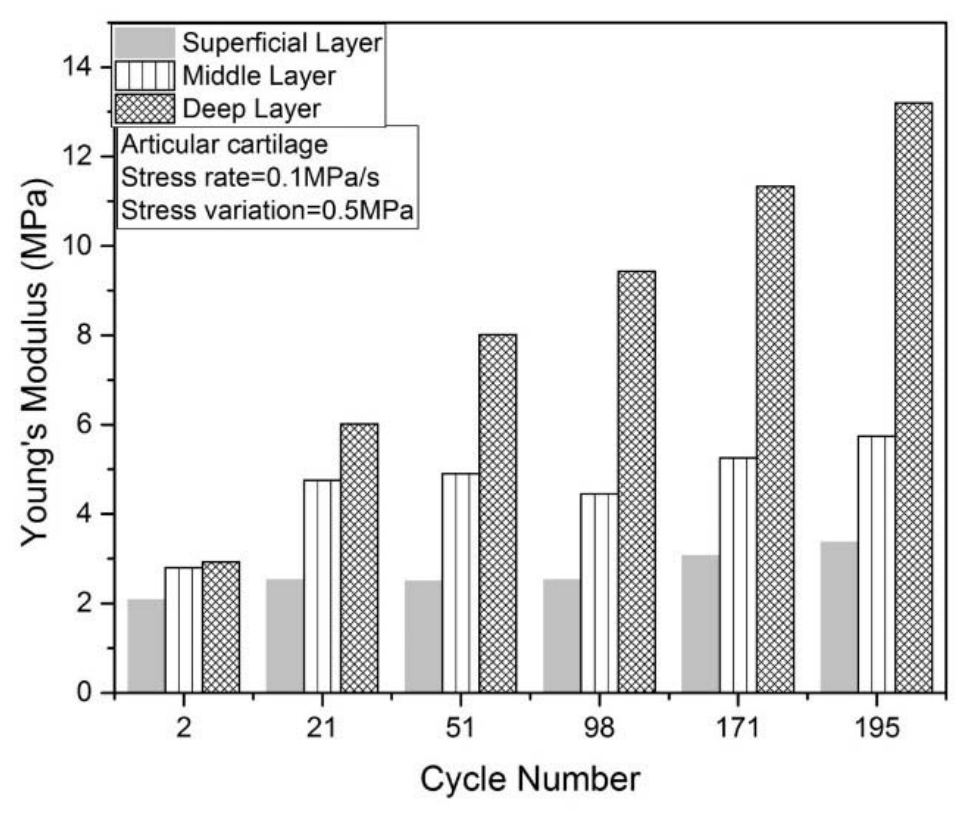

Fig. 6.16: The variation of modulus at layers of cartilage tissue and at different cycles (data from [49]). 


\subsection{Ratcheting of Trabecular Bone and Influential}

\section{Parameters}

Wei et al. [50] tested the ratcheting response of the porcine trabecular bone under stress cycles. Samples with dimensions of $8 \times 8 \times 20 \mathrm{~mm}$ were used in this experiment. The response of the cancellous bone was documented in the stress range of $0-1.56 \mathrm{MPa}$ and stress rate of $0.39 \mathrm{MPa} / \mathrm{s}$.

\subsubsection{Ratcheting Strain}

Fig. 3.5B presents ratcheting strain data obtained from a porcine trabecular bone sample tested at $0.78 \pm 0.78 \mathrm{MPa}$ and testing frequency of $0.125 \mathrm{~Hz}$. As shown, strain accumulation of trabecular bone like other tissues starts with a high rate at initial cycles, followed by a steady state.

\subsubsection{Hysteresis Loops and Stress-Strain Curve}

The stress-strain curve of spongy bone under cyclic loads (0-1.56 MPa) was presented earlier in Fig. 3.5A. When the tissue bears more cyclic stresses, the slope of the hysteresis loops increases and the trabecular bone becomes stiffer. As number of cycles increases, the loops become closer and the ratcheting strain is less promoted. It is expected that as bone withstands more compression, the dissipated energy in the mineralized tissue declines.

\subsubsection{Effect of Bone Marrow on Ratcheting Strain}

Trabecular bone, which has porous structure, is an important part of the human skeletal system. Bone marrow which produces blood cells is located inside the spongy bone. Despite its important 
physiological function, there are some doubts in regards to its role in mechanical properties of the bone. Some papers stated that in low strain rate $\left(0.01 \mathrm{~s}^{-1}\right)$, morrow does not have any effect on stiffness of the bone [68], while others have referred to its role in mechanical properties of the bone [69].

To investigate the effect of marrow on the bone mechanical behavior, Wei et al. [50] tested trabecular bone samples with marrow, and the another set of marrowless bone samples. Fig. 6.17 shows that the ratcheting strain of marrowy bone is less than the marrowless one which illustrates the importance of bone marrow on the stiffness of the spongy bone. During the first 10 cycles, ratcheting strain of both marrowy and marrowless bone has a rapid increase followed by a slower rise rate.

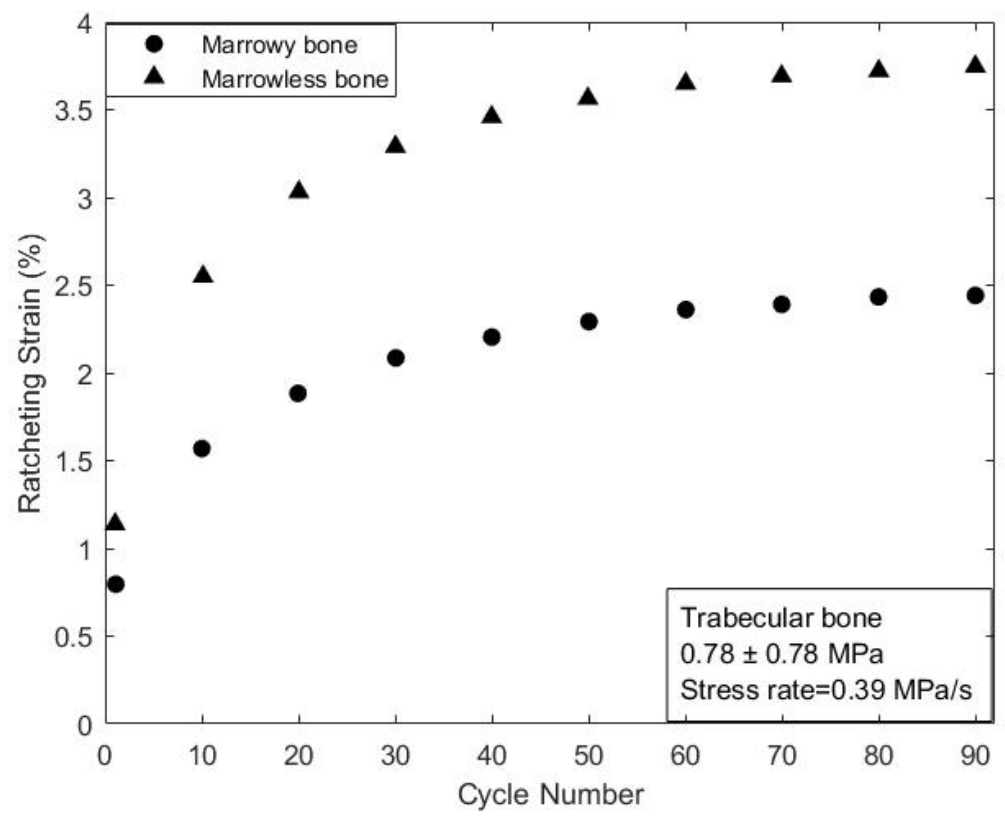

Fig. 6.17: Comparison of ratcheting strain of the marrowy and marrowless trabecular bone (data from [50]). 


\subsubsection{Ratcheting Strain on different depths of the Trabecular bone}

An experiment in three different points of marrowy and marrowless tissue was performed to study the changes of ratcheting strain throughout tissue depth [50]. The results indicate that unlike articular cartilage, the ratcheting strain of the spongy bone is not depth dependent and has almost the same value through tissue depth $[49,50]$. This was the same for marrowy and marrowless bone samples. The variation of ratcheting strain in three points $(A, B, C)$ of the marrowy bone is plotted in Fig. 6.18.

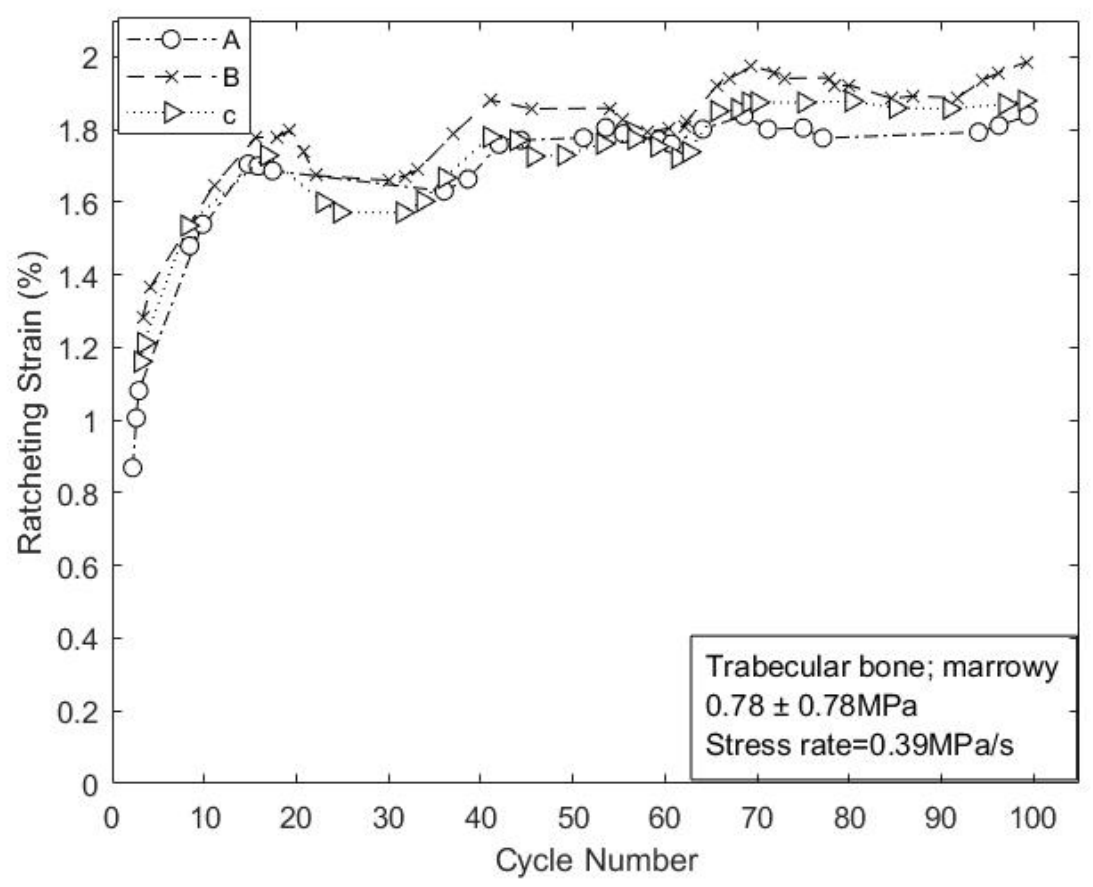

Fig. 6.18: Comparison of ratcheting strain of three points in marrowy trabecular bone (data from $[50])$. 


\subsection{Ratcheting Prediction through Phenomenological}

\section{Model}

Predicted ratcheting curves are plotted versus experimental data for various tissues of meniscus, cartilage, bone and skin tested at different loading conditions. The predicted results through the phenomenological model enabled ratcheting assessment of tissues involving various parameters of loading frequency, stress level, and stress rate. Fig. 6.19 shows how closely predicted values pursue the trend and magnitude of ratcheting data obtained experimentally.

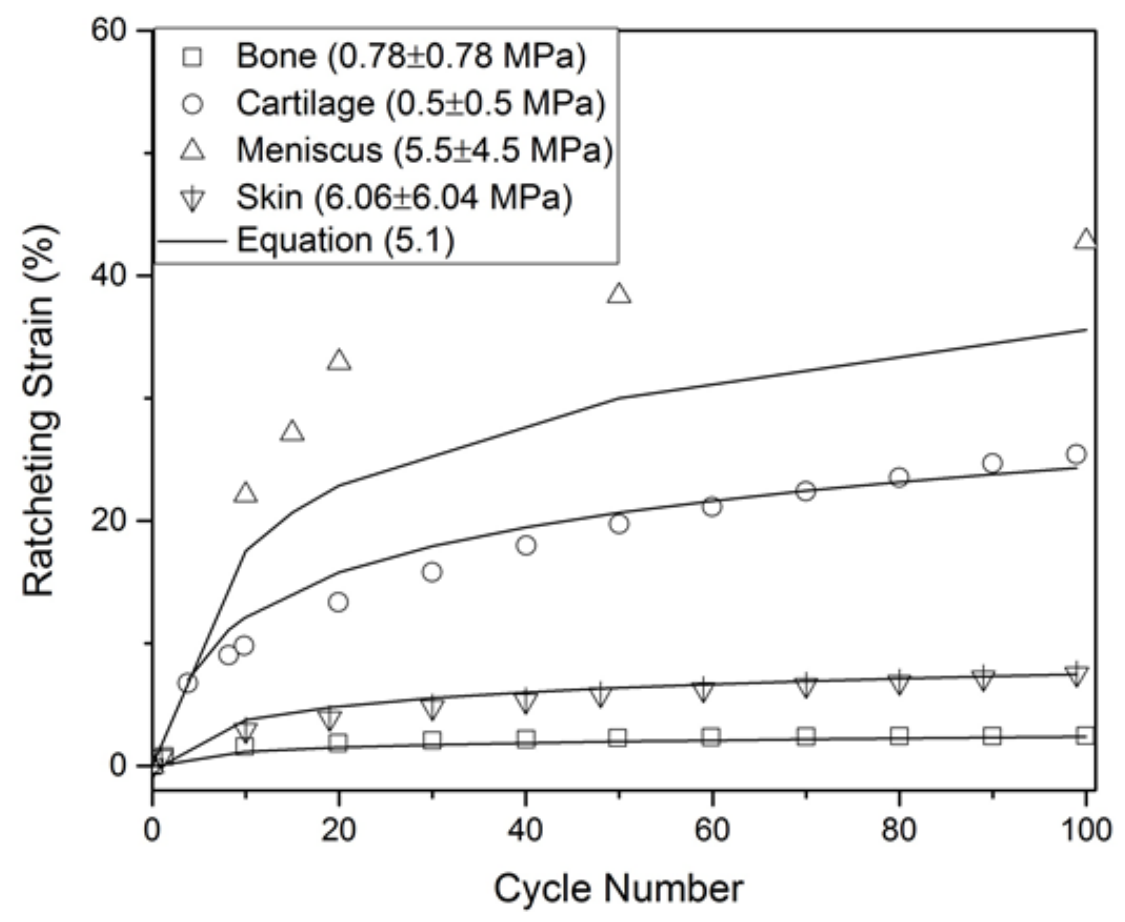

Fig. 6.19: Predicted and experimental ratcheting data for various biological tissues examined in this study. 


\subsection{Summary}

Ratcheting strain responses of biological tissues at various physiological, mechanical, and environmental conditions were discussed. In this chapter, the interaction of different factors and ratcheting strain was highlighted based on available data. Loading frequency and stress level had noticeable influence on ratcheting response of bovine meniscus and porcine articular cartilage. Applied stress level directly influenced ratcheting strain while, stress rate has an inverse impact on ratcheting strain in articular cartilage samples. Various parameters including water content, load magnitude, loading rate, testing frequency, and strain rate influenced ratcheting rate and magnitude in biological tissues. The predicted ratcheting results for various tissues were found in good agreement with those of experimentally obtained. 


\section{Chapter 7}

\section{Conclusion}

In this study, the ratcheting phenomenon in biological tissues was discussed. The biological properties of tissues, their composition and structure, and major factors impacting the tissue physiological characters were first discussed. The role of healthy composition and structure of tissues in their functionality and performance was then reviewed. Subsequently, the mechanical response of the meniscus, articular cartilage, and trabecular bone under static and dynamic loads were discussed. The viscoelastic and time dependent response of biological tissues and their responses under loading cycles were reviewed.

The behavior of the meniscus and articular cartilage, as biphasic materials, under the applied stress depended on load sharing between the liquid and solid phases, permeability, stiffness, aggregate modulus, and fluid content of the tissue and its environment. The meniscus, articular cartilage, trabecular bone, cortical bone, skin, and tendon respond to the asymmetric stress cycles by the ratcheting strain. Corresponding hysteresis loops were characterized. Bone as a composite material consists of organic and inorganic phases, which each component contributes to its unique mechanical properties. Different stages of the stress-strain curve of the cortical bone under compression and tension were discussed. The meniscus and articular cartilage tissues showed an inverse correlation between the ratcheting strain and frequency. The same relation is observed between the stress rate and ratcheting strain in the articular cartilage. However, an increase in stress

level while stress rate kept constant resulted in a rise in the ratcheting strain. Ratcheting strain of the articular cartilage altered in different depths of the tissue. The superficial layer has the highest 
ratcheting strain while the deep layer of the tissue builds less strain. Mimicking the cartilage physiological environment is another important factor considering the response of the tissue to the compressive stress cycles. Unlike articular cartilage, the trabecular bone ratcheting strain did not show a high variability in different depths of the tissue, but bone marrow enhances mechanical properties of the mineralized tissue as the marrowy bone showed less ratcheting strain compared to the marrowless one.

Predicting the strain of the biological tissues and developing and employing a phenomenological model to examine ratcheting of tissues over three stages involved several influencing parameters. The accumulated plastic strain indicates dependency of the ratcheting strain on loading frequency, stress level, stress rate, physiological and environmental conditions. The phenomenological ratcheting model was calibrated and employed to assess ratcheting of biological tissues. The predicted ratcheting results were found in close agreement with those of experimental data at various loading conditions.

As a future recommended work, it is primarily important to establish a comprehensive data bank of ratcheting behavior of biological tissues through several experiments as there are limited experimental data available in literature. Such a data bank of biological tissues' response to asymmetric stress cycles at different stress amplitudes, stress rates, and frequencies provides a better understanding of ratcheting phenomenon on these tissues and their related influential parameters. Moreover, an important factor in tissue lifetime under cyclic load is strain recovery. It is recommended to have some intervals between applied stress cycles to observe its effects on strain accumulation. This information would be very helpful to assess damage and failure in tissues. 


\section{Appendix A}

\section{Test Data}

In this appendix, some of the experimental data used in this study for investigating the ratcheting behavior of the biological tissues and evaluating the available numerical model [57] for predicting the response of tissues under cyclic loads are presented. This data was adopted from different sources [48], [49], [50], and [52] and was processed through Get Data, Origin Lab, and MATLAB software and tabulated as below. The uncertainty for ratcheting tests performed on unsoaked articular cartilage [49] was reported $25 \%$ and for trabecular bone [50] was given $8 \%-15 \%$.

\section{A.1. Data of Bovine Meniscus [48]}

This set of data, extracted from Miller et al. [48], represents points of the hysteresis loops of bovine meniscus under cyclic compression.

\section{A.1.1. Data of Bovine Meniscus at $1 \mathbf{H z}$}

The following table shows stress and corresponding strain of different points of the loops 20,50, $100,200,500$, and 1,000 at the frequency of $1 \mathrm{~Hz}[48]$. 
Data of Bovine Meniscus at $1 \mathrm{~Hz}$ [48] Continued...

\begin{tabular}{|c|c|c|c|c|c|c|c|c|c|c|c|}
\hline \multicolumn{2}{|c|}{$\begin{array}{c}\text { Cycle 20, } \\
\mathrm{f}=\mathbf{1} \mathrm{Hz}\end{array}$} & \multicolumn{2}{|c|}{$\begin{array}{c}\text { Cycle 50, } \\
f=1 \mathrm{~Hz}\end{array}$} & \multicolumn{2}{|c|}{$\begin{array}{c}\text { Cycle 100, } \\
\mathbf{f}=1 \mathrm{~Hz}\end{array}$} & \multicolumn{2}{|c|}{$\begin{array}{c}\text { Cycle 200, } \\
\mathbf{f}=1 \mathrm{~Hz}\end{array}$} & \multicolumn{2}{|c|}{$\begin{array}{c}\text { Cycle } 500 \\
\mathbf{f}=1 \mathrm{~Hz}\end{array}$} & \multicolumn{2}{|c|}{$\begin{array}{c}\text { Cycle 1,000, } \\
f=1 \mathrm{~Hz}\end{array}$} \\
\hline $\begin{array}{l}\text { Strain } \\
(\mathrm{mm} / \mathrm{mm})\end{array}$ & $\begin{array}{c}\text { Stress } \\
(\mathrm{MPa})\end{array}$ & $\begin{array}{l}\text { Strain } \\
(\mathrm{mm} / \mathrm{mm})\end{array}$ & $\begin{array}{c}\text { Stress } \\
(\mathrm{MPa})\end{array}$ & $\begin{array}{l}\text { Strain } \\
(\mathrm{mm} / \mathrm{mm})\end{array}$ & $\begin{array}{c}\text { Stress } \\
(\mathrm{MPa})\end{array}$ & $\begin{array}{l}\text { Strain } \\
(\mathrm{mm} / \mathrm{mm})\end{array}$ & $\begin{array}{c}\text { Stress } \\
(\mathrm{MPa})\end{array}$ & $\begin{array}{l}\text { Strain } \\
(\mathrm{mm} / \mathrm{mm})\end{array}$ & $\begin{array}{c}\text { Stress } \\
(\mathrm{MPa})\end{array}$ & $\begin{array}{l}\text { Strain } \\
(\mathrm{mm} / \mathrm{mm})\end{array}$ & $\begin{array}{c}\text { Stress } \\
(\mathrm{MPa})\end{array}$ \\
\hline 0.2771 & 1.0 & 0.3369 & 1.0 & 0.3874 & 1.0 & 0.4356 & 1.1 & 0.4972 & 1.0 & 0.5386 & 1.0 \\
\hline 0.2797 & 1.1 & 0.3457 & 1.5 & 0.3899 & 1.1 & 0.4395 & 1.5 & 0.4989 & 1.2 & 0.5409 & 1.3 \\
\hline 0.2824 & 1.3 & 0.3494 & 1.8 & 0.3919 & 1.3 & 0.4515 & 2.5 & 0.5017 & 1.4 & 0.5441 & 1.7 \\
\hline 0.2853 & 1.4 & 0.3553 & 2.2 & 0.3942 & 1.5 & 0.4588 & 3.3 & 0.5032 & 1.6 & 0.5457 & 1.9 \\
\hline 0.2881 & 1.6 & 0.3613 & 2.6 & 0.3965 & 1.6 & 0.4652 & 3.9 & 0.5047 & 1.8 & 0.5475 & 2.1 \\
\hline 0.2908 & 1.7 & 0.3712 & 3.5 & 0.3987 & 1.8 & 0.4725 & 5.1 & 0.5063 & 1.9 & 0.5490 & 2.3 \\
\hline 0.2934 & 1.9 & 0.3768 & 3.9 & 0.4008 & 1.9 & 0.4747 & 5.4 & 0.5070 & 2.0 & 0.5502 & 2.4 \\
\hline 0.2961 & 2.0 & 0.3821 & 4.6 & 0.4028 & 2.1 & 0.4802 & 6.4 & 0.5078 & 2.1 & 0.5513 & 2.6 \\
\hline 0.2986 & 2.2 & 0.3860 & 5.1 & 0.4046 & 2.2 & 0.4841 & 6.9 & 0.5093 & 2.3 & 0.5524 & 2.8 \\
\hline 0.3009 & 2.3 & 0.3978 & 6.4 & 0.4064 & 2.4 & 0.4878 & 7.8 & 0.5107 & 2.4 & 0.5536 & 2.9 \\
\hline 0.3032 & 2.5 & 0.3999 & 6.7 & 0.4082 & 2.6 & 0.4938 & 8.6 & 0.5120 & 2.6 & 0.5546 & 3.1 \\
\hline 0.3055 & 2.7 & 0.4057 & 7.5 & 0.4100 & 2.7 & 0.4946 & 8.9 & 0.5132 & 2.8 & 0.5556 & 3.3 \\
\hline 0.3077 & 2.8 & 0.4096 & 8.1 & 0.4118 & 2.9 & 0.4966 & 9.3 & 0.5143 & 2.9 & 0.5566 & 3.4 \\
\hline 0.3098 & 3.0 & 0.4113 & 8.4 & 0.4135 & 3.1 & 0.4989 & 9.6 & 0.5156 & 3.1 & 0.5576 & 3.6 \\
\hline 0.3117 & 3.1 & 0.4152 & 8.9 & 0.4150 & 3.2 & 0.5000 & 9.9 & 0.5168 & 3.3 & 0.5586 & 3.8 \\
\hline 0.3138 & 3.3 & 0.4173 & 9.2 & 0.4164 & 3.4 & 0.4979 & 9.3 & 0.5180 & 3.4 & 0.5596 & 3.9 \\
\hline 0.3158 & 3.4 & 0.4190 & 9.5 & 0.4180 & 3.5 & 0.4959 & 8.7 & 0.5190 & 3.6 & 0.5604 & 4.1 \\
\hline 0.3178 & 3.6 & 0.4210 & 9.8 & 0.4197 & 3.7 & 0.4918 & 8.0 & 0.5199 & 3.8 & 0.5611 & 4.3 \\
\hline 0.3197 & 3.8 & 0.4212 & 9.4 & 0.4212 & 3.9 & 0.4901 & 7.3 & 0.5212 & 3.9 & 0.5620 & 4.4 \\
\hline 0.3216 & 3.9 & 0.4173 & 8.7 & 0.4225 & 4.0 & 0.4879 & 6.8 & 0.5221 & 4.1 & 0.5629 & 4.6 \\
\hline 0.3235 & 4.1 & 0.4152 & 8.3 & 0.4237 & 4.2 & 0.4860 & 6.5 & 0.5231 & 4.2 & 0.5638 & 4.8 \\
\hline 0.3253 & 4.2 & 0.4094 & 7.3 & 0.4250 & 4.4 & 0.4843 & 6.1 & 0.5241 & 4.4 & 0.5645 & 4.9 \\
\hline 0.3271 & 4.4 & 0.4055 & 6.8 & 0.4265 & 4.5 & 0.4806 & 5.5 & 0.5252 & 4.6 & 0.5652 & 5.1 \\
\hline 0.3288 & 4.6 & 0.4033 & 6.5 & 0.4279 & 4.7 & 0.4742 & 4.7 & 0.5261 & 4.7 & 0.5661 & 5.3 \\
\hline 0.3307 & 4.7 & 0.4014 & 6.1 & 0.4293 & 4.9 & 0.4708 & 4.1 & 0.5271 & 4.9 & 0.5670 & 5.4 \\
\hline 0.3325 & 4.9 & 0.3995 & 5.7 & 0.4306 & 5.0 & 0.4669 & 3.6 & 0.5280 & 5.1 & 0.5679 & 5.6 \\
\hline 0.3341 & 5.1 & 0.3956 & 5.3 & 0.4318 & 5.2 & 0.4611 & 3.0 & 0.5290 & 5.2 & 0.5688 & 5.8 \\
\hline 0.3356 & 5.2 & 0.3920 & 4.9 & 0.4330 & 5.4 & 0.4553 & 2.4 & 0.5298 & 5.4 & 0.5696 & 5.9 \\
\hline 0.3371 & 5.4 & 0.3883 & 4.5 & 0.4343 & 5.5 & 0.4513 & 2.1 & 0.5308 & 5.6 & 0.5703 & 6.1 \\
\hline 0.3386 & 5.5 & 0.3823 & 3.9 & 0.4355 & 5.7 & 0.4457 & 1.6 & 0.5317 & 5.7 & 0.5710 & 6.3 \\
\hline 0.3400 & 5.7 & 0.3767 & 3.3 & 0.4367 & 5.9 & 0.4395 & 1.2 & 0.5352 & 6.4 & 0.5716 & 6.4 \\
\hline 0.3415 & 5.9 & 0.3708 & 2.9 & 0.4378 & 6.0 & 0.4354 & 1.0 & 0.5358 & 6.6 & 0.5723 & 6.6 \\
\hline 0.3430 & 6.0 & 0.3650 & 2.4 & 0.4391 & 6.2 & & & 0.5366 & 6.7 & 0.5730 & 6.8 \\
\hline 0.3444 & 6.2 & 0.3553 & 1.8 & 0.4402 & 6.4 & & & 0.5373 & 6.9 & 0.5736 & 6.9 \\
\hline 0.3460 & 6.4 & 0.3498 & 1.5 & 0.4413 & 6.5 & & & 0.5383 & 7.1 & 0.5742 & 7.1 \\
\hline
\end{tabular}


Data of Bovine Meniscus at $1 \mathrm{~Hz}$ [48] Continued...

\begin{tabular}{|c|c|c|c|c|c|c|c|c|c|c|c|}
\hline \multicolumn{2}{|c|}{$\begin{array}{l}\text { Cycle 20, } \\
\mathbf{f}=1 \mathrm{~Hz}\end{array}$} & \multicolumn{2}{|c|}{$\begin{array}{l}\text { Cycle 50, } \\
\mathrm{f}=1 \mathrm{~Hz}\end{array}$} & \multicolumn{2}{|c|}{$\begin{array}{c}\text { Cycle 100, } \\
\mathbf{f}=1 \mathrm{~Hz}\end{array}$} & \multicolumn{2}{|c|}{$\begin{array}{c}\text { Cycle } 200 \\
\mathbf{f}=1 \mathbf{H z}\end{array}$} & \multicolumn{2}{|c|}{$\begin{array}{c}\text { Cycle 500, } \\
\mathbf{f}=1 \mathrm{~Hz}\end{array}$} & \multicolumn{2}{|c|}{$\begin{array}{l}\text { Cycle 1,000, } \\
\text { f }=1 \mathrm{~Hz}\end{array}$} \\
\hline $\begin{array}{l}\text { Strain } \\
(\mathrm{mm} / \mathrm{mm})\end{array}$ & \begin{tabular}{|c|} 
Stress \\
$(\mathrm{MPa})$
\end{tabular} & $\begin{array}{l}\text { Strain } \\
(\mathrm{mm} / \mathrm{mm})\end{array}$ & $\begin{array}{c}\text { Stress } \\
(\mathrm{MPa})\end{array}$ & $\begin{array}{l}\text { Strain } \\
(\mathrm{mm} / \mathrm{mm})\end{array}$ & $\begin{array}{l}\text { Stress } \\
(\mathrm{MPa})\end{array}$ & $\begin{array}{l}\text { Strain } \\
(\mathrm{mm} / \mathrm{mm})\end{array}$ & $\begin{array}{l}\text { Stress } \\
(\mathrm{MPa})\end{array}$ & $\begin{array}{l}\text { Strain } \\
(\mathrm{mm} / \mathrm{mm})\end{array}$ & $\begin{array}{l}\text { Stress } \\
(\mathrm{MPa})\end{array}$ & $\begin{array}{l}\text { Strain } \\
(\mathrm{mm} / \mathrm{mm})\end{array}$ & $\begin{array}{c}\text { Stress } \\
(\mathrm{MPa})\end{array}$ \\
\hline 0.3475 & 6.5 & 0.3382 & 1.0 & 0.4423 & 6.7 & & & 0.5392 & 7.3 & 0.5749 & 7.3 \\
\hline 0.3490 & 6.7 & & & 0.4433 & 6.9 & & & 0.5401 & 7.4 & 0.5756 & 7.5 \\
\hline 0.3505 & 6.9 & & & 0.4442 & 7.0 & & & 0.5410 & 7.6 & 0.5762 & 7.6 \\
\hline 0.3520 & 7.0 & & & 0.4453 & 7.2 & & & 0.5416 & 7.8 & 0.5770 & 7.9 \\
\hline 0.3535 & 7.2 & & & 0.4463 & 7.4 & & & 0.5422 & 7.9 & 0.5804 & 8.4 \\
\hline 0.3548 & 7.4 & & & 0.4474 & 7.5 & & & 0.5418 & 8.1 & 0.5823 & 9.1 \\
\hline 0.3562 & 7.5 & & & 0.4484 & 7.7 & & & 0.5440 & 8.5 & 0.5839 & 9.5 \\
\hline 0.3577 & 7.7 & & & 0.4495 & 7.9 & & & 0.5453 & 8.8 & 0.5848 & 9.6 \\
\hline 0.3591 & 7.8 & & & 0.4505 & 8.0 & & & 0.5457 & 9.1 & 0.5847 & 9.8 \\
\hline 0.3603 & 8.0 & & & 0.4514 & 8.2 & & & 0.5472 & 9.5 & 0.5848 & 9.6 \\
\hline 0.3616 & 8.2 & & & 0.4524 & 8.4 & & & 0.5496 & 9.9 & 0.5841 & 9.4 \\
\hline 0.3628 & 8.3 & & & 0.4533 & 8.5 & & & 0.5478 & 9.1 & 0.5834 & 9.3 \\
\hline 0.3639 & 8.5 & & & 0.4542 & 8.7 & & & 0.5461 & 8.7 & 0.5830 & 8.8 \\
\hline 0.3651 & 8.7 & & & 0.4552 & 8.9 & & & 0.5457 & 8.4 & 0.5818 & 8.6 \\
\hline 0.3665 & 8.9 & & & 0.4567 & 9.0 & & & 0.5448 & 7.8 & 0.5814 & 8.4 \\
\hline 0.3680 & 9.0 & & & 0.4582 & 9.2 & & & 0.5442 & 7.7 & 0.5803 & 8.0 \\
\hline 0.3692 & 9.2 & & & 0.4594 & 9.4 & & & 0.5436 & 7.5 & 0.5797 & 7.8 \\
\hline 0.3706 & 9.3 & & & 0.4602 & 9.5 & & & 0.5429 & 7.3 & 0.5782 & 7.6 \\
\hline 0.3733 & 9.7 & & & 0.4609 & 9.7 & & & 0.5421 & 7.2 & 0.5783 & 7.4 \\
\hline 0.3742 & 9.8 & & & 0.4616 & 9.9 & & & 0.5414 & 7.0 & 0.5779 & 7.3 \\
\hline 0.3733 & 9.6 & & & 0.4605 & 9.7 & & & 0.5407 & 6.8 & 0.5771 & 7.1 \\
\hline 0.3736 & 9.4 & & & 0.4607 & 9.6 & & & 0.5399 & 6.7 & 0.5765 & 6.9 \\
\hline 0.3729 & 9.2 & & & 0.4597 & 9.4 & & & 0.5391 & 6.5 & 0.5760 & 6.8 \\
\hline 0.3720 & 9.1 & & & 0.4589 & 9.2 & & & 0.5382 & 6.3 & 0.5754 & 6.6 \\
\hline 0.3710 & 8.9 & & & 0.4587 & 9.1 & & & 0.5374 & 6.2 & 0.5748 & 6.4 \\
\hline 0.3700 & 8.7 & & & 0.4585 & 8.9 & & & 0.5365 & 6.0 & 0.5741 & 6.3 \\
\hline 0.3690 & 8.6 & & & 0.4578 & 8.7 & & & 0.5358 & 5.8 & 0.5734 & 6.1 \\
\hline 0.3679 & 8.4 & & & 0.4568 & 8.5 & & & 0.5352 & 5.7 & 0.5726 & 5.9 \\
\hline 0.3669 & 8.2 & & & 0.4560 & 8.4 & & & 0.5345 & 5.5 & 0.5718 & 5.8 \\
\hline 0.3659 & 8.1 & & & 0.4553 & 8.2 & & & 0.5337 & 5.3 & 0.5709 & 5.6 \\
\hline 0.3650 & 7.9 & & & 0.4545 & 8.0 & & & 0.5327 & 5.1 & 0.5702 & 5.4 \\
\hline 0.3639 & 7.7 & & & 0.4535 & 7.9 & & & 0.5319 & 5.0 & 0.5695 & 5.2 \\
\hline 0.3627 & 7.6 & & & 0.4524 & 7.7 & & & 0.5310 & 4.8 & 0.5690 & 5.1 \\
\hline 0.3616 & 7.4 & & & 0.4513 & 7.5 & & & 0.5301 & 4.6 & 0.5683 & 4.9 \\
\hline 0.3605 & 7.2 & & & 0.4505 & 7.4 & & & 0.5290 & 4.5 & 0.5674 & 4.7 \\
\hline 0.3594 & 7.1 & & & 0.4496 & 7.2 & & & 0.5281 & 4.3 & 0.5665 & 4.6 \\
\hline
\end{tabular}


Data of Bovine Meniscus at $1 \mathrm{~Hz}$ [48] Continued...

\begin{tabular}{|c|c|c|c|c|c|c|c|c|c|c|c|}
\hline \multicolumn{2}{|c|}{$\begin{array}{l}\text { Cycle 20, } \\
\mathbf{f}=1 \mathrm{~Hz}\end{array}$} & \multicolumn{2}{|c|}{$\begin{array}{l}\text { Cycle 50, } \\
\mathrm{f}=1 \mathrm{~Hz}\end{array}$} & \multicolumn{2}{|c|}{$\begin{array}{c}\text { Cycle 100, } \\
\mathbf{f}=1 \mathrm{~Hz}\end{array}$} & \multicolumn{2}{|c|}{$\begin{array}{c}\text { Cycle 200, } \\
\mathbf{f}=1 \mathrm{~Hz}\end{array}$} & \multicolumn{2}{|c|}{$\begin{array}{c}\text { Cycle 500, } \\
\mathbf{f}=1 \mathrm{~Hz}\end{array}$} & \multicolumn{2}{|c|}{$\begin{array}{l}\text { Cycle 1,000, } \\
\quad f=1 \mathrm{~Hz}\end{array}$} \\
\hline $\begin{array}{l}\text { Strain } \\
(\mathrm{mm} / \mathrm{mm})\end{array}$ & $\begin{array}{c}\text { Stress } \\
(\mathrm{MPa})\end{array}$ & $\begin{array}{l}\text { Strain } \\
(\mathrm{mm} / \mathrm{mm})\end{array}$ & $\begin{array}{c}\text { Stress } \\
(\mathrm{MPa})\end{array}$ & $\begin{array}{l}\text { Strain } \\
(\mathrm{mm} / \mathrm{mm})\end{array}$ & $\begin{array}{l}\text { Stress } \\
\text { (MPa) }\end{array}$ & $\begin{array}{l}\text { Strain } \\
(\mathrm{mm} / \mathrm{mm})\end{array}$ & $\begin{array}{l}\text { Stress } \\
\text { (MPa) }\end{array}$ & $\begin{array}{l}\text { Strain } \\
(\mathrm{mm} / \mathrm{mm})\end{array}$ & $\begin{array}{c}\text { Stress } \\
(\mathrm{MPa})\end{array}$ & $\begin{array}{l}\text { Strain } \\
(\mathrm{mm} / \mathrm{mm})\end{array}$ & $\begin{array}{c}\text { Stress } \\
\text { (MPa) }\end{array}$ \\
\hline 0.3582 & 6.9 & & & 0.4487 & 7.0 & & & 0.5271 & 4.1 & 0.5655 & 4.4 \\
\hline 0.3571 & 6.7 & & & 0.4479 & 6.9 & & & 0.5260 & 4.0 & 0.5646 & 4.2 \\
\hline 0.3559 & 6.6 & & & 0.4470 & 6.7 & & & 0.5249 & 3.8 & 0.5638 & 4.1 \\
\hline 0.3545 & 6.4 & & & 0.4460 & 6.5 & & & 0.5237 & 3.6 & 0.5631 & 3.9 \\
\hline 0.3530 & 6.2 & & & 0.4451 & 6.4 & & & 0.5226 & 3.5 & 0.5624 & 3.7 \\
\hline 0.3515 & 6.1 & & & 0.4441 & 6.2 & & & 0.5215 & 3.3 & 0.5617 & 3.6 \\
\hline 0.3500 & 5.9 & & & 0.4432 & 6.0 & & & 0.5204 & 3.1 & 0.5608 & 3.4 \\
\hline 0.3487 & 5.7 & & & 0.4421 & 5.9 & & & 0.5193 & 3.0 & 0.5597 & 3.2 \\
\hline 0.3473 & 5.6 & & & 0.4410 & 5.7 & & & 0.5181 & 2.8 & 0.5586 & 3.1 \\
\hline 0.3457 & 5.4 & & & 0.4398 & 5.5 & & & 0.5168 & 2.6 & 0.5574 & 2.9 \\
\hline 0.3441 & 5.3 & & & 0.4386 & 5.4 & & & 0.5089 & 1.8 & 0.5563 & 2.7 \\
\hline 0.3427 & 5.1 & & & 0.4375 & 5.2 & & & 0.5071 & 1.7 & 0.5496 & 1.9 \\
\hline 0.3347 & 4.3 & & & 0.4313 & 4.4 & & & 0.5051 & 1.5 & 0.5481 & 1.7 \\
\hline 0.3331 & 4.1 & & & 0.4299 & 4.2 & & & 0.5029 & 1.4 & 0.5464 & 1.6 \\
\hline 0.3314 & 3.9 & & & 0.4284 & 4.0 & & & 0.5005 & 1.2 & 0.5445 & 1.4 \\
\hline 0.3295 & 3.8 & & & 0.4269 & 3.9 & & & 0.4981 & 1.1 & 0.5428 & 1.2 \\
\hline 0.3274 & 3.6 & & & 0.4254 & 3.7 & & & & & 0.5413 & 1.1 \\
\hline 0.3254 & 3.5 & & & 0.4239 & 3.5 & & & & & 0.5388 & 0.9 \\
\hline 0.3233 & 3.3 & & & 0.4223 & 3.4 & & & & & & \\
\hline 0.3212 & 3.1 & & & 0.4208 & 3.2 & & & & & & \\
\hline 0.3190 & 3.0 & & & 0.4191 & 3.1 & & & & & & \\
\hline 0.3167 & 2.8 & & & 0.4173 & 2.9 & & & & & & \\
\hline 0.3143 & 2.7 & & & 0.4154 & 2.7 & & & & & & \\
\hline 0.3120 & 2.5 & & & 0.4136 & 2.6 & & & & & & \\
\hline 0.3094 & 2.4 & & & 0.4116 & 2.4 & & & & & & \\
\hline 0.3069 & 2.2 & & & 0.4095 & 2.3 & & & & & & \\
\hline 0.3043 & 2.1 & & & 0.4073 & 2.1 & & & & & & \\
\hline 0.3016 & 1.9 & & & 0.4051 & 1.9 & & & & & & \\
\hline 0.2989 & 1.8 & & & 0.4030 & 1.8 & & & & & & \\
\hline 0.2960 & 1.6 & & & 0.4006 & 1.6 & & & & & & \\
\hline 0.2931 & 1.5 & & & 0.3979 & 1.5 & & & & & & \\
\hline 0.2901 & 1.3 & & & 0.3946 & 1.3 & & & & & & \\
\hline 0.2867 & 1.2 & & & 0.3930 & 1.2 & & & & & & \\
\hline 0.2830 & 1.1 & & & 0.3891 & 1.1 & & & & & & \\
\hline 0.2794 & 0.9 & & & 0.3863 & 0.9 & & & & & & \\
\hline
\end{tabular}




\section{A.1.2. Data of Bovine Meniscus at $10 \mathrm{~Hz}$}

The following table shows stress and corresponding strain of the different points of the loops 20 , $50,100,200,500,1,000,2,000$, and 5,000 at the frequency of $10 \mathrm{~Hz}$ [48].

\begin{tabular}{|c|c|c|c|c|c|c|c|}
\hline \multicolumn{2}{|c|}{$\begin{array}{l}\text { Cycle 20, } \\
\text { f = } 10 \text { Hz }\end{array}$} & \multicolumn{2}{|c|}{$\begin{array}{l}\text { Cycle 50, } \\
\text { f = } 10 \mathrm{~Hz}\end{array}$} & \multicolumn{2}{|c|}{$\begin{array}{l}\text { Cycle 100, } \\
\mathrm{f}=10 \mathrm{~Hz}\end{array}$} & \multicolumn{2}{|c|}{$\begin{array}{l}\text { Cycle 200, } \\
\mathrm{f}=10 \mathrm{~Hz}\end{array}$} \\
\hline $\begin{array}{l}\text { Strain } \\
(\mathrm{mm} / \mathrm{mm})\end{array}$ & $\begin{array}{c}\text { Stress } \\
(\mathrm{MPa})\end{array}$ & $\begin{array}{l}\text { Strain } \\
(\mathrm{mm} / \mathrm{mm})\end{array}$ & $\begin{array}{c}\text { Stress } \\
(\mathrm{MPa})\end{array}$ & $\begin{array}{l}\text { Strain } \\
(\mathrm{mm} / \mathrm{mm})\end{array}$ & $\begin{array}{c}\text { Stress } \\
(\mathrm{MPa})\end{array}$ & $\begin{array}{l}\text { Strain } \\
(\mathrm{mm} / \mathrm{mm})\end{array}$ & $\begin{array}{c}\text { Stress } \\
(\mathrm{MPa})\end{array}$ \\
\hline 0.2972 & 1.1 & 0.3296 & 1.1 & 0.3554 & 0.9 & 0.3840 & 0.8 \\
\hline 0.2997 & 1.3 & 0.3297 & 0.9 & 0.3586 & 1.1 & 0.3851 & 1.0 \\
\hline 0.3019 & 1.4 & 0.3314 & 1.3 & 0.3607 & 1.3 & 0.3866 & 1.1 \\
\hline 0.3038 & 1.6 & 0.3338 & 1.4 & 0.3623 & 1.4 & 0.3883 & 1.3 \\
\hline 0.3056 & 1.7 & 0.3357 & 1.6 & 0.3639 & 1.6 & 0.3900 & 1.5 \\
\hline 0.3077 & 1.9 & 0.3375 & 1.7 & 0.3656 & 1.8 & 0.3918 & 1.6 \\
\hline 0.3097 & 2.1 & 0.3392 & 1.9 & 0.3673 & 1.9 & 0.3934 & 1.8 \\
\hline 0.3115 & 2.2 & 0.3409 & 2.1 & 0.3690 & 2.1 & 0.3948 & 1.9 \\
\hline 0.3134 & 2.4 & 0.3426 & 2.2 & 0.3707 & 2.3 & 0.3963 & 2.1 \\
\hline 0.3153 & 2.5 & 0.3444 & 2.4 & 0.3721 & 2.4 & 0.3979 & 2.3 \\
\hline 0.3170 & 2.7 & 0.3461 & 2.6 & 0.3735 & 2.6 & 0.3994 & 2.4 \\
\hline 0.3188 & 2.9 & 0.3479 & 2.7 & 0.3750 & 2.7 & 0.4007 & 2.6 \\
\hline 0.3204 & 3.0 & 0.3493 & 2.9 & 0.3764 & 2.9 & 0.4020 & 2.8 \\
\hline 0.3221 & 3.2 & 0.3507 & 3.0 & 0.3777 & 3.1 & 0.4031 & 2.9 \\
\hline 0.3238 & 3.3 & 0.3522 & 3.2 & 0.3790 & 3.2 & 0.4042 & 3.1 \\
\hline 0.3253 & 3.5 & 0.3537 & 3.4 & 0.3802 & 3.4 & 0.4053 & 3.3 \\
\hline 0.3267 & 3.7 & 0.3552 & 3.5 & 0.3814 & 3.6 & 0.4065 & 3.4 \\
\hline 0.3281 & 3.8 & 0.3566 & 3.7 & 0.3825 & 3.7 & 0.4078 & 3.6 \\
\hline 0.3295 & 4.0 & 0.3579 & 3.9 & 0.3836 & 3.9 & 0.4089 & 3.8 \\
\hline 0.3309 & 4.2 & 0.3590 & 4.0 & 0.3849 & 4.1 & 0.4100 & 3.9 \\
\hline 0.3324 & 4.3 & 0.3600 & 4.2 & 0.3860 & 4.2 & 0.4111 & 4.1 \\
\hline 0.3337 & 4.5 & 0.3612 & 4.4 & 0.3871 & 4.4 & 0.4121 & 4.3 \\
\hline 0.3350 & 4.7 & 0.3625 & 4.5 & 0.3882 & 4.6 & 0.4130 & 4.5 \\
\hline 0.3363 & 4.8 & 0.3636 & 4.7 & 0.3893 & 4.7 & 0.4139 & 4.6 \\
\hline 0.3374 & 5.0 & 0.3646 & 4.9 & 0.3904 & 4.9 & 0.4149 & 4.8 \\
\hline 0.3385 & 5.2 & 0.3657 & 5.0 & 0.3914 & 5.1 & 0.4159 & 5.0 \\
\hline 0.3397 & 5.3 & 0.3668 & 5.2 & 0.3925 & 5.2 & 0.4169 & 5.1 \\
\hline 0.3408 & 5.5 & 0.3678 & 5.4 & 0.3934 & 5.4 & 0.4178 & 5.3 \\
\hline 0.3420 & 5.7 & 0.3689 & 5.5 & 0.3944 & 5.6 & 0.4188 & 5.5 \\
\hline 0.3432 & 5.8 & 0.3699 & 5.7 & 0.3953 & 5.7 & 0.4197 & 5.6 \\
\hline
\end{tabular}


Data of Bovine Meniscus at $10 \mathrm{~Hz}$ [48] Continued...

\begin{tabular}{|c|c|c|c|c|c|c|c|}
\hline \multicolumn{2}{|c|}{$\begin{array}{l}\text { Cycle 20, } \\
\mathrm{f}=10 \mathrm{~Hz}\end{array}$} & \multicolumn{2}{|c|}{$\begin{array}{l}\text { Cycle 50, } \\
\mathrm{f}=10 \mathrm{~Hz}\end{array}$} & \multicolumn{2}{|c|}{$\begin{array}{c}\text { Cycle 100, } \\
\mathrm{f}=10 \mathrm{~Hz}\end{array}$} & \multicolumn{2}{|c|}{$\begin{array}{c}\text { Cycle 200, } \\
f=10 \mathrm{~Hz}\end{array}$} \\
\hline $\begin{array}{l}\text { Strain } \\
(\mathrm{mm} / \mathrm{mm})\end{array}$ & $\begin{array}{c}\text { Stress } \\
(\mathrm{MPa})\end{array}$ & $\begin{array}{l}\text { Strain } \\
(\mathrm{mm} / \mathrm{mm})\end{array}$ & $\begin{array}{c}\text { Stress } \\
(\mathrm{MPa})\end{array}$ & $\begin{array}{l}\text { Strain } \\
(\mathrm{mm} / \mathrm{mm})\end{array}$ & $\begin{array}{c}\text { Stress } \\
(\mathrm{MPa})\end{array}$ & $\begin{array}{l}\text { Strain } \\
(\mathrm{mm} / \mathrm{mm})\end{array}$ & $\begin{array}{c}\text { Stress } \\
(\mathrm{MPa})\end{array}$ \\
\hline 0.3444 & 6.0 & 0.3707 & 5.9 & 0.3963 & 5.9 & 0.4206 & 5.8 \\
\hline 0.3454 & 6.2 & 0.3716 & 6.0 & 0.3972 & 6.1 & 0.4214 & 6.0 \\
\hline 0.3464 & 6.3 & 0.3727 & 6.2 & 0.3982 & 6.3 & 0.4222 & 6.1 \\
\hline 0.3474 & 6.5 & 0.3737 & 6.4 & 0.3991 & 6.4 & 0.4229 & 6.3 \\
\hline 0.3484 & 6.7 & 0.3747 & 6.6 & 0.3999 & 6.6 & 0.4236 & 6.5 \\
\hline 0.3492 & 6.8 & 0.3757 & 6.7 & 0.4008 & 6.8 & 0.4243 & 6.6 \\
\hline 0.3503 & 7.0 & 0.3766 & 6.9 & 0.4015 & 6.9 & 0.4251 & 6.8 \\
\hline 0.3513 & 7.2 & 0.3775 & 7.1 & 0.4022 & 7.1 & 0.4261 & 7.0 \\
\hline 0.3523 & 7.3 & 0.3784 & 7.2 & 0.4045 & 7.6 & 0.4270 & 7.1 \\
\hline 0.3533 & 7.5 & 0.3793 & 7.4 & 0.4055 & 7.8 & 0.4278 & 7.3 \\
\hline 0.3543 & 7.7 & 0.3800 & 7.6 & 0.4063 & 7.9 & 0.4284 & 7.5 \\
\hline 0.3554 & 7.8 & 0.3807 & 7.7 & 0.4069 & 8.1 & 0.4290 & 7.7 \\
\hline 0.3562 & 8.0 & 0.3816 & 7.9 & 0.4076 & 8.3 & 0.4298 & 7.8 \\
\hline 0.3571 & 8.2 & 0.3825 & 8.1 & 0.4083 & 8.4 & 0.4305 & 8.0 \\
\hline 0.3581 & 8.3 & 0.3834 & 8.2 & 0.4090 & 8.6 & 0.4310 & 8.2 \\
\hline 0.3590 & 8.5 & 0.3842 & 8.4 & 0.4097 & 8.8 & 0.4317 & 8.3 \\
\hline 0.3601 & 8.7 & 0.3852 & 8.6 & 0.4104 & 8.9 & 0.4324 & 8.5 \\
\hline 0.3610 & 8.8 & 0.3860 & 8.7 & 0.4112 & 9.1 & 0.4331 & 8.7 \\
\hline 0.3619 & 9.0 & 0.3867 & 8.9 & 0.4119 & 9.3 & 0.4339 & 8.8 \\
\hline 0.3648 & 9.5 & 0.3875 & 9.1 & 0.4152 & 9.6 & 0.4348 & 9.0 \\
\hline 0.3658 & 9.6 & 0.3885 & 9.2 & 0.4158 & 9.7 & 0.4359 & 9.2 \\
\hline 0.3660 & 9.3 & 0.3896 & 9.4 & 0.4151 & 9.4 & 0.4369 & 9.3 \\
\hline 0.3652 & 9.1 & 0.3907 & 9.6 & 0.4143 & 9.2 & 0.4376 & 9.5 \\
\hline 0.3647 & 8.9 & 0.3904 & 9.4 & 0.4140 & 9.0 & 0.4382 & 9.7 \\
\hline 0.3643 & 8.8 & 0.3902 & 9.3 & 0.4135 & 8.8 & 0.4388 & 9.8 \\
\hline 0.3638 & 8.6 & 0.3898 & 8.9 & 0.4130 & 8.7 & 0.4384 & 9.6 \\
\hline 0.3631 & 8.4 & 0.3896 & 9.1 & 0.4126 & 8.5 & 0.4378 & 9.4 \\
\hline 0.3625 & 8.3 & 0.3889 & 8.6 & 0.4121 & 8.3 & 0.4370 & 9.3 \\
\hline 0.3619 & 8.1 & 0.3884 & 8.4 & 0.4116 & 8.2 & 0.4362 & 8.6 \\
\hline 0.3613 & 7.9 & 0.3879 & 8.2 & 0.4111 & 8.0 & 0.4359 & 8.4 \\
\hline 0.3609 & 7.8 & 0.3872 & 8.1 & 0.4104 & 7.8 & 0.4353 & 8.3 \\
\hline 0.3602 & 7.6 & 0.3866 & 7.9 & 0.4099 & 7.6 & 0.4348 & 8.1 \\
\hline 0.3570 & 6.9 & 0.3862 & 7.7 & 0.4092 & 7.5 & 0.4343 & 7.9 \\
\hline 0.3563 & 6.7 & 0.3856 & 7.6 & 0.4086 & 7.3 & 0.4337 & 7.7 \\
\hline 0.3556 & 6.6 & 0.3849 & 7.4 & 0.4080 & 7.1 & 0.4332 & 7.6 \\
\hline 0.3548 & 6.4 & 0.3843 & 7.2 & 0.4073 & 7.0 & 0.4325 & 7.4 \\
\hline
\end{tabular}


Data of Bovine Meniscus at $10 \mathrm{~Hz}$ [48] Continued...

\begin{tabular}{|c|c|c|c|c|c|c|c|}
\hline \multicolumn{2}{|c|}{$\begin{array}{l}\text { Cycle 20, } \\
f=10 \mathrm{~Hz}\end{array}$} & \multicolumn{2}{|c|}{$\begin{array}{l}\text { Cycle 50, } \\
f=10 \mathrm{~Hz}\end{array}$} & \multicolumn{2}{|c|}{$\begin{array}{c}\text { Cycle 100, } \\
f=10 ~ H z\end{array}$} & \multicolumn{2}{|c|}{$\begin{array}{c}\text { Cycle 200, } \\
\mathbf{f}=10 \mathrm{~Hz}\end{array}$} \\
\hline $\begin{array}{l}\text { Strain } \\
(\mathrm{mm} / \mathrm{mm})\end{array}$ & $\begin{array}{c}\text { Stress } \\
(\mathrm{MPa})\end{array}$ & $\begin{array}{l}\text { Strain } \\
(\mathrm{mm} / \mathrm{mm})\end{array}$ & $\begin{array}{c}\text { Stress } \\
(\mathrm{MPa})\end{array}$ & $\begin{array}{l}\text { Strain } \\
(\mathrm{mm} / \mathrm{mm})\end{array}$ & $\begin{array}{c}\text { Stress } \\
(\mathrm{MPa})\end{array}$ & $\begin{array}{l}\text { Strain } \\
(\mathrm{mm} / \mathrm{mm})\end{array}$ & $\begin{array}{c}\text { Stress } \\
(\mathrm{MPa})\end{array}$ \\
\hline 0.3539 & 6.2 & 0.3837 & 7.1 & 0.4064 & 6.8 & 0.4317 & 7.2 \\
\hline 0.3530 & 6.1 & 0.3831 & 6.9 & 0.4056 & 6.6 & 0.4311 & 7.1 \\
\hline 0.3520 & 5.9 & 0.3825 & 6.7 & 0.4050 & 6.5 & 0.4307 & 6.9 \\
\hline 0.3510 & 5.7 & 0.3816 & 6.5 & 0.4043 & 6.3 & 0.4305 & 6.7 \\
\hline 0.3501 & 5.6 & 0.3807 & 6.4 & 0.4035 & 6.1 & 0.4300 & 6.6 \\
\hline 0.3490 & 5.4 & 0.3800 & 6.2 & 0.4027 & 6.0 & 0.4292 & 6.4 \\
\hline 0.3479 & 5.2 & 0.3791 & 6.0 & 0.4021 & 5.8 & 0.4283 & 6.2 \\
\hline 0.3468 & 5.1 & 0.3783 & 5.9 & 0.4015 & 5.6 & 0.4274 & 6.1 \\
\hline 0.3456 & 4.9 & 0.3773 & 5.7 & 0.4008 & 5.5 & 0.4265 & 5.9 \\
\hline 0.3445 & 4.7 & 0.3764 & 5.5 & 0.4000 & 5.3 & 0.4257 & 5.7 \\
\hline 0.3433 & 4.6 & 0.3755 & 5.4 & 0.3991 & 5.1 & 0.4250 & 5.5 \\
\hline 0.3420 & 4.4 & 0.3744 & 5.2 & 0.3982 & 5.0 & 0.4242 & 5.4 \\
\hline 0.3409 & 4.2 & 0.3735 & 5.0 & 0.3971 & 4.8 & 0.4235 & 5.2 \\
\hline 0.3396 & 4.1 & 0.3726 & 4.9 & 0.3962 & 4.6 & 0.4227 & 5.0 \\
\hline 0.3383 & 3.9 & 0.3716 & 4.7 & 0.3952 & 4.5 & 0.4218 & 4.9 \\
\hline 0.3370 & 3.7 & 0.3705 & 4.5 & 0.3942 & 4.3 & 0.4209 & 4.7 \\
\hline 0.3357 & 3.6 & 0.3694 & 4.4 & 0.3930 & 4.1 & 0.4201 & 4.5 \\
\hline 0.3341 & 3.4 & 0.3683 & 4.2 & 0.3919 & 4.0 & 0.4193 & 4.4 \\
\hline 0.3325 & 3.2 & 0.3672 & 4.0 & 0.3907 & 3.8 & 0.4185 & 4.2 \\
\hline 0.3308 & 3.1 & 0.3661 & 3.9 & 0.3896 & 3.6 & 0.4177 & 4.0 \\
\hline 0.3292 & 2.9 & 0.3649 & 3.7 & 0.3884 & 3.5 & 0.4167 & 3.9 \\
\hline 0.3274 & 2.8 & 0.3635 & 3.5 & 0.3870 & 3.3 & 0.4157 & 3.7 \\
\hline 0.3256 & 2.6 & 0.3622 & 3.4 & 0.3857 & 3.1 & 0.4146 & 3.5 \\
\hline 0.3238 & 2.4 & 0.3609 & 3.2 & 0.3844 & 3.0 & 0.4134 & 3.4 \\
\hline 0.3219 & 2.3 & 0.3594 & 3.0 & 0.3830 & 2.8 & 0.4123 & 3.2 \\
\hline 0.3198 & 2.1 & 0.3577 & 2.9 & 0.3813 & 2.6 & 0.4111 & 3.0 \\
\hline 0.3174 & 2.0 & 0.3560 & 2.7 & 0.3796 & 2.5 & 0.4098 & 2.9 \\
\hline 0.3148 & 1.8 & 0.3544 & 2.5 & 0.3779 & 2.3 & 0.4083 & 2.7 \\
\hline 0.3120 & 1.7 & 0.3527 & 2.4 & 0.3762 & 2.1 & 0.4070 & 2.5 \\
\hline 0.3093 & 1.5 & 0.3508 & 2.2 & 0.3745 & 2.0 & 0.4056 & 2.4 \\
\hline 0.3067 & 1.4 & 0.3489 & 2.1 & 0.3726 & 1.8 & 0.4041 & 2.2 \\
\hline 0.2965 & 1.0 & 0.3469 & 1.9 & 0.3707 & 1.7 & 0.4024 & 2.0 \\
\hline & & 0.3447 & 1.7 & 0.3685 & 1.5 & 0.4007 & 1.9 \\
\hline & & 0.3424 & 1.6 & 0.3662 & 1.3 & 0.3990 & 1.7 \\
\hline & & 0.3400 & 1.4 & 0.3608 & 1.0 & 0.3971 & 1.6 \\
\hline & & 0.3375 & 1.3 & 0.3568 & 0.9 & 0.3949 & 1.4 \\
\hline & & 0.3349 & 1.1 & & & 0.3927 & 1.2 \\
\hline & & 0.3320 & 1.0 & & & 0.3904 & 1.1 \\
\hline & & 0.3282 & 0.9 & & & 0.3875 & 0.9 \\
\hline & & & & & & 0.3833 & 0.8 \\
\hline
\end{tabular}




\section{A.1.3. Ratcheting Strain of Bovine Meniscus at $1 \mathrm{~Hz}[48]$}

This following set of data, calculated based on data from Miller et al. [48], represents ratcheting strain and its calculation from the hysteresis loops of bovine meniscus under cyclic compression in different cycles at the frequency of $1 \mathrm{~Hz}$.

\begin{tabular}{|c|c|c|c|}
\hline Cycle No. & Min. Strain & Max. Strain & Ratcheting Strain (\%) \\
\hline 10 & 0.165 & 0.277 & 22.13 \\
11 & 0.182 & 0.295 & 23.83 \\
12 & 0.192 & 0.306 & 24.89 \\
13 & 0.202 & 0.312 & 25.71 \\
14 & 0.211 & 0.320 & 26.52 \\
15 & 0.218 & 0.326 & 27.16 \\
16 & 0.224 & 0.330 & 27.73 \\
17 & 0.230 & 0.335 & 28.30 \\
18 & 0.235 & 0.340 & 28.76 \\
19 & 0.241 & 0.344 & 29.26 \\
20 & 0.282 & 0.377 & 32.94 \\
50 & 0.342 & 0.426 & 38.37 \\
100 & 0.391 & 0.465 & 42.80 \\
200 & 0.439 & 0.504 & 47.13 \\
500 & 0.501 & 0.553 & 52.70 \\
1,000 & 0.543 & 0.589 & 56.60 \\
\hline
\end{tabular}




\section{A.1.4. Ratcheting Strain of Bovine Meniscus at $10 \mathrm{~Hz}$ [48]}

This following set of data, calculated based on data from Miller et al. [48], represents ratcheting strain and its calculation from the hysteresis loops of bovine meniscus under cyclic compression in different cycles at the frequency of $10 \mathrm{~Hz}$.

\begin{tabular}{|c|c|c|c|}
\hline Cycle No. & Min. Strain & Max. Strain & Ratcheting Strain (\%) \\
\hline 10 & 0.16 & 0.22 & 18.93 \\
11 & 0.21 & 0.27 & 23.63 \\
12 & 0.23 & 0.29 & 26.03 \\
13 & 0.24 & 0.31 & 27.55 \\
14 & 0.25 & 0.32 & 28.57 \\
15 & 0.26 & 0.33 & 29.35 \\
16 & 0.26 & 0.33 & 29.87 \\
17 & 0.27 & 0.34 & 30.32 \\
18 & 0.27 & 0.34 & 30.76 \\
19 & 0.28 & 0.35 & 31.35 \\
20 & 0.30 & 0.37 & 33.08 \\
50 & 0.33 & 0.39 & 35.87 \\
100 & 0.36 & 0.41 & 38.52 \\
200 & 0.38 & 0.44 & 41.06 \\
500 & 0.42 & 0.47 & 44.60 \\
1,000 & 0.45 & 0.49 & 47.18 \\
2,000 & 0.48 & 0.51 & 49.50 \\
5,000 & 0.51 & 0.54 & 52.30 \\
\hline
\end{tabular}




\section{A.2. Data of Porcine Articular Cartilage [49]}

This set of data, extracted from Gao et al. [49], represents ratcheting strain of different cycles in different stress variations of soaked porcine articular cartilage under cyclic compression.

\begin{tabular}{|c|c|c|c|c|c|}
\hline \multicolumn{2}{|c|}{$\begin{array}{c}\Delta \sigma=0.5 \mathrm{MPa}, \\
\text { Stress Rate }=0.1 \mathrm{MPa} / \mathrm{s}\end{array}$} & \multicolumn{2}{|c|}{$\begin{array}{c}\Delta \sigma=1 \mathrm{MPa} \\
\text { Stress Rate }=0.1 \mathrm{MPa} / \mathrm{s}\end{array}$} & \multicolumn{2}{|c|}{$\begin{array}{c}\Delta \sigma=1.5 \mathrm{MPa} \\
\text { Stress Rate }=0.1 \mathrm{MPa} / \mathrm{s}\end{array}$} \\
\hline Cycle No. & $\begin{array}{l}\text { Ratcheting } \\
\text { Strain (\%) }\end{array}$ & Cycle No. & $\begin{array}{l}\text { Ratcheting } \\
\text { Strain (\%) }\end{array}$ & Cycle No & $\begin{array}{l}\text { Ratcheting } \\
\text { Strain (\%) }\end{array}$ \\
\hline 2 & 3.37 & 1 & 6.66 & 2 & 8.56 \\
\hline 5 & 4.80 & 3 & 10.69 & 6 & 16.44 \\
\hline 10 & 5.80 & 9 & 17.23 & 10 & 21.38 \\
\hline 20 & 7.41 & 10 & 17.99 & 15 & 25.38 \\
\hline 30 & 8.54 & 15 & 21.53 & 20 & 28.44 \\
\hline 40 & 9.45 & 20 & 24.29 & 25 & 31.17 \\
\hline 50 & 10.64 & 26 & 27.20 & 30 & 32.71 \\
\hline 60 & 11.39 & 30 & 28.65 & 36 & 34.78 \\
\hline 70 & 12.06 & 33 & 29.59 & 40 & 35.88 \\
\hline 80 & 12.68 & 40 & 31.78 & 42 & 36.27 \\
\hline 90 & 13.23 & 45 & 32.94 & 50 & 38.18 \\
\hline 96 & 13.60 & 50 & 34.04 & 54 & 39.05 \\
\hline & & 57 & 35.37 & 60 & 40.11 \\
\hline & & 60 & 36.07 & 66 & 41.08 \\
\hline & & 70 & 37.63 & 70 & 41.50 \\
\hline & & 75 & 38.40 & 80 & 42.95 \\
\hline & & 80 & 38.90 & 90 & 44.20 \\
\hline & & 86 & 39.69 & 97 & 44.84 \\
\hline & & 90 & 40.04 & & \\
\hline & & 96 & 40.77 & & \\
\hline
\end{tabular}


This set of data, extracted from Gao et al. [49], represents ratcheting strain of different cycles in different stress rates of soaked porcine articular cartilage under cyclic compression.

\begin{tabular}{|c|c|c|c|c|c|}
\hline \multicolumn{2}{|c|}{$\begin{array}{c}\Delta \sigma=1.0 \mathrm{MPa} \\
\text { Stress } \text { Rate }=0.1 \mathrm{MPa} / \mathrm{s}\end{array}$} & \multicolumn{2}{|c|}{$\begin{array}{c}\Delta \sigma=1.0 \mathrm{MPa} \\
\text { Stress } R \text { ate }=0.2 \mathrm{MPa} / \mathrm{s}\end{array}$} & \multicolumn{2}{|c|}{$\begin{array}{c}\Delta \sigma=1.0 \mathrm{MPa} \\
\text { Stress Rate }=0.4 \mathrm{MPa} / \mathrm{s}\end{array}$} \\
\hline Cycle No. & $\begin{array}{l}\text { Ratcheting } \\
\text { Strain (\%) }\end{array}$ & Cycle No. & $\begin{array}{l}\text { Ratcheting } \\
\text { Strain (\%) }\end{array}$ & Cycle No. & $\begin{array}{l}\text { Ratcheting } \\
\text { Strain (\%) }\end{array}$ \\
\hline 1 & 6.66 & 7 & 8.38 & 1 & 3.75 \\
\hline 3 & 10.69 & 12 & 10.77 & 10 & 8.10 \\
\hline 9 & 17.23 & 18 & 12.78 & 20 & 10.24 \\
\hline 10 & 17.99 & 24 & 14.35 & 30 & 12.00 \\
\hline 15 & 21.53 & 30 & 15.82 & 40 & 13.34 \\
\hline 20 & 24.29 & 36 & 17.22 & 50 & 14.27 \\
\hline 26 & 27.20 & 48 & 19.26 & 60 & 15.40 \\
\hline 30 & 28.65 & 54 & 20.20 & 70 & 16.37 \\
\hline 33 & 29.59 & 66 & 21.97 & 80 & 17.15 \\
\hline 40 & 31.78 & 72 & 22.62 & 90 & 18.03 \\
\hline 45 & 32.94 & 84 & 23.99 & 99 & 18.51 \\
\hline 50 & 34.04 & 90 & 24.68 & & \\
\hline 57 & 35.37 & 96 & 25.23 & & \\
\hline 60 & 36.07 & & & & \\
\hline 70 & 37.63 & & & & \\
\hline 75 & 38.40 & & & & \\
\hline 80 & 38.90 & & & & \\
\hline 86 & 39.69 & & & & \\
\hline 90 & 40.04 & & & & \\
\hline 96 & 40.77 & & & & \\
\hline
\end{tabular}




\section{A.3. Data of Porcine Trabecular Bone [50]}

This set of data, extracted from Wei et al. [50], represents ratcheting strain of different cycles of porcine trabecular bone under cyclic compression.

\begin{tabular}{|c|c|}
\hline Cycle No. & Ratcheting Strain (\%) \\
\hline 1 & 0.76 \\
10 & 1.58 \\
20 & 1.87 \\
30 & 2.08 \\
40 & 2.20 \\
50 & 2.29 \\
60 & 2.36 \\
70 & 2.39 \\
80 & 2.43 \\
90 & 2.45 \\
100 & 2.47 \\
110 & 2.49 \\
120 & 2.51 \\
130 & 2.52 \\
140 & 2.53 \\
150 & 2.54 \\
160 & 2.55 \\
170 & 2.56 \\
180 & 2.56 \\
190 & 2.57 \\
200 & 2.58 \\
\hline
\end{tabular}




\section{A.4. Data of Porcine Skin [52]}

This set of data, calculated based on data from Kang and $\mathrm{Wu}$ [52], represents ratcheting strain of different cycles of porcine skin under cyclic tension at $6.06 \pm 6.04 \mathrm{MPa}$, in Langer's direction.

\begin{tabular}{|c|c|c|c|c|c|}
\hline Cycle No. & $\begin{array}{c}\text { Ratcheting } \\
\text { Strain }(\%)\end{array}$ & $\begin{array}{c}\text { Cycle } \\
\text { No. }\end{array}$ & $\begin{array}{c}\text { Ratcheting } \\
\text { Strain }(\%)\end{array}$ & $\begin{array}{c}\text { Cycle } \\
\text { No. }\end{array}$ & $\begin{array}{c}\text { Ratcheting } \\
\text { Strain } \mathbf{( \% )}\end{array}$ \\
\hline 1 & 0.729 & 34 & 4.980 & 67 & 6.449 \\
2 & 1.192 & 35 & 5.076 & 68 & 6.537 \\
3 & 1.528 & 36 & 5.187 & 69 & 6.544 \\
4 & 1.793 & 37 & 5.212 & 70 & 6.590 \\
5 & 2.020 & 38 & 5.273 & 71 & 6.627 \\
6 & 2.317 & 39 & 5.337 & 72 & 6.572 \\
7 & 2.438 & 40 & 5.317 & 73 & 6.717 \\
8 & 2.678 & 41 & 5.371 & 74 & 6.720 \\
9 & 2.799 & 42 & 5.463 & 75 & 6.780 \\
10 & 2.913 & 43 & 5.454 & 76 & 6.836 \\
11 & 3.066 & 44 & 5.587 & 77 & 6.708 \\
12 & 3.170 & 45 & 5.647 & 78 & 6.949 \\
13 & 3.318 & 46 & 5.716 & 79 & 6.886 \\
14 & 3.450 & 47 & 5.670 & 80 & 6.847 \\
15 & 3.479 & 48 & 5.816 & 81 & 6.948 \\
16 & 3.778 & 49 & 5.858 & 82 & 6.938 \\
17 & 3.773 & 50 & 5.824 & 83 & 6.939 \\
18 & 3.845 & 51 & 5.921 & 84 & 7.039 \\
19 & 3.899 & 52 & 5.876 & 85 & 7.124 \\
20 & 4.046 & 53 & 6.013 & 86 & 7.140 \\
21 & 4.078 & 54 & 6.037 & 87 & 7.093 \\
22 & 4.199 & 55 & 6.017 & 88 & 7.145 \\
23 & 4.238 & 56 & 6.122 & 89 & 7.180 \\
24 & 4.392 & 57 & 6.114 & 90 & 7.308 \\
25 & 4.481 & 58 & 6.140 & 91 & 7.373 \\
26 & 4.549 & 59 & 6.240 & 92 & 7.191 \\
27 & 4.621 & 60 & 6.349 & 93 & 7.260 \\
28 & 4.651 & 61 & 6.381 & 94 & 7.443 \\
29 & 4.803 & 62 & 6.419 & 95 & 7.397 \\
30 & 4.790 & 63 & 6.405 & 96 & 7.403 \\
31 & 4.866 & 64 & 6.372 & 97 & 7.417 \\
32 & 4.964 & 65 & 6.411 & 98 & 7.499 \\
33 & 4.933 & 66 & 6.502 & 99 & 7.507 \\
\hline
\end{tabular}




\section{REFERENCES}

[1] Lees, D., Partington, P., 2016, “Articular cartilage”, Journal of Orthopaedics and Trauma Journal 30(3):265-272.

[2] Makris, M.A., Hadidi, P., Athanasiou, K.A., 2011, "The knee meniscus: Structurefunction, pathophysiology, current repair techniques, and prospects for regeneration", Journal of Biomaterials 32:7411-7431.

[3] Herwig, J., Egner, E., Buddecke, E., 1984, "Chemical changes of human knee joint menisci in various stages of degeneration", Journal of Annals of the Rheumatic Diseases 43:635-640.

[4] Proctor, C.S., Schmidt, M.B., Whipple, R.R., Kelly, M.A., Mow, V.C., 1989, “Material properties of the normal medial bovine meniscus", Journal of Orthopaedic Research 7:771-782.

[5] Eyre, D.R., Muir, H., 1975, "The distribution of different molecular species of collagen in fibrous, elastic and hyaline cartilages of the pig", Biochemical J. 151:595-602.

[6] McDermott, I.D., Masouros, S.D., Bull, A.M.J., Amis, A.A., 2010, “Anatomy” In "The meniscus", P. Beaufils and R. Verdonk (Eds.), Springer, pp. 11-18.

[7] Eyre, D.R., Wu, J.J., 1983, "Collagen of fibrocartilage: A distinctive molecular phenotype in bovine meniscus", FEBS Letters 158(2):265-270.

[8] Scott, P.G, Nakano, T., Dodd, C.M., 1997, "Isolation and characterization of small proteoglycans from different zones of the porcine knee meniscus", Journal of Biochimica et Biophysica Acta 1336:254-262.

[9] Petersen, W., Tillmann, B., 1998, "Collagenous fibril texture of the human knee joint menisci”, Journal of Anatomy and Embryology 197:317-324. 
[10] Mansour, J.M., 2013, "Kinesiology: The mechanics and pathomechanics of human movement: second edition, biomechanics of cartilage-chapter", Wolters Kluwer Health Publisher, pp. 66-79.

[11] Athanasiou, K.A., Darling, E.M., Hu, J.C., 2010, "Articular cartilage tissue engineering", Morgan \& Claypool Publishers.

[12] McCredie, A.J., Stride, E., Saffari, N., 2009, “Ultrasound elastography to determine the layered mechanical Properties of Articular Cartilage and the Importance of Such Structural Characteristics under Load", Proceedings of the $31^{\text {st }}$ Annual International Conference of the IEEE EMBS, Minneapolis, Minnesota, USA.

[13] Sophia, A.J., Bedi, A., Rodeo, S.A., 2009, "The basic science of articular cartilage: Structure, composition, and function", Journal of Sports Health: A Multidisciplinary Approach 1(6):461-468.

[14] Bhosale, A.M., Richardson, J.B., 2008, "Articular cartilage: structure, injuries and review of management", British Medical Bulletin 87:77-95.

[15] Brody, L.T., 2015, "Knee Osteoarthritis: Clinical connections to articular cartilage structure and function", Journal of Physical Therapy in Sport 16:301-316.

[16] Launey, M.E., Buehler, M.J., Ritchie, R.O., 2010, "On the mechanistic origins of toughness in bone", Journal of Annual Review of Materials Research 40:25-53.

[17] Safadi. F.F., Barbe, M.F., Abdelmagid, S.M., Rico, M.C., Aswad, R.A., Litvin, J., Popoff, S.N., 2009, "Bone structure, development and bone biology", In: "Bone Pathology", Humana Press, pp. 1-50.

[18] Qing, Q.H., 2013, "Mechanics of cellular bone remodeling: coupled thermal, electrical, and mechanical field effects", CRC Press, Boca Raton, Florida, USA.

[19] Wang, X., Nyman, J.S., Dong, X., Leng, H., Reyes, M., 2010, "Fundamental biomechanics in bone tissue engineering", Morgan \& Claypool Publishers. 
[20] Keaveny, T.M., Morgan, E.F., Yeh, O.C., 2003, "Bone mechanics" in "Standard handbook of biomedical engineering \& design”, Myer Kutz, McGraw-Hill.

[21] Hamed, E., Jasiuk, I., Yoo, A., Lee, Y., Liszka, T., 2012, “Multi-scale modelling of elastic moduli of trabecular bone”, Journal of the Royal Society Interface 9:1654-1673.

[22] Pal, S., 2014, “Design of artificial human joints \& organs”, Springer, New York.

[23] McDermott, I.D., Masouros, S.D., Amis, A.A., 2008, "Biomechanics of the menisci of the knee", Journal of Current Orthopaedics 22:193-201.

[24] Fithian, D.C., Kelly, M.A., Mow, V.C., 1990, "Material properties and structurefunction relationships in the menisci", Journal of Clinical Orthopaedics and Related Research 252:19-31.

[25] Athanasiou, K.A., Sanchez-Adams, J., 2009, “Engineering the knee meniscus”, Morgan \& Claypool.

[26] Masouros, S.D., McDermott. I.D., Amis. A.A., Bull, A.M.J., 2010, “Biomechanics” In “The Meniscus", P. Beaufils and R. Verdonk (Eds.), Springer, pp. 29-37.

[27] Danso, E.K., Honkanen, J.T.J., Saarakkala, S., Korhonen, R.K., 2014, “Comparison of nonlinear mechanical properties of bovine articular cartilage and meniscus", Journal of Biomechanics 47:200-206.

[28] Juang, Y.-C., Tsai, L., Lin, H.R., 2011, "Dynamic response of porcine articular cartilage and meniscus under shock loading”, In "Dynamic Behavior of Materials, Volume 1", Tom Proulx (Ed.), Springer, New York, pp.393-398.

[29] Fischenich, K.M., Boncella, K., Lewis, J.T., Bailey, T.S., Haut Donahue, T.L., 2017, "Dynamic compression of human and ovine meniscal tissue compared with a potential thermoplastic elastomer hydrogel replacement", Journal of Biomedical Materials Research 105A:2722-2728. 
[30] Pujol, N., Boisrenoult, P., 2010, “Meniscus and Osteoarthritis" In "The Meniscus", P. Beaufils and R. Verdonk (Eds.), Springer, pp. 61-65.

[31] Adams, M.E., Billingham, M.E.J., Muir, H., 1983, "The glycosaminoglycans in menisci in experimental and natural osteoarthritis", Journal of Arthritis \& Rheumatology 26(1):69-76.

[32] Tsujii, A., Nakamura, N., Horibe, S., 2017, “Age-related changes in the knee meniscus”, Journal of The Knee 24:1262-1270.

[33] Athanasiou, K.A., Rosenwasser, M.P., Buckwalter, J.A., Malinin, T.I., Mow, V.C., 1991, "Interspecies comparisons of in situ intrinsic mechanical properties of distal femoral cartilage", Journal of Orthopaedic Research 9:330-340.

[34] Temple, D.K., Cederlund, A.A., Lawless, B.M., Aspden, R.M., Espino, D.M., 2016, "Viscoelastic properties of human and bovine articular cartilage: a comparison of frequency-dependent trends", Journal of BMC Musculoskeletal Disorders 17(1):419.

[35] Sadeghi, H., Lawless, B.M., Espino, D.M., Shepherd, D.E.T., 2018, "Effect of frequency on crack growth in articular cartilage", Journal of the Mechanical Behavior of Biomedical Materials 77:40-46.

[36] Li, L.P., Herzog, W., 2004, "Strain-rate dependence of cartilage stiffness in unconfined compression: the role of fibril reinforcement versus tissue volume change in fluid pressurization", Journal of Biomechanics 37:375-382.

[37] McCormack, T., Mansour, J.M., 1998, "Reduction in tensile strength of cartilage precedes surface damage under repeated compressive loading in vitro", Journal of Biomechanics 31:55-61.

[38] Matzat, S.J., Tiel, J., Gold, G.E., Oei, E.H.G, 2013, “Quantitative MRI techniques of cartilage composition", Journal of Quantitative Imaging in Medicine and Surgery 3(3):162-174. 
[39] Zhao, J.M., Song, X.X., Liu, B., 2016, “Standardized compliance matrixes for general anisotropic materials and a simple measure of anisotropy degree based on shearextension coupling coefficient", International Journal of Applied Mechanics 8(6).

[40] Odgaard, A., Kabel, J., Rietbergen, B., Dalstra, M., Huiskes, R., 1997, "Fabric and elastic principal directions of cancellous bone are closely related", Journal of Biomechanics 30(5):487-495.

[41] Wald, M.J., Magland, J.F., Rajapakse, C.S., Bhagat, Y.A., Wehrli, F.W., 2012, "Predicting trabecular bone elastic properties from measures of bone volume fraction and fabric on the basis of micro magnetic resonance images", Journal of Magnetic Resonance in Medicine 68(2):463-473.

[42] Kefalas, V., Eftaxiopoulos, D.A., 2012, "Experimental study of cancellous bone under large strains and a constitutive probabilistic model", Journal of the Mechanical Behavior of Biomedical Materials 6:41-52.

[43] Keaveny, T.M., Morgan, E.F., Niebur, G.L., Yeh, O.C., 2001, "Biomechanics of trabecular bone", Annual Review of Biomedical Engineering 3:307-333.

[44] Kreider, J.M., Goldstein, S.A., 2009, "Trabecular bone mechanical properties in patients with fragility fractures", Journal of Clinical Orthopaedics and Related Research 467:1955-1963.

[45] Ciarelli, T.E., Fyhrie, D.P., Schaffler, M.B., Goldstein, S.A., 2000, “Variations in threedimensional cancellous bone architecture of the proximal femur in female hip fractures and in controls", Journal of Bone and Mineral research 15(1):32-40.

[46] McCalden, R.W., McGeough, J.A., Court-Brown, C.M., 1997, “Age-related changes in the compressive strength of cancellous bone", Journal of Bone and Joint Surgery 79(3):421-427.

[47] Van Der Linden, J.C., Homminga, J., Verhaar, J.A.N., Weinans, H., 2001, “Mechanical consequences of bone loss in cancellous bone", Journal of Bone and Mineral research 16(3):457-465. 
[48] Miller, A.T., Safranski, D.L., Smith, K.E., Guldberg, R.E., Gall, K., 2016, “Compressive cyclic ratcheting and fatigue of synthetic, soft biomedical polymers in solution", Journal of the Mechanical Behavior of Biomedical Materials 54:268-282.

[49] Gao, L.L., Qin, X.Y., Zhang, C.Q., Gao, H., Ge, H.Y., Zhang, X.Z., 2015, “Ratcheting behavior of articular cartilage under cyclic unconfined compression", Journal of Materials Science and Engineering 57:371-377.

[50] Wei, C.L., Gao, L.L., Zhang, C.Q., 2016, "Study on ratcheting behavior of trabecular bone with and without marrow under cyclic compression", 3rd International Conference on Biomedical and Bioinformatics Engineering, Taipei, Taiwan.

[51] Pattin, C.A., Caler, W.E., Carter, D.R., 1996, "Cyclic mechanical property degradation during fatigue loading of cortical bone", Journal of Biomechanics 29(1):69-79.

[52] Kang, G., Wu, X., 2011, "Ratchetting of porcine skin under uniaxial cyclic loading", Journal of the Mechanical Behavior of Biomedical Materials 4:498-506 (data obtained from the author, Mr. G. Kang, from Southwest Jiaotong University through private communication dated 1/13/2018).

[53] Wren, T.A.L., Lindsey, D.P., Beaupre, G.S., Carter, D.R., 2003, "Effects of creep and cyclic loading on the mechanical properties and failure of human achilles tendons", Journal of Annals of Biomedical Engineering 31:710-717.

[54] Gao, L.L., Wei, C.L., Zhang, C.Q., Gao, H., Yang, N., Dong, L.M., 2017, “Quasi-static and ratcheting properties of trabecular bone under uniaxial and cyclic compression", Journal of Materials Science and Engineering: C 77:1050-1059.

[55] Onaran, K., Findley, W.N., 1965, “Combined stress-creep experiments on a nonlinear viscoelastic material to determine the kernel functions for a multiple integral representation of creep", Transactions of the Society of Rheology 9(2).

[56] Lai, J.S.Y., Findley, W.N., 1968, "Prediction of uniaxial stress relaxation from creep of nonlinear viscoelastic material", Transactions of the Society of Rheology 12(2). 
[57] Ahmadzadeh, G.R., Varvani-Farahani, A., 2012, "Triphasic ratcheting strain prediction of materials over stress cycles", Journal of Fatigue \& Fracture of Engineering Materials \& Structures 35:929-935.

[58] Creechley, J., 2016, "Bi-directional fatigue life behavior of bovine meniscus", MASc thesis, Boise State University, Boise, Idaho-USA.

[59] Jeng, Y.R., Mao, C.P., Wu, K.T., 2013, "Instrumented indentation investigation on the viscoelastic properties of porcine cartilage", Journal of Bionic Engineering 10:522531.

[60] Poumarat, G., Squire, P., 1993, "Comparison of mechanical properties of human, bovine bone and a new processed bone xenograft", J. of Biomaterials 14(5):337-340.

[61] Matsuura, M., Eckstein, F., Lochmüller, E.M., Zysset, P.K., 2008, "The role of fabric in the quasi-static compressive mechanical properties of human trabecular bone from various anatomical locations", Journal of Biomechanics and Modeling in Mechanobiology 7(1):27-42.

[62] Rapillard, L., Charlebois, M., Zysset, P.K., 2006, "Compressive fatigue behavior of human vertebral trabecular bone", Journal of Biomechanics 39:2133-2139.

[63] Pramudita, J.A., Shimizu, Y., Tanabe, Y., Ito, M., Watanabe, R., 2014, "Tensile properties of porcine skin in dorsal and ventral regions", Journal of Japanese Society for Emergency Medicine 14:s245-s250.

[64] Yao, J.Q., Seedhom, B.B., 1993, "Mechanical conditioning of articular cartilage to prevalent stresses", British Journal of Rheumatology 32:956-965.

[65] Verteramo, A., Seedhom, B.B., 2007, "Effect of a single impact loading on the structure and mechanical properties of articular cartilage", J. of Biomechanics 40:3580-3589.

[66] Bartel, D.L., Davy, D.T., Keaveny, T.M., 2006, “Orthopaedic biomechanics: mechanics and design in musculoskeletal systems", Pearson. 
[67] Becerra, J., Andrades, J.A., Guerado, E., Zamora-Navas, P., Lo'pez-Puertas, J.M., Reddi, A.H., 2010, "Articular cartilage: structure and regeneration", Journal of Tissue Engineering 16(6):617-627.

[68] Manda, K., Wallace, R.J., Xie, S., Levrero-Florencio, F., Pankaj, P., 2017, “Nonlinear viscoelastic characterization of bovine trabecular bone", Journal of Biomechanics and Modeling in Mechanobiology 16:173-189.

[69] Kafka, V., 1993, “On hydraulic strengthening of bones", Journal of Biomechanics 26(6):761-762. 